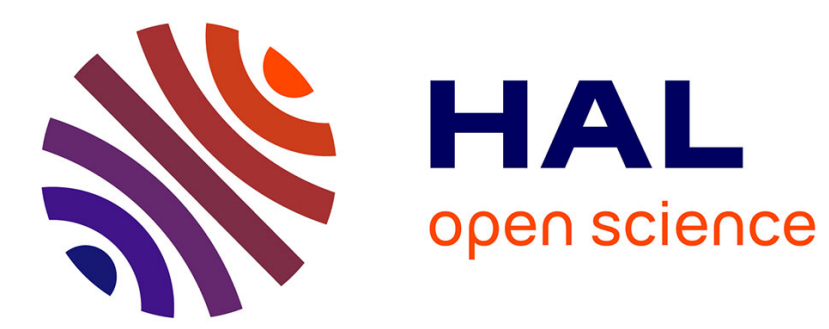

\title{
MACHIAVEL ET LA TRADITION PHILOSOPHIQUE
}

Marie Gaille-Nikodimov

\section{To cite this version:}

Marie Gaille-Nikodimov. MACHIAVEL ET LA TRADITION PHILOSOPHIQUE. 2007. hal01309051

\section{HAL Id: hal-01309051 \\ https://hal.science/hal-01309051}

Submitted on 28 Apr 2016

HAL is a multi-disciplinary open access archive for the deposit and dissemination of scientific research documents, whether they are published or not. The documents may come from teaching and research institutions in France or abroad, or from public or private research centers.
L'archive ouverte pluridisciplinaire HAL, est destinée au dépôt et à la diffusion de documents scientifiques de niveau recherche, publiés ou non, émanant des établissements d'enseignement et de recherche français ou étrangers, des laboratoires publics ou privés. 


\section{MACHIAVEL ET LA TRADITION PHILOSOPHIQUE}

Marie Gaille-Nikodimov 
À Pierre-François Moreau, avec qui l'on philosophe librement et joyeusement. 


\section{REMERCIEMENTS}

La réflexion proposée dans cet ouvrage se nourrit de divers matériaux, élaborés au cours d'un doctorat de philosophie à l'Université de Nanterre Paris 10 (1998-2001) et surtout d'un post-doctorat, effectué au CNRS, dans l'UMR d'histoire de la pensée classique (20022005). Pour les excellentes conditions de travail et la qualité de leur accueil, je remercie Antony McKenna et Pierre-François Moreau. Je suis également reconnaissante à l'égard des personnes qui m'ont permis d'exposer dans leurs séminaires des hypothèses qui ont nourri l'écriture de ce livre : Laurent Bove, Paolo Carta, Didier Deleule, Jean-Louis Fournel, Eric Méchoulan, Michel Senellart, Xavier Tabet et Ghislain Waterlot. 


\section{RÉFÉRENCES}

Les citations extraites du Prince, des Discours sur la première décade de Tite-Live et de L'Histoire de Florence sont indiquées en note sans nom d'auteur et sans référence bibliographiques. Elles sont empruntées,

pour les Discours sur la première décade de Tite-Live : à la traduction d'Alessandro Fontana et de Xavier Tabet (Paris, Gallimard, Bibliothèque de philosophie, 2004)

pour Le Prince : à la traduction que j'en ai proposée (Le Livre de poche, Classiques de philosophie, Paris, 2000)

pour L'Histoire de Florence : à la traduction proposée dans l'édition des Euvres de Machiavel dirigée par Christian Bec (Paris, Laffont, Bouquins, 1996).

Les autres textes de Machiavel (écrits politiques, correspondance, poèmes) font l'objet de références complètes. 


\section{SOMMAIRE}

1. Machiavel, l'étranger respectable de la philosophie p. 6

2. La «scientia civilis » ou les nœuds serrés de la religion et de la politique p. 14

$\begin{array}{ll}\text { 3. Instabilité, corruption et conflit civil p. } 29 & \text { p }\end{array}$

$\begin{array}{ll}\text { 4. Du mal, de l'être et de la norme en politique } 40 & \text { p. } 40\end{array}$

5. Vérité et fiction, expérience et point de vue : la nature du savoir politique p. 61

6. Les «moments machiavéliens »: la démocratie face à la pensée de p. 71 Machiavel

$\begin{array}{ll}\text { 7. Épilogue p. } 87 & \text { p. }\end{array}$ 
"Amitiés d'astres. Nous étions amis et nous sommes devenus étrangers l'un à l'autre. Mais il est bon qu'il en soit ainsi, et nous ne chercherons pas à nous le dissimuler ni à l'obscurcir comme si nous devions en avoir honte. Tels deux navires dont chacun poursuit sa voie et son but propres (...) Que nous dussions devenir étrangers l'un à l'autre, tel le voulait la loi au-dessus de nous: c'est par là même que nous devons devenir l'un pour l'autre plus respectables ! ${ }^{1}$

De commentaire en commentaire, l'on rencontre l'affirmation selon laquelle Machiavel n'est pas un philosophe. Christian Bec, l'un des traducteurs contemporains de l'œuvre de Machiavel en français introduit ainsi son travail en déclarant que Machiavel n'est pas un "philosophe », mais un "praticien de la politique », serviteur de la chancellerie florentine pendant de longues années. ${ }^{2}$ Lorsqu'on s'en tient à ses écrits, en mettant de côté sa carrière, l'on retrouve la même idée. Jean-Louis Fournel et Jean-Claude Zancarini, traducteurs et commentateurs du Prince, ont discuté le principe même de l'appropriation philosophique de cette œuvre: Machiavel n'y ferait œuvre philosophique que « de surcroît ». Ce texte «n'est en rien un classique traité de philosophie politique», il ne répond pas "aux injonctions du principe de non-contradiction $»,{ }^{3}$ il témoigne d'un mouvement inachevé de théorisation des «affaires de l'état» ». ${ }^{4}$ Son écriture repose sur l'invention d'une langue politique avant tout matérielle et florentine, sans souci des recherches formelles. ${ }^{5}$ Machiavel parle une langue mélangée composée des mots entendus dans les boutiques et sur les places, dans les couloirs de la chancellerie et les auditions d'ambassade. ${ }^{6}$

\footnotetext{
${ }^{1}$ Fr. Nietzsche, Le Gai savoir, tr. de P. Klossowski, Paris, Gallimard, Folio essais, 1982, p. 191.

${ }^{2}$ Ch. Bec, in : Machiavel, Euvres, Préface, tr. de Ch. Bec, Paris, Laffont, Bouquins, 1996, p. III.

3 J.-L. Fournel et J.-Cl. Zancarini, in : Machiavel, Le Prince, tr. de J.-L. Fournel et J.-Cl. Zancarini, Paris, PUF, Fondements de la politique, 2000, p. 31 et p. 609.

${ }^{4}$ Ibid., p. 552.

${ }^{5}$ Ibid., pp. 545-546.

${ }^{6}$ Ibid., pp. 550-551. cf. sur le sujet L. Gerbier, 'La composition de la langue civile. Sources, enjeux et construction de l'écriture machiavélienne', in: M. Gaille-Nikodimov et Th. Ménissier, Machiavel, Paris, Ellipses, Lectures de ..., 2006, pp. 51-91.
} 
L'on s'étonne, l'on s'interroge. Machiavel n'est certes pas un philosophe. Du moins pas un philosophe de profession. Pourquoi dire et répéter ce qui semble aux yeux de tous relever de l'évidence? Quelle pourrait être l'intention de ceux, iconoclastes, qui se risqueraient à dire que les choses ne sont pas si simples?

En s'interrogeant ainsi, l'on se souvient que, parmi les ouvrages de philosophie qui ont accompagné notre formation philosophique, ceux qui mentionnaient la pensée de Machiavel s'attardaient souvent sur son existence. On apprenait ainsi que Machiavel était issu de la moyenne bourgeoisie florentine. À partir de 1498, il avait occupé des fonctions de « secrétaire » au sein de la chancellerie républicaine, tant pour les affaires intérieures de la cité que pour ses relations avec les puissances étrangères. Il avait beaucoup voyagé, en Italie, mais aussi au-delà des monts alpins, dans l'Empire allemand, les cantons suisses et le Royaume de France, observant et relatant ce qu'il avait vu pour le compte de son gouvernement. En 1512, lorsque les Médicis étaient revenus au pouvoir dans la cité dont ils avaient été chassés en 1494, ils avaient déchu de ses fonctions et assigné Machiavel à résidence, après l'avoir fait emprisonner, torturer et interdit de séjour à Florence pendant une année. Il avait alors pris ses quartiers dans ses terres non loin de Florence, un petit domaine dont il disait retirer à peine de quoi vivre et où, disait-il encore, il s'ennuyait.

C'est pendant ces années de retraite qu'il avait écrit Le Prince et les Discours sur la première décade de Tite-Live, œuvres souvent présentées comme une sorte de pis-aller : il aurait écrit à défaut de pouvoir agir et n'aurait eu de cesse de retrouver une fonction dans les organes du pouvoir florentin, fût-ce auprès des Médicis. De fait, à partir de la fin des années 1510, après avoir appartenu à un cercle d'hommes de lettres et de bourgeois florentins préoccupés par l'avenir politique de leur cité, il était revenu sur la scène publique par le biais du théâtre, de l'histoire et de la politique. Jusqu'à sa mort en 1527, il avait rempli des missions d'importance limitée pour le compte du gouvernement médicéen. Parallèlement, il s'était fait connaître, en particulier à Florence, Venise et Rome, pour ses comédies et avait rédigé une Histoire de Florence en huit livre qu'il présenta au pape, un Médicis, en 1525.

Dans ces ouvrages de philosophie, la présentation de la vie de Machiavel attestait qu'il avait mené une existence passablement active et ce, dans une période particulièrement mouvementée de l'histoire du territoire italien et de sa cité. Il en avait été le témoin, mais aussi 
l'acteur à sa modeste mesure, et enfin le commentateur. Les biographes de Machiavel le savent bien : ils ne relatent pas la vie d'un pur esprit. ${ }^{7}$

Ces indications biographiques sur Machiavel dans les manuels de philosophie indique que l'affirmation récurrente selon laquelle Machiavel n'est pas un philosophe, bien qu'il figure dans ces manuels, tient au moins pour partie à la conception que l'on se fait couramment des vies de philosophe. Au contraire de Machiavel, le philosophe n'est-il pas celui qui, par vocation, mène une vie de loisir et consacre tout son temps à la réflexion, au point que le rythme propre de sa pensée devient celui de son existence même ? Le philosophe est celui qui a fait le geste de se libérer du temps de l'action : «nous forçant toujours à conclure, le temps de la cité, de l'action, du monde des hommes, ne nous laisse jamais le loisir de comprendre. Le loisir à vrai dire n'existe que pour qui le prend, et délivre le temps. Ce temps libéré libère à son tour le discours de toute critériologie externe, du souci de l'efficacité comme des considérations 'esthétiques' de longueur ou de brièveté ${ }^{8} .{ }^{8}$ Des « vrais » philosophes, on dit le plus souvent qu'ils sont nés, qu'ils ont pensé et qu'ils sont morts. C'est une caractéristique qu'ils sont censés d'ailleurs partager avec les savants. Lorsqu'il écrit son autobiographie en 1947, Albert Einstein affirme en substance que seul importait ce qu'il avait pensé, et non vécu ou éprouvé. Ce propos semble aller de soi et même relever du bon sens. De fait, à l'exception de David Hume, Giambattista Vico et René Descartes, les philosophes eux-mêmes n'ont pas, le plus souvent, rédigé d'autobiographie et ne se sont guère livrés sur leur existence.

En effet, si le philosophe mène une vie délivrée des contraintes du temps de la cité, Machiavel n'est pas un philosophe car le temps de la réflexion et le temps de l'action se sont, tout au long de son existence, nourris réciproquement : lorsqu'il travaille pour la chancellerie florentine, le temps de l'écriture succède au temps de l'observation; lorsqu'il est assigné à résidence, son expérience des «choses modernes" alimente, de pair avec la lecture des Anciens, l'écriture de ses œuvres. De ce fait, l'opposition entre vita activa et vita contemplativa n'a guère de sens à son propos, pas plus qu'elle n'en a eu au sujet de certains chanceliers humanistes, tels que Leonardo Bruni ou Coluccio Salutati. La vie de Machiavel est une vie mêlée. ${ }^{9}$

\footnotetext{
${ }^{7}$ Pour de plus amples détails biographiques, je me permets de renvoyer à mon travail sur la vie de Machiavel : Machiavel, Paris, Tallandier, 2005.

${ }^{8}$ M. Dixsaut, Le naturel philosophe, Paris, Vrin, 1998, p. 301.

${ }^{9}$ G. Sfez, Le Prince sans qualités, Paris, Kimé, 1998, p. 16.
} 
L'on a à faire ici, avec cette conception de la vie du philosophe, à un véritable lieu commun de la pensée occidentale et de sa tradition philosophique et scientifique, fondé sur le point de vue socratique d'une nécessaire division entre la vie et les idées. ${ }^{10}$ Tout le monde ne se rend pas, cependant, à ce lieu commun. Le « grand public », à travers le succès des biographies de philosophes et de savants, témoigne à sa manière que « la cloison que les penseurs érigent contre les débordements de la vie n'a rien d'étanche. Il soupçonne à juste titre que l'expérience de la pensée modifie les manières d'être au monde et qu'inversement les manières d'être au monde façonnent la pensée $»{ }^{11}$ Certains philosophes refusent également de manière explicite la division entre la vie et les idées. Le jugement que porte Michel Foucault sur son travail théorique, toujours en rapport avec des processus qui se déroulent autour de lui, toujours fondé sur des éléments de son expériences propre, constitue à sa manière une critique de ce lieu commun. ${ }^{12}$

On tirerait profit dans cette perspective à ne pas se contenter de relater la vie de Machiavel, mais à s'intéresser aux vies de tous les penseurs, non sur le mode de dévoilement de la vie intime, car « on n'expliquera pas l'intuition philosophique par les origines familiales ou par les notes de blanchisserie $»,{ }^{13}$ mais sur celui d'une enquête sur les points de rencontre entre vie et œuvre qui éclairent la réflexion philosophique. Machiavel gagnerait à cette entreprise de n'être plus le seul penseur dont on relate l'existence dans les ouvrages de philosophie et le fait de relater l'existence d'un auteur ne serait plus la marque de son exclusion hors du champ de la philosophie.

Ceci étant dit, l'affirmation fréquente selon laquelle Machiavel n'est pas un philosophe a sans doute d'autres raisons d'être que la conception, finalement discutable, d'une vie de philosophe exclusivement dédiée à l'exercice de la pensée et à l'interrogation. Elle est en fait autant l'écho d'une position adoptée par Machiavel lui-même. En effet, lorsqu'on affirme que Machiavel n'est pas un philosophe, l'on a pour soi la conviction et le désir de Machiavel luimême de ne pas «en être ». Il lui arrive, rarement, de reprendre les thèses avancées par des philosophes (par exemple celles d'Aristote sur les causes de la ruine des tyrannies, et sur divers sujets, celles de Xénophon) $;{ }^{14}$ il estime aussi sans doute partager avec certains d'entre eux et

\footnotetext{
${ }^{10}$ Fr. Balibar, 'Vies de savants, vies brèves', in : Critique, août-septembre 1999, n 627-628, p. 757.

${ }^{11}$ Ibid., p. 758.

${ }^{12}$ M. Foucault, 'Est-il donc important de penser ?' [1981], in : Dits et écrits, II, 1976-1988, Paris, Gallimard, 2001, pp. 1000-1001.

${ }^{13} \mathrm{Ph}$. Soulez et Fr. Worms, Bergson. Biographie, Paris, Flammarion, 1997, p. 286.

${ }^{14}$ Discours sur la première décade de Tite-Live, II 2 et 13, III 20, 22, 36 et 39; Le Prince, 14.
} 
non des moindres (Platon et Aristote) le sort d'un écrivain politique qui, en raison de conditions historiques défavorables, n'a pas vu pas se réaliser ses idées et a du se contenter de les coucher par écrit. ${ }^{15}$

Mais domine dans son œuvre une position critique à l'égard des «philosophes », liée à des considérations d'ordre moral et politique. Selon lui, les philosophes seraient par excellence des êtres oisifs qui contribuent à provoquer la ruine des cités. Il faut se féliciter, souligne-t-il, que Caton ait interdit l'accès de Rome aux philosophes, après avoir observé l'effet de fascination qu'exerçaient Diogène et Carnéade sur la jeunesse de la ville et deviné les effets délétères que leur « honnête oisiveté » pouvait engendrer. ${ }^{16}$ Philosophie, vie facile, femmes, paix et luxe : autant d'éléments qui détournent les citoyens de la discipline et de l'exercice militaire et affaiblit leur vertu. En outre, Machiavel critique aussi les philosophes d'un point de vue spéculatif : ils imaginent des « cités » qui n'ont jamais vu le jour et n'existeront jamais. Ils mènent donc une réflexion politique inutile, et cela parce qu'ils n'ont pas le souci de «la vérité effective de la chose $\gg{ }^{17}$ À quoi bon les lire ? Lui-même dit ignorer, non sans provocation, la pensée d'Aristote. ${ }^{18}$

Il n'est guère surprenant que Machiavel ne s'identifie pas à la figure du philosophe : ni ses études, assez sommaires et avant tout destinées à le doter d'une formation nécessaire à un métier, ni son parcours à la chancellerie florentine ne le rattachent à la profession de philosophe qui s'exerce avant tout dans les universités ou dans des académies et se concentre le plus souvent sur des questions relatives à la métaphysique, la logique, la philosophie naturelle et par conséquent aux sciences de la nature. ${ }^{19}$ La philosophie, telle qu'elle a été enseignée dans les universités européennes à partir du $13^{\text {ème }}$ siècle, s'est en effet constituée autour d'un programme de travail spécifique : il s'agissait d'accorder l'enseignement biblique avec les œuvres métaphysiques et scientifiques d'Aristote ainsi que leurs commentaires par Alfarabi, Avicenne et Averroès. Ce cahier des charges de la philosophie ne connaît pas de changement majeur à l'époque de Machiavel. Les « philosophes » s'occupent peu de politique et de morale, à la différence des humanistes. De plus, avec l'émergence des universités apparaît le philosophe de métier, c'est-à-dire celui qui est « dévoué d'une manière exclusive,

\footnotetext{
${ }^{15}$ Machiavel, Discours sur les choses de Florence après la mort de Laurent de Médicis le jeune, pp. 89-90.

${ }^{16}$ Histoire de Florence, V, 1, p. 829.

${ }^{17}$ Le Prince, 15 et Histoires de Florence, VIII, 29, p. 990.

${ }^{18}$ Machiavel, Lettere, éd. de F. Gaeta, Feltrinelli, 1961, p. 294.

${ }^{19}$ A. Buck, L'Eredità classica nelle letterature neolatina del Rinascimento, Paideia Editrice, 1980, p. 118 ; R. R. Bolgar, The Classical Heritage and its Beneficiaries : from the Carolingian Age to the End of the Renaissance, Harper Torchbooks, 1964, p. 224 sqq. ; L. Bianchi (éd.), La filosofia nelle università secoli XIII-XIV, La Nuova italia, 1997, p. XIV.
} 
même pour une période limitée de son existence comme c'était en général le cas, à l'élaboration de solutions à des problèmes spéculatifs, à la recherche et à l'enseignement, à la contemplation désintéressée du vrai $\gg .{ }^{20}$ De ce point de vue, Machiavel ne peut concevoir sa réflexion comme une forme de pensée philosophique et la philosophie, telle qu'elle se développe à son époque, ne contribue pas, ou guère, à la réflexion sur la vie en cité. Même s’il rencontre de temps à autres les questions traitées par les "philosophes » (le rôle des astres dans le cours de l'histoire humaine, l'éternité du monde), ${ }^{21}$ il ne partage pas avec eux le même objet de réflexion puisqu'il s'intéresse avant tout aux conditions d'émergence et de durée des régimes politiques.

Ainsi Machiavel ne veut pas qu'on l'identifie aux philosophes de son temps. Après 1527, date de la mort de Machiavel, nombreux sont ceux qui, par ailleurs, n'ont pas voulu lui accorder de place dans la koinonia philosophique. Face à ce double déni, on est tenté de passer sur cet élément récurrent de présentation et de poursuivre sa lecture. Après tout, qu'importe que Machiavel ne soit pas philosophe, si l'interrogation philosophique trouve une matière féconde dans ses écrits?

Il demeure cependant des motifs de questionnement face à cette forme de présentation du penseur politique. L'invocation de la nature d'une véritable vie philosophique et la référence à la posture non-philosophique adoptée par Machiavel lui-même ne constituent pas des raisons suffisantes pour expliquer qu'on affirme si fréquemment et avec fermeté que Machiavel n'est pas un philosophe. On a vu que ces deux éléments étaient partiellement critiquables. En outre, on peut avancer deux arguments qui, au contraire, permettent de rapprocher Machiavel de la philosophie.

Le premier est qu'il existe d'autres figures du philosophe que celle évoquée initialement, dont l'existence est entièrement dédiée à la méditation, hors du temps de l'action et de la cité, d'autres figures qui, pour n'être pas prégnantes dans les représentations de la philosophie, n'en sont pas moins intéressantes et significatives pour la compréhension de celle-ci. Parmi elles, il en est une dont Machiavel n'est pas si éloigné : c'est celle du lutteur solitaire formulée par Nietzsche, ${ }^{22}$ lutteur que sa pensée isole de la société et de la culture de son temps et qui préfère être seul plutôt que de renoncer à sa pensée. Machiavel peut être,

\footnotetext{
${ }^{20}$ L. Bianchi (éd.), La filosofia nelle università secoli XIII-XIV, Opus cit., p. XIV.

${ }^{21}$ E. Garin, 'Aspetti del pensiero di Machiavelli', in : Dal Rinascimento all'Illuminismo : studi e ricerche, Pise, Nistri-Lischi, 1970, pp. 43-44.

${ }^{22}$ L'expression est de Fr. Nietzsche, Considérations inactuelles, II, De l'utilité et de l'inconvénient de l'histoire pour la vie', in : Euvres, I, tr. H. Albert, revue paar J. Le Rider, Paris, Robert Laffont, coll. Bouquins, 1993, p. 254.
} 
dans une certaine mesure, assimilé à cette figure de lutteur solitaire, d'abord parce que, de son vivant, il énonça des jugements politiques tout à fait hétérodoxes sur la réforme institutionnelle et militaire de Florence et l'intérêt qu'il y a à faire référence à l'histoire romaine, cultivant, aux dires de ses amis, un certain goût du paradoxe et de la provocation. Et surtout parce que son œuvre occupe une position particulière dans cette histoire, celle d'un penseur solitaire au point que nous avons bien du mal à entrer dans sa pensée. Comme l'a bien dit Louis Althusser, Machiavel a occupé, dans l'histoire de la pensée politique, une « place unique et précaire », « entre une longue tradition moralisante religieuse et idéaliste de la pensée politique, qu'il a refusée radicalement, et la nouvelle tradition de la philosophie politique du droit naturel, qui allait tout submerger et dans laquelle la bourgeoisie montante s'est reconnue » : «la solitude de Machiavel c'est de s'être libéré de la première tradition avant que la seconde ne submerge tout $» .^{23}$

Par ailleurs, si Machiavel n'est pas un philosophe aux yeux de certains, son œuvre est au contraire constitutive d'une manière de philosopher pour d'autres. Ainsi, Remo Bodei, décrivant la «physionomie» propre de la philosophie italienne, insiste sur sa «constante et prédominante vocation civile » : il s'agit d'une philosophie qui n'est pas immédiatement liée à l'État, à la religion ou à l'intériorité, mais à « la société civile qu'[ils] cherchent à orienter, persuader, façonner ». Or, pour Remo Bodei, cette conception italienne de la philosophie a des racines humanistes et renaissantes. Elle a ses origines directes chez un auteur comme Machiavel, un auteur qui, parmi d'autres, a «pris pour objet d'enquête des questions qui impliquent virtuellement la majeure partie des hommes (les non-philosophes' comme les appelait Croce), en sachant bien qu'il s'agit non seulement d'animaux doués de raison, mais aussi d'animaux qui nourrissent des désirs et formulent des projets, des animaux dont les pensées, les actes et les attentes se soustraient aux statuts argumentatifs fixés d'avance ou encore à des méthodes et des langages définis, certes rigoureusement, mais de manière abstraite et générale $» .^{24}$

Finalement, l'on a raison de s'étonner et de s'interroger sur la présence, ça et là dans l'exégèse machiavélienne, de l'affirmation selon laquelle Machiavel n'est pas un philosophe. En effet, cette thèse ne nous apprend pas grand chose de Machiavel et engendre des

\footnotetext{
${ }^{23}$ L. Althusser, 'Solitude de Machiavel' : Solitude de Machiavel, éd. préparée et commentée par Y. Sintomer, Paris, PUF/ Actuel Marx confrontation, 1998, p. 319.

${ }^{24}$ R. Bodei, 'Italien, Langue italienne : une philosophie, aussi, pour les non-philosophes', in : Vocabulaire européen de philosophies, dir. B. Cassin, Paris, Seuil/Le Robert, 2004, pp. 625-626.
} 
interrogations plutôt qu'elle ne délivre des réponses : qu'est-ce qu'une vie de philosophe ? Qu'est-ce que la philosophie, et singulièrement la philosophie politique ? En réalité, ce qui se dissimule dans l'affirmation selon laquelle que Machiavel n'est pas un philosophe, c'est une certaine conception de la philosophie et sans doute, plus particulièrement, de la philosophie politique. Dans le rapport à Machiavel se joue une définition de la philosophie. Ainsi devra-ton plutôt se demander : pour qui «l'étrangèreté » de Machiavel par rapport à la philosophie est-elle significative ? De quelle conception de la philosophie témoigne-t-elle ? Et décider du statut et de l'importance que l'on veut conférer à cette "étrangèreté » de Machiavel à la philosophie dans la compréhension de son œuvre.

Afin de penser à distance la relation étrange qui semble s'être nouée entre certains philosophes et l'œuvre de Machiavel, voire la posture du penseur Machiavel au sein de la cité et par rapport au gouvernement politique, l'on préfèrera prendre pour point de départ le modeste constat que les dits de Machiavel paraissent, à l'échelle de plusieurs siècles, « concerner ${ }^{25}$ les philosophes, au point que certains discutent ses thèses, sans passion particulière mais avec constance, pour les reprendre à leur compte ou les critiquer, tel David Hume qui évoque certaines des idées machiavéliennes les plus importantes comme des évidences (la nécessité d'un retour régulier aux principes premiers du gouvernement, la corruption et la mort inéluctable de tout corps politique) ou indique que le «politician» Machiavel a fait erreur sur tel ou tel point parce qu'il n'a pas bénéficié d'un recul historique suffisant pour élaborer « l'une de ces vérités éternelles insensibles au temps et aux accidents de l'histoire $» .{ }^{26}$ Philosophe ou pas, Machiavel a été un interlocuteur privilégié des philosophes. C'est ce privilège attaché à sa pensée politique, doublé d'une exclusion hors de la communauté philosophante, qu'il faut comprendre.

\footnotetext{
${ }_{25}$ P-F. Moreau, 'Machiavel ou la philosophie', in: Revue philosophique de la France et de l'étranger, Machiavel, PUF, Janvier/ Mars 1999, pp. 4-5.

${ }^{26}$ D. Hume, 'La politique peut-elle être réduite à une science?', Essais moraux, politiques et littéraires et autres essais, tr. de G. Robel, Paris, PUF, 2001, p. 138.
} 
« Si la religion disparaissait du monde, c'est dans le cour d'un athée qu'on la retrouverait $\gg^{27}$

Lorsqu'on aborde Machiavel en philosophe, on peut être en désaccord avec ses thèses, estimer qu'il ne poursuit pas les fins véritables de la philosophie politique, pose les mauvaises questions ou procède selon une méthode inappropriée à son objet. Tout au moins n'aura-t-on pas le sentiment de lire une langue étrangère à la philosophie : la «solitude» de Machiavel, soulignée par L. Althusser, n'est pas absolue. Si, peut-être, comme ce dernier le soutient, nous n'avons pas pensé dans sa pensée, si celle-ci a été recouverte par le jusnaturalisme et le contractualisme et parfois nous déroute, elle ne nous est pas hermétique. Cela tient en partie au fait que Machiavel n'écrit pas dans un langage technique, et que, de temps à autres, il cite et discute des philosophes et leurs thèses : nous avons avec lui en commun un certain corpus de pensées et de textes. Enfin, nous nous reconnaissons volontiers dans cette scène, où Machiavel dit entrer dans « les antiques cours des Anciens » et se repaittre du mets qui est par excellence le sien et pour lequel il est né : « et là je n'ai pas honte de parler avec eux et de leur demander les raisons de leurs actes ; et eux, par humanité, ils me répondent ; et pendant quatre heures de temps, je ne ressens aucun ennui, j'oublie tout tracas, je ne crains pas la pauvreté, la mort ne m'effraie pas : je me transporte tout entier en eux $\gg .^{28}$ Comme Machiavel, les philosophes nourrissent leur pensée et leur interrogation de la lecture d'autres philosophes, contemporains ou passés.

Cette relative (et parfois trompeuse) familiarité avec Machiavel est liée à un autre fait essentiel : lorsque Machiavel écrit ses œuvres dans le premier quart du $15^{\text {eme }}$ siècle, il est l'héritier, volens nolens, du geste fondateur de la philosophie politique dans l'Occident

\footnotetext{
${ }^{27} \mathrm{Ch}$. Baudelaire, Aphorismes, carnet d'Asselineau, in : Euvres complètes, I, Paris, Gallimard, Bibliothèque de la pléiade, 1975 , p. 710.

${ }^{28}$ Machiavel, Lettre à Francesco Vettori du 10 décembre 1513, tr. de J-Cl. Zancarini et J-L. Fournel, in : Le Prince, Paris, PUF, 2000, p. 531.
} 
chrétien. Celui-ci a été accompli deux siècles auparavant par Thomas d'Aquin qui, en lecteur d'Aristote, a posé les fondements d'une «scientia civilis ». Adossée à la détermination d'un domaine d'exercice propre à la raison, distinct du domaine de la foi, la «scientia civilis » est affirmée avec vigueur comme un savoir pratique nécessaire :

«Tout ce que nous pouvons connaître rationnellement, il faut bien en effet que quelque doctrine l'élève vers cette perfection de la sagesse humaine recherchée par la philosophie. Or ce 'tout' constitué par la cité est, lui aussi, sujet de certains jugements rationnels. Il s'est donc révélé nécessaire à l'achèvement de la philosophie d'élaborer sur la cité une doctrine appelée 'politique' - autrement dit, une science sociale [civilis scientia].

(...) Les sciences pratiques, on le sait, se distinguent des sciences spéculatives en cela que ces dernières sont axées sur la seule connaissance de la vérité, tandis qu'elles-mêmes sont orientées vers l'action. Nous devrons donc inclure la science politique dans le domaine de la philosophie pratique : la cité est un certain ensemble que la raison humaine ne se contente pas de connaître mais qu'elle fait $\gg{ }^{29}$

Au Moyen Âge et au début de la Renaissance, une telle affirmation contribue à renouveler les interrogations relatives à la mission du roi : désormais, la nature des différentes formes de régime politique, la détermination du meilleur d'entre eux, du site adéquat pour fonder une cité, des conditions matérielles nécessaires à la vie du royaume sont des objets pertinents de réflexion pour le philosophe politique. Pour autant, chez Thomas d'Aquin, l'idée du fondement divin du pouvoir et la subordination de l'action politique à la mission chrétienne du salut des âmes ne sont jamais remises en cause. L'argument de la naturalité de la cité, repris de manière plus ou moins fidèle à Aristote par le dominicain et ses successeurs, n'est pas utilisé pour promouvoir une pensée politique déliée de la religion. Cependant, un espace est assigné au travail de la raison dans le champ politique. La prudence, jusque là perçue comme synonyme de sapientia (connaissance spirituelle du bien et du mal), est désormais la vertu qui permet à l'homme d'atteindre ses buts dans l'ordre des choses contingentes. ${ }^{30}$

De manière différente, chez Machiavel, le gouvernant a une mission exclusivement terrestre. En aucun cas, son action n'est subordonnée à une fin chrétienne. De ce point de vue, la pensée de Machiavel entretient des liens distendus avec le geste fondateur de Thomas d'Aquin, dans la mesure où celui-ci ne peut être correctement interprété qu'en relation avec la conviction d'une mission chrétienne du roi. Il n'en reste pas moins que la «scientia civilis » entendue comme champ d'exercice de la raison pratique est bien le lieu dans lequel se déploie également la réflexion machiavélienne.

\footnotetext{
${ }^{29}$ Thomas d'Aquin, Préface à la politique, avant-propos, tr. et explication de H. Kéraly, Collection Docteur Commun, Paris, Nouvelles éditions latines, 1974, pp. 21-27.

${ }^{30}$ Thomas d'Aquin, Somme théologique I-II, Question 62, art. 2, Paris, Le Cerf, 1998, p. 378.
} 
Cette inscription dans un cadre de pensée commun avec la philosophie se double, chez Machiavel, d'un questionnement nourri sur la relation entre politique et religion. Or, celui-est également essentiel, sous des formes diverses à la tradition philosophique qui le précède et le suit. Machiavel se situe exclusivement dans l'espace assigné à la raison par Thomas d'Aquin et tourne le dos à celui attribué à la foi par ce dernier. Mais cela ne signifie pas que la figure de Dieu et le fait de la croyance des hommes en un ou des Dieux sont absents de sa réflexion. Dieu, les dieux, le fait de la croyance sont constitués en phénomènes essentiels pour une pensée politique par l'auteur du Prince et des Discours sur la première décade de Tite-Live. Pourtant, la vision la plus courante de Machiavel, à la fois comme personne et comme penseur, est celle, corrélative d'une certaine conception de la modernité politique, d'un esprit athée. Il convient d'expliquer cette vision et d'énoncer les raisons qui invitent à la corriger.

Parmi les philosophes qui ont contribué à forger cette représentation de Machiavel, on retiendra notamment le napolitain Giambattista Vico qui lui reprochait, au début du $18^{\text {ème }}$ siècle, de n'avoir pas su déchiffrer le véritable cours de l'histoire politique des hommes. Selon Vico, celui-ci s'éclaire si l'on distingue le droit et la loi. Dans l'histoire humaine, le premier droit naturel est divin. C'est l'âge des sacrifices humains et des familles dans lesquels les pères sont les chefs. Lui succède un droit naturel héroïque, qui conserve dans une certaine mesure la sauvagerie et la férocité de l'état précédent, mais lui donne une forme institutionnelle. C'est le droit qui, dans l'esprit de Vico, correspond aux premières cités et à l'émergence de l'aristocratie. Un premier désir véritable de loi voit le jour, lorsque les clients des pères-chefs prennent conscience de leur servitude et qu'elle leur devient insupportable. Vient ensuite un troisième temps où les hommes conquièrent l'égalité, temps où ce désir de la loi s'est étendu à la majorité.

Or, selon Vico, ce passage d'une étape à l'autre du droit naturel est déterminé par la Providence, qui a pourvu l'homme d'un tel désir de loi, sorte de conatus civil. Celui-ci l'empêche de rester indifférent à la souffrance qui lui est imposée et lui donne les moyens de revendiquer l'égalité prévue, du reste, par le droit naturel lui-même. La Providence détermine en ce sens les conditions d'un droit naturel à l'insurrection, puisque ce conatus tend vers une insurrection de la liberté, d'où surgit un droit commun. C'est ce que Machiavel, selon Vico, n'a pas compris ou su voir : pour lui, la Providence est absente de l'histoire. De ce fait, il a confondu l'occasion et la cause. Comme Épicure, Hobbes, Spinoza et Bayle, il voit dans l'utilité personnelle la raison des actions humaines, alors qu'elle est seulement l'occasion qui 
amène les hommes à se regrouper et que la cause véritable de ce regroupement est la Providence qui destine les hommes à réaliser, au cours de l'histoire, un droit commun. ${ }^{31}$

Deux siècles plus tard, Benedetto Croce a repris cette interprétation en affirmant qu'il a appartenu à l'ensemble de l'historiographie de la Renaissance « de nier la transcendance chrétienne », Machiavel jouant pour lui dans ce processus un rôle de premier plan. ${ }^{32}$ Antonio Gramsci a également contribué à diffuser la réputation de Machiavel comme penseur athée, en reprenant la lecture de Vico, mais en un sens positif cette fois-ci. Loin de reprocher à Machiavel son oubli de la Providence, il estime que l'auteur du Prince «a exprimé une conception du monde originale, que l'on pourrait appeler, elle aussi, une 'philosophie de la praxis', ou un 'néo-humanisme' dans la mesure où elle ne reconnaît pas d'éléments transcendentaux ou immanents (dans le sens métaphysique) mais se fonde entièrement sur l'action concrète de l'homme qui, pour ses nécessités historiques, agit sur la réalité et la transforme $\gg .{ }^{33} \mathrm{La}$ distance de Machiavel à l'égard de la religion est évoquée à plusieurs reprises dans les Cahiers de prison, que ce soit pour souligner l'instrumentation de la religion, l'autonomie de la politique machiavélienne à l'égard de la morale et de la religion ou l'absence d'éléments transcendentaux dans la vision de l'histoire qui émane de ses œuvres.

Cette vision d'un Machiavel, penseur athée, est pluriséculaire. Elle s'enracine également dans une autre source : la critique du " machiavélisme » qui se développe dès le $16^{\text {ème }}$ siècle dans le cadre d'une réaffirmation de la puissance de l'Église chrétienne, de sa capacité militaire à combattre « Le Turc » et du rôle politique prééminent de la papauté. Dans ce cadre, Machiavel incarne l'athée par excellence. Il est lu comme celui qui, en politique, voit l'État comme une entité indépendante de l'Église et de tout fondement religieux. Le Discours d'Estat sur les moyens de bien gouverner et maintenir en bonne paix un royaume ou autre principauté. Divisez en trois parties à savoir du Conseil, de la Religion et Police que doit tenir un Prince; Contre Nicolas Machiavel ou, plus brièvement l'Anti-Machiavel témoigne d'une telle interprétation de la pensée machiavélienne. ${ }^{34}$ Paru quatre ans après la Saint Barthélemy, l'ouvrage de Gentillet porte autant sur les Discours que sur Le Prince. Il met en scène le soldat

\footnotetext{
${ }^{31}$ G. Vico, La Science nouvelle, Conclusion de l'œuvre, 1108-1109, tr. de A. Pons, Paris, Fayard, L'esprit de la cité, 2001, pp. 538-639.

${ }^{32}$ B. Croce, Théorie et histoire de l'historiographie, tr. de A. Dufour, Genève, Droz, 1968, pp. 146-156.

${ }^{33}$ A. Gramsci, Cahiers de prison 1-5, 5 (IX), 1930-1932, 127, tr. de M. Aymard et Fr. Bouillot, Paris, NRF Gallimard, Bibliothèque de philosophie, 1996, p. 493. cf. aussi Cahier 4 (XIII), 8.

${ }^{34} \mathrm{Cf}$. le dossier 'L'antimachiavélisme de la Renaissance aux Lumières, in : Problèmes d'histoire des religions, éd. A. Dierkens, 8/ 1997.
} 
chrétien et réfute l'idée selon laquelle le christianisme est responsable d'un affaiblissement des mœurs civiques et militaires. Il critique sévèrement le point de vue de Machiavel et l'accuse de détourner les hommes de la religion: " voila la maxime et les raisons que ce malheureux atheiste a vomies en ses beaux discours, pour blasmer et mettre du tout en mespris la religion chrestienne, et nous mener à son atheisme, et nous despouiller de toutes religion, crainte de Dieu, et de toute conscience, foy et loyauté, qui nous sont enseignées par nostre religion chrestienne $»{ }^{35}$ Gentillet s'attache à souligner la valeur militaire des chrétiens, invoquant l'histoire ancienne et moderne et notamment les hauts faits de Charles Quint : «c'est merveille que ce vilain athéiste ose mettre chose si absurdes en avant, et qui sont eloisgnes de toute experience et verité. Si ce qu'il dit estoit vray, il s'ensuyvroit que nul prince chrestien ne pourrait tenir contre les princes payens et infidèles. Mais les histoires anciennes et modernes ne nous monstrent elles pas tout le contraire $? »{ }^{36}$

Écrit par un protestant, L'Anti-Machiavel a une portée qui transcende le conflit des confessions et contribue à une critique également développée dans le cadre de la contreréforme. Le De regia sapientia (1582, publié à Milan en 1583) de Giovanni Botéro, puis son Della ragion di Stato (Venise, 1589) envisagent la pensée de Machiavel comme le vecteur et le support d'une émancipation du pouvoir politique vis-à-vis de la religion. La curie romaine lui oppose une « raison d'Église », selon laquelle le pouvoir spirituel prime sur le temporel. Elle fait de la politique «machiavéliste » l'ennemi à combattre comme l'illustre ce jugement sur le gouvernement du royaume de France : « la France, comme elle est la plus grande et la plus puissante de tous ses voysins, elle est aussi la plus dangereuse, tant à cause de la liberté de conscience qui y est permise, qui veut dire le grand chemin à l'athéisme, à la nullité de religion et à une dissolution entière de toutes les bonnes moeurs (...) Et comme elle se conduit entièrement par politique machiavelliste, n'ayant d'autre but que son intérêt et grandeur, elle n'a ny foy, ni loy, ni religion, qu'autant qu'ils servent à son avancement $»{ }^{37}$

Dans cette perspective, la curie romaine oppose à Machiavel une raison d'État conforme aux enseignements chrétiens. Parmi d'autres, la réflexion d'un haut fonctionnaire espagnol au service de Philippe III, Fernando Alvia de Castro, qui publie en 1616 à Lisbonne la Verdadera razon de Estado. Discurso politico, illustre cette tentative. Rejetant la conception de la raison d'État comme stratégie visant l'utilité du prince, il fait appel à Cicéron, Sénèque et Saint-Thomas pour défendre les principes d'une politique morale et

\footnotetext{
${ }^{35}$ Gentillet, Anti-Machiavel, éd. de C. Edward Rathé, Genève, Droz, 1968, pp. 215-216.

${ }^{36}$ Ibid., p. 216-217.

${ }^{37}$ A. L. P. Robaulx de Soumoy (éd.), Considérations sur le gouvernement des Pays-Bas, Bruxelles-La Haye, 1872, t. 1, p. 197.
} 
l'idée qu'une action faite au dépens de la justice n'est utile qu'en apparence et nuit à la réputation et à la sécurité du prince.

Cette vision de Machiavel comme penseur athée trouve plusieurs raisons d'être dans son œuvre. La première de ces raisons, et sans doute la plus frappante à la lecture, est la conception non-chrétienne de l'histoire qu'il développe, en contraste avec le contexte historique et spirituel dans lequel il élabore sa pensée. Son époque est marquée, à Florence, par la mémoire vive du projet de réforme savonarolien et, plus généralement, par l'attente de la fin des temps, qui prédomine dans l'histoire chrétienne jusqu'à la moitié du $16^{\text {ème }}$ siècle. $^{38}$ Machiavel interprète d'un point de vue « temporel » des événements ou des phénomènes qui relèvent initialement de l'histoire biblique. Le traitement accordé aux principats ecclésiastiques est à cet égard exemplaire. Dans le chapitre 11 du Prince, qui clôt l'évocation des différents types de principats, Machiavel semble tout d'abord concéder un statut particulier aux principats ecclésiastiques : « ceux-ci étant soutenus par des causes supérieures, auxquelles l'esprit humain n'atteint pas, je renoncerai à en parler, parce que, étant élevés et maintenus par Dieu, discourir à leur propos serait office d'homme présomptueux et téméraire $» .{ }^{39}$ Cependant, ce principe d'analyse est rapidement remis en cause : Machiavel affirme ensuite s'intéresser à l'acquisition récente et spectaculaire du pouvoir par la papauté « dans le temporel ». L'explication qu'il en donne est semblable à celle qu'il a fournie à propos d'autres principats, républiques ou empires, dans les chapitres précédents de l'ouvrage : elle est fondée sur la considération des rapports de puissance entre les cités, de leurs forces matérielles respectives, de leurs appuis diplomatiques et de la vertu des papes. Contrairement à l'affirmation liminaire, Machiavel applique donc les mêmes critères d'évaluation aux principats ecclésiastiques qu'aux autres. Pour rendre compte de la situation des principats ecclésiastiques «dans le temporel», il n'est nul besoin de faire appel à la puissance divine. C'est encore un tel point de vue qu'il adopte dans L'Histoire de Florence, I, où la papauté est présentée à travers son rôle «géopolitique » au sein de l'espace italien, depuis le déclin de l'empire romain jusqu'à 1434, rôle toujours important, voire prépondérant, malgré « une situation interne de faiblesse et de désagrégation ${ }^{40}$

\footnotetext{
${ }^{38}$ R. Koselleck, Le Futur passé. Contribution à la sémantique des temps modernes, Paris, EHESS, 1990, p. 21.

${ }^{39}$ Le Prince, 11, p. 101.

${ }^{40}$ E. Cutinelli-Rendina, Chiesa e religione in Machiavelli, Pise, Istituto ed. e poligrafici internazionali, 1998, p. 303 [ma tr.].
} 
Moïse devient aussi, sous la plume de Machiavel, un fondateur comme les autres. Comme il l'a fait à propos des principats ecclésiastiques, Machiavel exclut tout d'abord Moïse de ses considérations : on ne doit pas raisonner sur lui car ses actions ont été ordonnées par Dieu. ${ }^{41}$ Puis il formule un point de vue à partir duquel il devient possible d'examiner à égalité l'action de Moïse et celle des autres fondateurs. Il parvient donc à lui ôter sa singularité, en dépit de sa relation particulière à Dieu : « en examinant leurs actions et leur vie, on ne voit pas qu'ils eurent de la fortune autre chose que l'occasion, qui leur donna la matière pour pouvoir y introduire cette forme qui leur parut bonne et sans cette occasion, la vertu de leur esprit se serait éteinte, et sans cette vertu, l'occasion serait venue en vain $\gg{ }^{42}$ Dans les Discours, le regard porté sur les actions de Moïse est également issu de ce renversement de perspective : sa relation à Dieu n'est pas évoquée, que ce soit dans les chapitres qui ont pu être rédigés avant Le Prince ou ceux qui lui font suite. Son action et les difficultés qu'il rencontre ne lui sont pas spécifiques, mais semblables à celles des autres fondateurs. $^{43}$

La papauté, Moïse, et enfin la religion. Tous sont soumis au même traitement. Les Discours, II, 5, considèrent en effet les religions d'un point de vue «temporel ». Il est consacré à l'examen d'un fait historique notable : l'oubli, à toute époque, des temps précédents. Machiavel y affirme que les hommes perdent la mémoire des temps et qu'il est de ce fait impossible de statuer sur la question de l'éternité du monde. À l'occasion de cette analyse de la mémoire, les religions sont présentées comme des phénomènes historiques : corps mixtes, et donc mortels, elles apparaissent et disparaissent dans le temps; elles s'empressent en outre de faire disparaître toute trace de celles qui les ont précédées. ${ }^{44}$

Le traitement accordé aux principats ecclésiastiques, à l'histoire de la papauté, à Moïse et aux « sectes» sont autant de signes d'une conception non-chrétienne de l'histoire. Dans l'œuvre de Machiavel, cette perspective se double d'une instrumentalisation politique de la religion. L'existence du Dieu chrétien ou des dieux romains est d'emblée envisagée comme une croyance susceptible de servir le pouvoir politique. Elle est un outil puissant de domination et s'avère particulièrement utile en temps de guerre, comme l'illustre de façon récurrente les Discours. La croyance aux prodiges et à l'interprétation des auspices, interprétation faite

\footnotetext{
${ }^{41}$ Le Prince, 6, p. 77.

${ }^{42}$ Le Prince, 6, pp. 77-78.

${ }^{43}$ Discours, I, 1 et 9, II, 8, III, 30.

${ }^{44}$ Discours, II, 5, p. 277-281. Nous retrouvons dans L'Histoire de Florence, I, 5, un développement similaire, p. 665.
} 
«selon les nécessités », permet aux soldats de faire preuve de courage et d'endurance au combat. ${ }^{45}$ Par ailleurs, la religiosité (ou l'apparence de religiosité) est, selon Machiavel, une « vertu » princière appréciée. ${ }^{46}$

Interprétation de l'histoire en rupture, et bien souvent en contradiction, avec le christianisme, instrumentalisation de la religion : deux aspects qui semblent légitimer la vision d'un pensée athée. Pourtant, Machiavel ne répugne pas à l'emploi de termes ou d'arguments empruntés au texte biblique. Ainsi, le chapitre 26 du Prince fait un usage récurrent du terme « rédemption » à propos du sort de l'Italie qu'il faut libérer des armées étrangères. ${ }^{47}$ De prime abord, nous pourrions être tentés d'interpréter ces propos comme la marque d'une certaine irrévérence religieuse : Machiavel utiliserait, au sein de sa réflexion sur les conditions de la libération de l'Italie, un vocabulaire religieux, au mépris de la signification spirituelle ou mystique de celui-ci. Toutefois, cette interprétation est doublement superficielle. Tout d'abord, ce chapitre a une forte charge émotionnelle et il est probable que Machiavel ait cherché à tirer profit de l'influence du discours prophétique à Florence, essentielle à l'histoire politique de la cité entre 1470 et $1525 .^{48}$ En outre, l'usage machiavélien des épisodes bibliques met en avant une modalité non déterministe de l'intervention divine. Autrement dit, Machiavel affirme l'existence de Dieu en même temps qu'il met en valeur la liberté humaine. C'est qu'en réalité, il n'a pas besoin de nier la première pour fonder la seconde. Ainsi encourage-t-il les Italiens à prendre les armes et à se défendre contre les invasions étrangères, en soulignant que Dieu ne fera pas tout à leur place : " on voit ici des faits extraordinaires, sans exemple, conduits par Dieu : la mer s'est ouverte, un nuage Vous a escorté sur le chemin, la pierre a versé de l'eau, ici il a plu la manne. Chaque chose a concouru à votre grandeur. Le restant, vous devez le faire ; Dieu ne veut pas faire chaque chose, pour ne pas nous ôter le libre-arbitre et la part de cette gloire qui nous revient $\gg .{ }^{49}$

Cette façon de concevoir la liberté humaine dans un cadre d'action marqué par l'existence de Dieu n'est pas, au début du $15^{\text {ème }}$ siècle, propre à Machiavel. La présence de la notion de libre-arbitre, entendue comme faculté de l'homme à déterminer lui-même ses actions, diffusée par la pensée scolastique, n'a pas débouché sur la négation de Dieu et de son

\footnotetext{
${ }^{45}$ Discours, I, 13-15.

${ }^{46}$ Le Prince, 18, p. 130.

${ }^{47}$ Le Prince, 26, pp. 163-166.

${ }^{48} \mathrm{Cf}$. à ce propos : D. Weinstein, Savonarole et Florence, prophétie et patriotisme à la Renaissance, tr. De M-F. de Palomera, Paris, Calmann-Lévy, 1973 ; L. Polizzotto, The Savonarolan movement in Florence, 1494-1545, Oxford, Oxford university press, 1994.

${ }^{49}$ Le Prince, 26, p. 164.
} 
pouvoir. Comme le souligne le Dialogue sur le libre arbitre de Lorenzo Valla, la pensée chrétienne elle-même a fait place au libre-arbitre et il est possible d'affirmer de manière tout à fait cohérente à la fois l'existence de Dieu et le libre-arbitre des hommes, comme le fait ici Machiavel. ${ }^{50}$ Le texte biblique offre des passages qui peuvent être interprétés en ce sens, comme cette recommandation de l'Ecclésiaste : « Ne dis pas : 'C'est le Seigneur qui m'a fait pécher', car il ne fait pas ce qu'il a en horreur (...) Devant toi, il a mis le feu et l'eau, selon ton désir, étends la main. Devant les hommes sont la vie et la mort, à leur gré l'une ou l'autre leur est donnée $» .^{51}$

Cette première incursion dans l'œuvre de Machiavel montre que nous ne pouvons nous contenter, à son égard, de l'opposition, aujourd'hui coutumière, entre une conception athée et une interprétation religieuse de l'histoire humaine. Au-delà du fait qu'il ne nie pas l'existence de Dieu (parce que cette négation n'est pas une condition de possibilité de l'affirmation de la liberté humaine), il faut en outre reconnaître que Machiavel accorde une place essentielle à la religion comme institution et à la croyance religieuse en tant que fait politique. Plusieurs hypothèses interprétatives doivent être mobilisées pour rendre compte de cette place dans la pensée politique présentée par Le Prince et les Discours sur la première décade de Tite-Live. Une première piste à l'égard de la manière dont Machiavel traite de la religion et de son lien avec la sphère politique nous est fournie par la thèse schmittienne énoncée en 1922, selon laquelle «tous les concepts prégnants de la théorie moderne de l'État sont des concepts théologiques sécularisés ».$^{52}$ Certes, Carl Schmitt n'a pas illustré sa thèse à partir de l'œuvre de Machiavel et pour cause : ce dernier constitue un être à part dans l'analyse de C. Schmitt qui s'intéresse aux penseurs de l'État souverain et envisage seulement la religion chrétienne, alors que la pensée politique de Machiavel repose sur une confrontation entre le christianisme et la religion romaine et ne fait pas de place à l'idée de souveraineté. Cependant, l'hypothèse schmittienne s'avère pertinente au moins à propos du concept machiavélien de "rénovation » que l'on rencontre dans son analyse de la corruption des cités. Dans le chapitre III, 1 des Discours, Machiavel prône un «retour aux commencements » pour éviter la corruption ou amoindrir ses effets destructeurs sur la vie politique de la cité. ${ }^{53}$ Ce retour est présenté comme une espèce d'altération [alterazione] au sens aristotélicien du terme, c'est-à-dire comme une

\footnotetext{
${ }^{50}$ L. Valla, Dialogue sur le libre arbitre, éd. de J. Chomarat, Paris, Vrin, 1983, p. 28. cf. aussi La Divine comédie, Le Purgatoire, XVI, vv. 67-83.

${ }^{51}$ La Bible, L'Ecclésiaste, 15, 11 et 16-17, pp. 1193.

${ }^{52}$ C. Schmitt, Théologie politique, tr. et prés. de J-L. Schlegel, Paris, NRF Gallimard, 1988, p. 46.

${ }^{53}$ Discours, III, 1, p. 390.
} 
modification des qualités du sujet, mais non du sujet lui-même. Le retour aux commencements ne modifie pas l'être de la cité : il la fait revenir à son état initial. Machiavel qualifie aussi ce retour de rénovation [rinnovazione]. ${ }^{54} \mathrm{Si}$ l'idée de « renovatio » est diffusée par l'astrologie, si La Politique de Platon a pu en inspirer la formulation au tournant du $16^{\text {ème }}$ siècle, sa source est également chrétienne : «la confiance dans le renouveau, dans le retour aux principes, en lesquels 'il convient' toujours 'qu'il y ait quelque chose de bon', est exactement analogue à la confiance qui, dans le champ religieux, avait dominé tout le moyen âge chrétien - orientation caractéristique de la mentalité religieuse en général et de la mentalité chrétienne en particulier, qui disposait, à un certain moment de l'histoire humaine, celui de son origine, dans la parole du Christ, des tables éternelles de sa loi, les principes qui encadraient, du début à la fin, toute la vie de l'humanité chrétienne. Le mythe du renouveau, sous la forme du retour à la vie morale élevée et pure des origines, contemplées comme l'âge de la perfection, avait été un mythe religieux, relevant de l'orthodoxie, ou au contraire, issue de l'ardeur des sectes hérétiques, mais quoiqu'il en soit, témoignage exemplaire de la vie morale médiévale $\gg{ }^{55}$ Et c'est cette référence qui semble dominer dans l'esprit de Machiavel. En effet, dans le chapitre III, 1 des Discours, il fait allusion aux pratiques des ordres religieux dominicain et franciscain. ${ }^{56} \mathrm{La}$ renovatio correspond à un retour à la perfection morale des origines du christianisme ou à l'esprit de la règle dans un ordre religieux. Le fait que les cités soient pour Machiavel de même nature que les religions (des «corps mixtes» et des «vivere commune ») et qu'avant lui, Savonarole ait envisagé la réforme de la cité florentine à partir de cette idée de rénovation, facilitent l'application d'une telle idée à la cité politique.

Machiavel ne se contente pas d'emprunter des idées à la pensée chrétienne et de les retravailler en fonction des questions politiques qu'il traite. Il envisage par ailleurs comme essentiel le rôle de la religion dans la vie politique des cités, et singulièrement dans celle qui constitue à ses yeux un paradigme pour penser la liberté, ses conditions d'épanouissement comme son déclin : Rome. Sur ce point, la réflexion de C. Schmitt sur la dimension théologicopolitique de la philosophie moderne n'est plus d'aucune aide et il faut revenir aux Discours sans béquille exégétique. Dans ce texte, Machiavel souligne que la référence aux dieux est entretenue à Rome tant pour vaincre à la guerre que pour maintenir la vie civile. Cette double instrumentalisation de la religion n'est pas identique à celle suggérée dans Le Prince, où la

\footnotetext{
${ }^{54}$ Discours, I, 3, p. 390.

${ }^{55}$ Cf. à ce sujet F. Chabod, 'Niccolò Machiavelli' (1934), in : Scritti sul Machiavelli, Einaudi, 1964, pp. 218-219 [ma trad.].

${ }^{56}$ Discours, III, 1, p. 394.
} 
pensée politique de Machiavel se déploie dans un contexte chrétien marqué par la distinction entre le pouvoir temporel et le pouvoir spirituel. À Rome, la religion n'est pas extérieure aux institutions de la cité, mais leur est consubstantielle. La religion romaine joue leur rôle en amont des lois et des organes institutionnels destinés à réfréner ou à satisfaire les humeurs, en forgeant des coutumes ou des mœurs appropriées à la liberté. Ainsi, la religion, comme élément de l'ordre institutionnel, incite au respect des lois; elle crée ou affermit un style de vie favorable au « vivere civile».

Cette thèse est étayée dans les chapitres consacrés à la religion des Romains dans la vie civile qui font immédiatement suite à l'analyse de la fondation des cités libres et des conditions de leur maintien (Discours, I, 11 à 15). Dans le chapitre I, 11, Numa est présenté comme le second fondateur de Rome. Il y a, en effet, nous dit Machiavel, organisé le culte des dieux afin $\mathrm{d}^{\prime}$ « amener à l'obéissance civile » un peuple romain encore « très féroce $» .{ }^{57}$ Pour Machiavel, ce qui importe ici est l'effet d'obéissance qui découle de la croyance dans les Dieux, lié à la crainte qu'éprouvent les hommes à l'égard de ces derniers. ${ }^{58}$ Dans le domaine militaire, l'effet visé est l'espoir ; dans la vie civile, c'est la "paura religiosa », qui peut confiner à la terreur [terrore..$^{59}$ Elle est un vecteur d'obéissance essentiel à travers le serment, et apparaît de ce fait comme le nécessaire adjuvant aux lois : elle crée des obligations plus fortes que les lois ellesmêmes. Au même titre que la loi, mais avec plus d'efficacité, le serment est un instrument de gouvernement au sein de la cité et de commandement sur le champ de bataille.

L'analyse arendtienne de la notion d'autorité éclaire le sens de ce recours aux divinités dans la vie civile romaine, essentiel pour Machiavel dans l'analyse des institutions de la république romaine. Si Numa et d'autres se sont réclamés des dieux, ce n'est pas parce qu'ils « commandent» aux hommes d'obéir à telle ou telle loi. La force liante de la religion tient plutôt à l'autorité des dieux, qui est un pouvoir d'un genre particulier : selon le sens du verbe latin «augere », dont est issu le substantif «auctoritas », cette autorité « augmente » la loi. Les dieux n'imposent pas les lois, mais les « approuvent» : ils les recommandent [consigliare]. Mais selon les termes de Mommsen rappelés par H. Arendt, une loi approuvée par les dieux est "plus qu'un conseil et moins qu'un ordre, un avis auquel on ne peut passer outre sans dommage $»{ }^{60}$

\footnotetext{
${ }^{57}$ Discours, I, 11, p. 101.

${ }^{58}$ Ibid.

${ }^{59}$ Le De Rerum natura développe cette idée de la peur religieuse (V, v. 1161 sqq.) et a pu inspirer Machiavel. À l'époque médiévale et à la Renaissance, il s'agit aussi d'un thème qui circule de manière large et diffuse, à partir de la philosophie d'Averroès et de l'œuvre de Marsile de Padoue, le Défenseur de la paix.
} 
Comme le suggère par ailleurs l'analyse du droit romain développée par Émile Benvéniste à partir d'une analyse du terme «ius » et de sa relation avec le verbe « iurare », il n'est pas étonnant que Machiavel ait pu formuler une telle relation entre la loi et la religion à partir du cas romain. ${ }^{61}$ En effet, le verbe «iurare », qui correspond à l'acte de répéter la formule prononcée «in verba alicuius qui praeit [dans les termes que celui qui précède a indiqués] $»,{ }^{62}$ a une signification religieuse, comme l'avaient déjà souligné les historiens de Rome lus par Machiavel : Polybe, Denys d'Halicarnasse, Tite-Live. ${ }^{63}$

À l'issue de cette analyse des conditions de la liberté à Rome, il apparaît tout d'abord que la pensée politique de Machiavel ne peut être qualifiée d' " athée » (il ne nie pas l'existence de Dieu) ni même de «laïque " (au sens où il prônerait un espace civil qui serait neutre du point de vue religieux). Il rejette l'idée d'un fondement religieux du pouvoir et l'histoire écrite d'un point de vue chrétien, mais estime qu'à Rome, l'une des conditions essentielles du maintien de la liberté républicaine est la croyance religieuse des citoyens, en ce qu'elle produit ou du moins favorise l'obéissance aux lois de la cité.

En outre, cette thèse n'a pas, pour Machiavel, une portée restreinte à Rome. Dans la mesure où l'histoire de la république romaine est utilisée dans les Discours sur la première décade de Tite-Live et L'Histoire de Florence comme un instrument d'analyse et d'évaluation du devenir de la cité florentine, sa réflexion sur les conditions de la liberté à Florence est soustendue par la conviction que la religion serait également utile à cette cité pour y affermir des mœurs favorables à la république et favoriser son maintien durable. Or, pour Machiavel, il semble que le christianisme, bien interprété, soit à même de jouer, pour Florence, le même rôle que la religion à Rome. Les Florentins, bien que « citadins », ne sont pas dépourvus de piété comme le montre le succès des prêches de Savonarole. ${ }^{64}$ Même si elle souffre de la comparaison avec celle des Anciens ou des hommes «frustes», la piété des Florentins peut soutenir, selon lui, une réforme de l'ordre institutionnel de la cité en vue de la liberté. Bien qu'il laisse en suspens la tâche de définir cette juste interprétation du christianisme, il est clair

\footnotetext{
${ }^{60}$ H. Arendt, 'Qu'est-ce que l'autorité ?', in : La Crise de la culture, tr. dir. par P. Lévy, Paris, Gallimard, Folio Essais, 1972, p. 162.

${ }^{61}$ É. Benvéniste, Le vocabulaire des institutions indo-européeennes, 2, Opus cit., pp. 111-112.

${ }^{62}$ Ibid., pp. 118-119.

${ }^{63}$ Polybe, Histoires, VI, 56, tr. de R. Weil, coll. de Cl. Nicolet, Paris, Les Belles Lettres, 1977, p. 139-140 ; Denys d'Halicarnasse, Les origines de Rome, II, 61, tr. de V. Fromentin et J. Schnäbele, Paris, Les Belles lettres, La roue à livres, 1990., p. 189 et II, 75, p. 191 et p. 206 ; Tite-Live, Histoire romaine, I, 19, tr. de A. Flobert, Paris, GF Flammarion, 1995, p. 86-90.

${ }^{64}$ Discours, I, 11, pp. 105.
} 
qu'à ses yeux, le problème qui se posait pour les Romains à l'époque de la république se pose autant aux Florentins.

L'intention de Machiavel n'est pas de promouvoir un retour à la confusion du pouvoir spirituel et du pouvoir temporel et encore moins à la domination du second par le premier. Il n'entend pas non plus pallier les insuffisances des valeurs politiques communes en faisant appel aux valeurs inscrites dans les religions. Son problème fondamental est celui de l'obéissance des citoyens à la loi. C'est pourquoi sa thèse concerne aussi, finalement, les partisans d'un espace politique laïc et à ce titre, retrouve un questionnement philosophique récurrent depuis les guerres de religion. En effet, ce que suggère sa réflexion sur la religion des Romains est qu'un état où la loi régit les relations entre les citoyens peut difficilement se passer d'une « béquille » pour déterminer ces derniers à lui obéir. En cela, il est proche de J-J. Rousseau qui soulève, dans Le Contrat social, IV, 8, la même question et définit une religion susceptible de contrarier l'intérêt égoïste de l'homme et d'inscrire dans son cœur l'amour des lois. Ce que nous pouvons entendre aujourd'hui, en lisant Machiavel, c'est le soupçon sur la capacité de la démocratie laïque à susciter sans un appui ou un artifice quelconque un «amour des lois » dans le cœur de ses citoyens. ${ }^{65}$

Pour autant, il n'est pas certain que nous devions nous rendre à la solution suggérée par Machiavel. N'oublions pas, en effet, que la religion invoquée par Machiavel est associée de manière primordiale à l'affect de la crainte, dont on peut douter qu'il ait sa place dans une politique de la liberté, comme l'a souligné Spinoza de façon magistrale dans son Traité politique. $^{66}$ Mais pour Machiavel comme pour nous, le problème des motivations de l'obéissance aux lois demeure entier, en particulier lorsqu'on s'inscrit dans le temps long de l'histoire des cités libres.

Aborder l'œuvre de Machiavel en s'interrogeant sur son rapport à la religion et au fait de la croyance religieuse dans l'existence des dieux ou d'un dieu s'avère riche d'enseignements. On apprend tout d'abord que, contrairement à sa réputation de penseur athée, Machiavel ne nie pas l'existence du Dieu chrétien dans Le Prince parce qu'il n'a pas besoin de le faire, d'un point de vue théorique, pour affirmer la liberté humaine. Il suffit pour lui, et c'est ce qu'il fait, de lui conférer une place mineure dans l'explication des événements politiques qui jalonnent l'histoire des hommes, aspect que l'on retrouve également dans les Discours et

\footnotetext{
${ }^{65}$ Ce sujet, G. Waterlot, Rousseau, Religion et politique, Paris, PUF, Philosophies, 2004, p. 73 sqq.

${ }^{66}$ B. Spinoza, Traité politique, V, édition bilingue latin-français de Ch. Ramond, PUF, Épiméthée, 2005, p. 137.
} 
L'Histoire de Florence. On constate par ailleurs qu'il propose une interprétation de l'histoire humaine centrée sur les conditions de succès d'une action strictement humaine et les jeux de pouvoir entre les individus et les cités. On observe enfin qu'il envisage la croyance religieuse d'un point de vue exclusivement politique, en soulignant l'utilité qu'elle a eue pour le maintien de la république romaine et ses victoires militaires, en suggérant qu'un tel rôle pourrait être assumé à l'époque contemporaine (la sienne) par le christianisme.

La religion occupe donc une place importante dans sa pensée politique, en tant qu'instrument de gouvernement, de domination et d'orientation de l'action des citoyens et des soldats. Pour une pensée contemporaine de la démocratie, une telle réflexion est intéressante en ce que la vision instrumentale de la religion proposée par Machiavel est articulée à une interrogation essentielle au fonctionnement des institutions d'un Etat, quel que soit son régime politique, relative aux motifs de l'obéissance aux lois. Cette thèse et l'interrogation à laquelle elle est associée ont fait de lui une source précieuse pour les philosophies politiques modernes, par exemple Rousseau, qui se sont intéressés au statut de la religion dans la cité.

De ce point de vue, quelles que soient les convictions des uns et des autres, on constate que le traitement machiavélien du fait religieux constitue un point de rencontre avec un questionnement philosophique récurrent dans la pensée politique moderne. Machiavel étant l'héritier du geste fondateur de la philosophie politique dans l'Occident chrétien médiéval, il existe donc deux éléments de filiation entre Machiavel et les philosophes. En amont comme en aval, «l'étrangèreté » de Machiavel a la philosophie se trouve donc, sans pour autant être gommée, quelque peu relativisée. 


\section{INSTABILITÉ, CORRUPTION ET CONFLIT CIVIL}

"Vous allez me demander tout ce qui, chez les philosophes, relève de l'idiosyncrasie? ... C'est, par exemple, leur absence de sens historique, leur haine contre l'idée même de devenir, leur "égypticisme ». Ils croient faire honneur à une cause en la 'déhistorisant', en la considérant sub specie aeterni, en la momifiant? (...) Ils tuent, ces Messieurs les idolâtres des notions abstraites, ils empaillent lorsqu'ils adorent, ils mettent tout en péril de mort lorsqu'ils adorent. La mort, le changement, le vieillissement, tout autant que la procréation et la croissance, suscitent en eux des objections, si ce n'est une réfutation! $»^{67}$

Jean Bodin, à la fin du $16^{\text {ème }}$ siècle, estime que la pensée de Machiavel est dépassée, inactuelle, incapable de contribuer à la réflexion sur les enjeux politiques de son temps. Il s'exprime en ces termes moins d'un siècle après l'écriture et la publication posthume des œuvres machiavéliennes. Avec un certain mordant, il inscrit Machiavel parmi ceux qui discourent des affaires du monde « sans aucune connaissance des lois, et pareillement du droit public » et qui, partant, " ont profané les sacrés mystères de la Philosophie politique ». Machiavel est détestable pour son athéisme, son mépris de la justice, mais plus encore parce qu'il fait partie des hommes qui concourent à la ruine des Républiques, non pas tant par malice que « par ignorance des affaires d'état ». ${ }^{6}$

On ne peut sans doute prendre l'accusation d'ignorance du droit au pied de la lettre : Machiavel est un penseur du gouvernement selon la loi, par différence avec un gouvernement selon les désirs d'un seul homme, d'un petit ou d'un grand nombre d'entre eux : la loi est, chez lui, ce qui oblige les membres d'une cité à privilégier le bien commun à leurs intérêts particuliers et il consacre une partie importante des Discours à commenter différents aspects législatifs de la république romaine ; Machiavel est également un penseur de l'institutionnalisation du conflit civil, c'est-à-dire des modalités selon lesquelles un différend,

\footnotetext{
${ }^{67}$ Fr. Nietzsche, Le Crépuscule des idoles, Opus cit., tr. de J-Cl. Hémery, Paris, Gallimard, 1974, La raison dans la philosophie, 1, p. 25.

${ }^{68}$ J. Bodin, Les Six livres de la république, Préface, éd. de G. Mairet, Paris, Le Livre de Poche, Classiques de philosophie, 1993, cf. pp. 47-51.
} 
une dissension peuvent s'exprimer dans un cadre légal ou aboutit à une réforme institutionnelle ; enfin, Machiavel est un penseur de la légalité en temps de crise. Lorsqu'il invite, à l'imitation des Romains, à prévoir un cadre institutionnel (la dictature) qui rende la cité apte à survivre à une agression extérieure d'une exceptionnelle intensité ou une situation interne particulièrement problématique, il conçoit les modalité d'un gouvernement temporaire, défini par une mission particulière, destiné à disparaître une fois celle-ci accomplie, et partant une forme de continuité de la loi dans la cité, quelle que soit la qualité des temps. ${ }^{69}$

À la lumière de ces trois éléments, il y aurait donc sans doute matière à discuter la critique bodinienne. Mais elle n'en reste pas moins significative en ce qu'elle repose sur la conviction qu'un changement de paradigme a eu lieu dans la réflexion philosophique sur les «affaires de l'état»: on ne pense plus en 1576 comme l'on avait pu penser dans les années 1510. Or, si nous sommes encore aujourd'hui, au moins en partie, les héritiers de ce changement de paradigme, il est intéressant d'examiner si «l'étrangèreté » de Machiavel par rapport à la philosophie politique ne tient pas en partie à ce changement.

L'interprétation que propose Thomas Berns de la pensée bodinienne permet d'avancer en ce sens quelques éléments de réflexion. Il insiste sur le fait qu'en articulant la politique au droit et en introduisant le principe de souveraineté, Jean Bodin a ouvert la voie à un discours politique clos et maîtrisé, qui ne laisse aucune place à l'idée de mixité du pouvoir, à l'éventualité du conflit civil, à la violence, au trouble, autrement dit à tout ce qui occupe une place centrale dans la pensée machiavélienne : «l'établissement d'un savoir et d'un registre de langage juridique et fondé sur la souveraineté est donc produit par l'exclusion hors de son champ de ce qui, chez Machiavel principalement, faisait le politique en l'exposant à ce qui s'affirme désormais définitivement comme son autre, comme ce qui ne peut plus le concerner : la corruption, mais aussi la division, la discorde, la guerre, la violence de la prise du pouvoir $\ldots{ }{ }^{70}$

Plus précisément, Jean Bodin ne se montre pas, loin de là, aveugle à tout ce qui a intéressé Machiavel au premier chef. Comment le pourrait-il d'ailleurs, lui dont le souci est de redonner des fondements solides à la concorde civile, en un temps où le royaume de France a été très éprouvé par les guerres de religion? Il existe, indique Berns, dans sa pensée un espace où l'on peut aborder et traiter de la division, de la ruine et de la corruption : c'est celui du

\footnotetext{
${ }^{69} \mathrm{cf}$. les chapitres consacrés par Machiavel à l'institution romaine de la dictature, in : Discours sur la première décade de Tite-Live, I, 33-35.

${ }^{70} \mathrm{Th}$. Berns, Souveraineté, droit et gouvernementalité, Lectures du politique moderne à partir de Bodin, Clamecy, Paris, Éditions Léo Scheer, Non \& Non, 2005, p. 131.
} 
"gouvernement». En ce sens, le thème de la souveraineté et celui du gouvernement sont complémentaires dans sa réflexion, chacun abordant des dimensions distinctes des « affaires de l'État ». Mais le premier occupe une place prééminente. La souveraineté est, chez Bodin et à partir de lui, le centre de la philosophie politique, à la fois comme objet principal de la réflexion, et norme à l'égard de laquelle tout ce qui relève de l'accidentel, du variable, du multiple doit être considéré comme second.

Au-delà de Bodin, l'on constate que les figures majeures de la philosophie politique moderne sont loin d'être insensibles à ces réalités et se montrent au contraire attachées à élaborer des modèles de régime politique qui immunisent la cité contre ces dangers. On peut même dire que l'un des fils directeurs de la tradition philosophique est de construire des «digues» destinées à protéger l'ordre politique de mouvements destructeurs et de changements imprévus. Après Machiavel, Hobbes, pour ne citer qu'un exemple, a écrit le Léviathan mais aussi Béhémoth. Et sans aucun doute, l'intention de la pensée politique qui se déploie dans la première œuvre, toute à la construction d'un ordre politique sans failles, s'éclaire à la lumière du dialogue consacré aux guerres civiles anglaises.

Cependant, il demeure vrai que par différences avec ces figures philosophique majeures, Machiavel plonge son lecteur dans un univers où le sentiment de fragilité de l'ordre politique est prégnant et l'illusion de solidité constamment dénoncée. Ainsi pouvons-nous avoir le sentiment que Machiavel met au centre de la réflexion politique des objets et des interrogations placés aux périphéries de la tradition philosophique moderne ou traités de manière limitée.

Présente dans les Discours, l'interrogation sur les moyens de faire face à la variation de la « qualité des temps » est avant tout exposée dans Le Prince, où Machiavel cherche à énoncer les conditions d'une action politique efficace. Il s'y adresse au "prince », mais une lecture conjuguée des deux œuvres montre que son analyse concerne tout autant les gouvernements républicains. Les Discours sont plus particulièrement le lieu d'un questionnement sur une modalité spécifique de la variation et les moyens de lutter contre elle : la corruption. Cette dernière est relative aux cités en tant que corps soumis aux lois biologiques de la vie et de la mort. Elle entraîne la cité vers sa «ruine ». Ses différentes phases structurent l'histoire des cités : leur scansion imprime un rythme, à chaque fois différent selon la résistance opposée à ce processus inéluctable, au devenir des régimes politiques. 
Dans Le Prince, Machiavel insiste sur la fragilité essentielle de tout pouvoir politique, conquis ou hérité, d'acquisition récente ou de longue possession. On pourrait croire que les principats héréditaires et anciens sont plus faciles à conserver que les principats nouveaux, pourvu qu'on ne cherche pas à «passer outre les ordres de ses ancêtres » et que l'on sache « temporiser face aux accidents ». ${ }^{71}$ Toute nouveauté est dangereuse, en particulier lorsqu'il s'agit de la langue et des coutumes. ${ }^{72}$ Néanmoins, le chapitre 24 du Prince vient fortement minimiser la portée et la pertinence de la distinction entre prince nouveau et prince ancien. La paresse des princes anciens les rend tout aussi vulnérables que les princes nouveaux. ${ }^{73} \mathrm{Se}$ reposer sur un pouvoir acquis de longue date sans chercher incessamment à le garantir est une cause de ruine. En effet, les temps et les circonstances connaissent une variation perpétuelle, créant toujours des situations nouvelles, voire inattendues, auxquelles les princes doivent faire face.

L'état de crise et d'urgence que Machiavel, comme homme et comme serviteur de la chancellerie florentine, a personnellement connu, devient dans son œuvre le pain quotidien de l'homme au pouvoir, son horizon permanent: toute paix est comme un temps suspendu, provisoire et destinée à ne pas se prolonger indéfiniment. C'est un des leitmotivs du Prince : de l'évocation de l'inconstance des hommes face au pouvoir et de leur désir de changement à l'affirmation d'un principe général de variation des temps, de l'éloge du caractère prévoyant des Romains à la critique de la paresse des princes italiens, sans oublier l'analyse de l'échec de César Borgia. ${ }^{74}$ Le prince est mis en situation dans un espace d'action structuré par l'opposition de ce que Machiavel appelle, par exemple au chapitre 24 du Prince, la bonace et la tempête, ou encore les temps tranquilles et les temps adverses. Il est sans cesse confronté au rappel du changement constant des circonstances, de la «variation» de la « qualité des temps».

Les Discours réitèrent cette thèse à travers une image qui rappelle la nature inconstante de la fortune évoquée dans Le Prince : «toutes les choses humaines étant en mouvement, et ne pouvant rester stables, il faut qu'elles montent ou qu'elles descendent, et la nécessité vous entraîne à beaucoup de choses auxquelles la raison ne vous entraînent pas $\gg .{ }^{75} \mathrm{D}$ 'où l'impératif, indiqué dans les chapitres 24 et 25 du Prince, d'anticiper les «variations» des temps indépendantes de la volonté humaine et les « caprices de la fortune ». La fortune est d'autant plus dévastatrice, à l'image d'un fleuve qui déborde et détruit tout sur son passage, qu'on a

\footnotetext{
${ }^{71}$ Le Prince, 2, p. 60.

${ }^{72}$ Le Prince, 3, pp. 62-63.

${ }^{73}$ Le Prince, 24.

${ }^{74}$ Respectivement : Le Prince, chapitres 3, p. 61 et 4, p. 72 ; chapitres 25, p. 162 ; chapitre 3, p. 67 ; chapitre 24 , pp. 157-158; chapitre 7, p. 87.

${ }^{75}$ Discours, I, 6, p. 82.
} 
omis d'élever des digues pour protéger le sol des inondations : "il advient de même pour la fortune, qui démontre sa puissance là où on n'a ordonné aucune vertu pour lui résister ${ }^{76}$ Michel Foucault a souligné cet aspect: le prince de Machiavel est, de manière substantielle " en rapport de singularité, d'extériorité, de transcendance par rapport à sa principauté », autrement dit dans un rapport de fragilité, toujours «menacé de l'extérieur par les ennemis du Prince qui veulent prendre ou reprendre sa principauté ; de l'intérieur également, car il n'y a pas de raison a priori, de raison immédiate, pour que les sujets acceptent l'autorité du Prince $\gg .{ }^{77}$

La corruption pensée dans Les Discours peut être présentée, nous l'avons dit, comme une complication de l'idée de variation qualitative des temps : c'est une variation orientée dans une direction spécifique, celle de la « ruine» des cités. En outre, elle est graduelle et présente plusieurs moments distincts, à la fois par leurs caractéristiques propres et la nature des moyens mis en œuvre pour lutter contre elle. La conception machiavélienne de la corruption a deux sujets, qui s'avèrent confondus dans l'analyse grâce à la métaphore organique : la cité et son régime politique. Elle s'articule ainsi à sa pensée de la cité comme «corps mixte »: comme tous les corps, la cité a un temps d'existence fini. Elle peut s'enfoncer dans la maladie et en guérir, mais elle s'achemine néanmoins, de manière progressive et inéluctable, vers sa propre mort.

Cette conception de la corruption se développe aussi dans une réflexion sur les régimes politiques, pensés comme des compositions de rapports entre deux éléments, les « grands » et le "peuple ». Ces deux éléments sont désignés par Machiavel sous le terme d' " humeur», emprunté à la pensée médicale de son temps qui conçoit le corps humain comme un composé d'humeurs et envisage la santé ou la maladie comme des fonctions de l'équilibre proportionnel entre ces humeurs. Si l'une abonde de façon excessive (ou l'inverse), elle provoquera la maladie (l'excès et le manque ne désignant pas ici une quantité fixe, mais relative à la « constitution » particulière de chaque corps). Chaque «humeur» détient, en fonction du rapport de forces qui les oppose, une part des magistratures. L'on peut ainsi avoir à faire à une république populaire ou à une république aristocratique, ou encore au gouvernement d'un seul homme lorsque, des «grands », émerge un primum inter pares.

Pour rendre compte de la corruption dans les Discours, Machiavel prend quelques libertés avec la théorie médicale dont il s’inspire, tout en continuant à filer la métaphore

\footnotetext{
${ }^{76}$ Le Prince, 25, p. 159.

${ }^{77}$ M. Foucault, 'La gouvernementalité' (N²39), in : Dits et écrits, II, 1978, Paris, Quarto Gallimard, 2001, pp. 638-639.
} 
thérapeutique pour décrire la lutte contre la corruption : les «grands » désignent une humeur plus ou moins toujours déjà corrompue, en ce qu'ils « désirent commander et opprimer le peuple », tandis que le peuple « désire ne pas être commandé ni opprimé des grands $»{ }^{78} \mathrm{La}$ liberté propre à la république populaire romaine, c'est-à-dire au régime issu de la création des Tribuns de la plèbe à la suite de la « sécession » de la plèbe romaine sur le Mont Sacré, tient à la résistance qu'oppose, selon Machiavel, l'humeur du « peuple» à l'ambition des " grands ». Cependant, le ver est dans le fruit. La corruption sourd de cette opposition même, en ce que, au fil du temps, le «peuple » lui-même en vient à désirer le pouvoir, en raison de la dynamique propre au désir. Dans Les Discours, I, 37, Machiavel propose à ce sujet une explication de la corruption de la république populaire romaine qui n'est plus politique mais ontologique. Elle renvoie à la nature du désir comme tel, conçu comme tendant vers son propre excès : « une partie des hommes désirant avoir plus, une partie craignant de perdre l'acquis, on en vient aux inimitiés et à la guerre, d'où naît la ruine de telle province et l'ascension de telle autre. J'ai tenu ce discours, parce qu'il ne suffit pas à la plèbe romaine de s'assurer des nobles par la création des Tribuns, désir auquel elle fut contrainte par la nécessité ; aussitôt après avoir obtenu cela, elle commença même à se battre par ambition, et à vouloir partager avec la noblesse les honneurs et les biens, qui sont la chose la plus estimée par les hommes. De là naquit le mal qui engendra la lutte de la loi agraire, loi qui fut à la fin la cause de la destruction de la République $»{ }^{79}$

La dynamique des désirs populaire et aristocratique induit donc une progressivité de la corruption qui exige une adaptation constante des moyens déployés pour lutter contre elle. Elle est contraignante : la matière qu'est la cité impose de trouver des formes qui lui sont adéquates, selon l'état des mœurs à tel ou tel moment. Face à la corruption, nous sommes dans un cadre de pensée où la forme (institutionnelle) ne s'impose pas systématiquement à une matière (la cité et les mœurs de ses habitants) malléable. Schématiquement, il semble que Machiavel distingue un temps où la peur du châtiment est encore si vivace que les habitants de la cité n'osent pas transgresser la loi. Il suffit, à ce moment, qu'un homme de vertu montre l'exemple pour que la loi soit respectée et que celle-ci soit retouchée à travers de nouvelles mesures ou des réformes afin que la république s'adapte constamment à la qualité des temps. La peur et la vertu s'étiolant peu à peu, un temps nouveau succède au premier moment. Le bon exemple, les petites retouches ne suffisent plus : il faut un événement extérieur, par exemple l'attaque d'un voisin conquérant, pour renouveler l'obéissance aux lois et la mobilisation des citoyens autour

\footnotetext{
${ }^{78}$ Le Prince, 9, p. 94.

${ }^{79}$ Discours, I, 37, p. 178.
} 
de leur cité, de sa survie institutionnelle et de son indépendance, ou une réforme interne de l'ordre institutionnel (et plus seulement de certaines lois). Le mouvement institutionnel provoqué par l'attaque extérieure ou la réforme peut apparaître violent : il n'en est pas moins « naturel » si l'on entend par là, sur un mode aristotélicien, un mouvement qui ramène un corps vers son lieu propre. ${ }^{80} \mathrm{Si}$ un tel événement ne se produit pas ou que la réforme n'est pas mise en œuvre par un gouvernement prévoyant, le troisième temps de la corruption survient, qui implique une transformation de la nature même de la cité, décrite à travers le terme de «mutazione ». Ce temps est celui dans lequel une intervention efficace est la plus difficile à produire, car il s'agit de modifier la forme même du régime. Dans ce temps de corruption extrême, Machiavel estime que seul un homme "méchant» et prêt à user de violence peut recréer un ordre institutionnel viable. Dans sa description, Machiavel se montre extrêmement attentif aux différences qualitatives du processus de corruption et des moyens employés pour lutter contre elle. C'est cette minutie dans l'analyse du mouvement et de la variation, de la dégradation et de la ruine qui, sans doute, fait naître le sentiment de lecture selon lequel Machiavel se singularise dans la tradition philosophique occidentale par son attention soutenue au changement et à la qualité des temps.

C'est à propos de la corruption que Machiavel mobilise l'idée de retour aux commencements, rencontrée précédemment, dans la perspective d'instiller à nouveau dans le cœur des hommes une peur favorable à l'obéissance aux lois. Il ressort du récit de la fondation des cités proposé par Machiavel au début des Discours que la vie en cité, a fortiori lorsque des lois sont établies pour faire régner la justice, est le seul moyen pour les hommes de préserver leur vie. ${ }^{81}$ Ce récit des origines suggère que les hommes peuvent éprouver une crainte, plus forte que n'importe quelle autre, celle qui est liée à la préservation de leur existence : ce qu'ils doivent éviter à tout prix, c'est de voir la cité disparaître, et être contraint de retourner à un état de dispersion et caractérisé par l'anomie. Face à la corruption, l'idée du « retour aux commencements » renvoie à ce temps des origines, temps où les hommes seraient reconduits à la crainte absolue d'un moment antérieur à la formation de la cité, moment où les passions s'expriment sans retenue, où le risque de violence est le plus fort, et où, de ce fait, la peur est omniprésente. ${ }^{82}$ Dans cet état d'esprit, les hommes sont enclins à respecter les lois de la cité et à ne pas cultiver de comportements favorables à la corruption de la cité.

\footnotetext{
${ }^{80}$ Cf. en ce sens Aristote, Physique, II, tr. de P. Pellegrin, Paris, GF Flammarion, 2000.

${ }^{81}$ Discours, I, 2, pp. 60-61.

${ }^{82} \mathrm{Cf}$. à ce sujet R. Esposito, Ordine e conflitto, Machiavelli e la letteratura politica del Rinascimento italiano, Liguori editore, 1984.

p. 34, et N. Badaloni, 'Natura e società in Machiavelli, in : Studi storici, 4, X, 1969, pp. 689-691.
} 
La fragilité du pouvoir ne tient pas seulement à la difficulté qu'il y a pour tout gouvernement, princier ou républicain, à faire face au cours varié et relativement imprévisible de l'histoire et à la progressive corruption des mœurs. Elle relève aussi, pour Machiavel, de la présence d'un conflit irréductible entre les deux humeurs précédemment évoquées. "Les grands » et « le peuple », dans Le Prince comme dans Les Discours, ne renvoient pas à des groupes identifiables d'un point de vue socio-économique, mais sont des catégories dont la signification est avant tout politique : elles désignent les entités dont la relation est la source de la dynamique institutionnelle et de l'histoire de la cité : les «grands » désirant commander et opprimer, le «peuple », avant d'être corrompu, désirant pour sa part ne pas être commandé ni opprimé sont dans un rapport irréductiblement conflictuel.

Machiavel s'intéresse à ce conflit dans deux cas de figure. Dans le cas des républiques, dont nous reparlerons de façon plus détaillée au dernier chapitre, la fragilité suscitée par la présence du conflit civil est dans son œuvre exemplifiée à travers le cas de Florence. Selon Machiavel, le conflit y a toujours pris des formes meurtrières et nuisibles à la liberté : insultes et calomnies, meurtres, pillages, transgression de la loi et instabilité institutionnelle, tel est le lot de la cité florentine qui ne parvient pas, malgré sa nature favorable à la république, à mettre en place de manière durable les institutions de la liberté.

Dans le cas des principats, le discours machiavélien met l'accent sur la question de la capacité du prince à réguler à son avantage la relation d'opposition entre grands et peuple. Il lui faut faire en sorte que leur conflit ne dégénère pas, suscitant meurtres, pillages et désordres civils. Une telle situation fragiliserait son pouvoir en cas d'attaque extérieure et rendrait son territoire difficilement gouvernable. Cela implique qu'il satisfasse, autant que faire se peut, les deux désirs. L'entreprise est par définition impossible. C'est néanmoins ce qu'il doit viser. Priorité est donné à la satisfaction du désir populaire, bien qu'aucun principe d'action n'ait une valeur absolue chez Machiavel: «celui qui vient au principat avec l'aide des grands se maintient avec plus de difficultés que celui qui le devient avec l'aide du peuple ». Cette priorité relative s'explique pour plusieurs raisons : les grands sont ambitieux et toujours soupçonnables de vouloir prendre la place du prince ; le peuple est comparativement « plus honnête » et plus facile à satisfaire puisqu'il cherche seulement à ne pas être opprimé ; en outre, le soutien du grand nombre est toujours nécessaire à un prince dont le territoire fait l'objet de convoitises étrangères; enfin, «le prince est aussi dans la nécessité de vivre toujours avec ce même peuple, mais il peut bien faire sans ces mêmes grands, pouvant chaque jour en faire et en 
défaire $\gg .^{83}$ Le royaume de France constitue pour Machiavel un exemple intéressant d'organisation institutionnelle pour réguler le conflit entre grands et peuple au profit du pouvoir princier et de minimiser les effets d'instabilité et de fragilité inhérente à toute situation conflictuelle. C'est le Parlement, et non le roi lui-même, qui se charge de contrôler l'expression des désirs, en particulier du désir de domination des grands. Le roi est ainsi épargné de la rancœur des grands, mais le désir de celui-ci n'en est pas moins contrôlé. ${ }^{84}$

Dans son analyse du conflit civil, Machiavel se rapproche de certaines idées exposées dans La Politique d'Aristote. ${ }^{85}$ S'il s'éloigne de la philosophie politique moderne, en raison de la centralité de l'idée de variation, de celle de corruption et du thème du conflit civil dans sa pensée, il semble en revanche avoir des affinités avec certaines perspectives développées dans la philosophie antique. De ce fait, l'on est tenté de délimiter, au moins pour certains aspects de sa réflexion, un temps spécifique dans l'histoire de la pensée, où le sentiment d' « étrangèreté » de Machiavel par rapport à la philosophie a lieu de s'exprimer, et non lui accorder une valeur générale.

Aristote se présente en effet au livre V comme un penseur des « mutations » et propose à cette fin une description spécifique du corps de la cité politique, distincte de celle avancée au livre III consacré aux citoyens et à la nature de la citoyenneté. Le Livre III des La Politique se développe en une recherche de la définition du «citoyen», présenté comme l'élément constitutif de la cité.$^{86}$ Cependant, la figure du citoyen en tant que telle est absente lorsqu'au chapitre 7 du même livre, il aborde l'analyse des différentes conceptions de la citoyenneté. Apparaissent les «parties» de la cité, que décrivent les expressions de "petit nombre», « grand nombre » et son équivalent, « la multitude ». C'est avec elles qu'Aristote procède à la distinction des différentes constitutions. ${ }^{87}$ Le Livre IV poursuit la réflexion sur les constitutions. Comme précédemment, ce n'est pas à partir de la figure du citoyen, mais des «parties » de la cité que ces manières de concevoir la citoyenneté sont examinées. Aristote y établit une relation de causalité entre l'existence de plusieurs constitutions et la pluralité des parties de la cité. ${ }^{8}$

\footnotetext{
${ }^{83}$ Le Prince, 9, p. 95.

${ }^{84}$ Le Prince, 19, pp. 134-135.

${ }^{85} \mathrm{P}$. Pasquino est l'un des premiers et des seuls à avoir indiqué cette proximité entre Aristote et Machiavel cf. 'Liberté et république chez Machiavel', Les Annales de Clermont-Ferrand, vol. 32, 1996, pp. 33-49.

${ }^{86}$ Aristote, Les Politiques, III, 1, 1274 b, tr. de P. Pellegrin, Paris, GF Flammarion, 1990, pp. 205-206.

${ }^{87}$ Aristote, Ibid., III, 7, 1279 a, p. 229.

${ }^{88}$ Aristote, Ibid., IV, 3, 1289 b, p. 284.
} 
L'analyse des différentes constitutions se complète, au Livre V, d'une vision différente de ces parties, destinée à penser les causes des «séditions" et des "changements de constitutions ». Ce nouvel objet de réflexion induit en effet une description nouvelle, qui repose sur la notion d'égalité : «provoquent des séditions, d'une part, ceux qui revendiquent l'égalité pour peu qu'ils estiment avoir moins, eux qui sont les égaux de ceux qui ont plus qu'eux, d'autre part, ceux qui revendiquent l'inégalité c'est-à-dire la supériorité, s'ils tiennent pour acquis qu'ils n'ont pas plus que les autres mais qu'ils ont autant sinon moins, alors qu'ils sont inégaux. Et ces deux aspirations sont parfois justes et parfois injustes. Ceux qui sont inférieurs, en effet, deviennent séditieux pour obtenir l'égalité et ceux qui sont égaux pour être supérieurs $\rangle^{89}$ Aristote met ici en place une description de la cité spécifique à sa pensée des réformes institutionnelles et des conflits internes à la cité.

Dans les Discours, Machiavel procède de la même manière : comme Aristote, il a éprouvé la nécessité de concevoir une description particulière pour penser la dynamique conflictuelle de l'histoire des cités. En outre, leur description présente le point commun de ce concentrer sur les désirs des parties de la cité. Pour Aristote, le conflit se situe ente deux parties, dont l'une revendique l'égalité et l'autre l'inégalité ; pour Machiavel, il a lieu entre deux humeurs, dont l'une se définit par le désir de dominer et l'autre par le désir de ne pas être dominé. Or, Aristote, tout en distinguant les catégories de gens aisés, de gens modestes et de gens de condition moyenne, envisage le conflit à partir des effets politiques des différents degrés de richesse, c'est-à-dire à partir des désirs et des habitus relatifs à ces degrés : «ceux qui ont un excès de bonne fortune, de force, de richesse, d'amis et autres $<$ biens $>$ de ce genre ne veulent ni ne savent obéir (et cela leur vient, dans leur famille, dès l'enfance, car du fait de leur relâchement, même à l'école, ils ne prennent pas l'habitude d'obéir), tandis que ceux qui sont excessivement privés de ces biens sont par trop abjects. De sorte que ceux-ci ne savent pas commander mais seulement obéir comme des esclaves, et ceux-là <ne savent $>$ obéir à aucun pouvoir mais seulement exercer un pouvoir despotique. Il se constitue donc une cité d'esclaves et de maîtres, et non d'hommes libres, les uns envieux, les autres méprisants, ce qui est très éloigné de l'amitié et de la communauté politiques $\gg .^{90}$ Cette description permet notamment de comprendre l'esprit d'inégalité : par le biais de l'éducation et des habitudes de vie, certains membres de la cité développent une idée d'eux-mêmes qui leur rend insupportable l'égalité dans la cité. On voit apparaître ici une proximité théorique entre Aristote et Machiavel, dans le

\footnotetext{
${ }^{89}$ Aristote, Ibid., V, 2, 1302 a, p. 346.

${ }^{90}$ Aristote, Ibid., IV, 11, 1295 b - 1296 a, pp. 312-313.
} 
souci de rendre compte des mutations et de leurs causes et dans l'invention d'une catégorisation spécifique des parties de la cité et de leurs revendications respectives.

Le constat de cette proximité pourrait servir l'argument d'un rapprochement entre Machiavel et la philosophie politique, que la référence à Aristote soit assumée ou non par Machiavel. Il convient de remarquer que cette proximité est rarement soulignée dans l'exégèse machiavélienne contemporaine. En la passant sous silence, on entretient, en partie à tort, l'idée d'une singularité en général de la réflexion machiavélienne sur les raisons de la fragilité du pouvoir politique.

En 1576, au moment où Bodin énonce son jugement mordant sur Machiavel et affirme l'inactualité de sa pensée, jugement dont nous avons hérité jusqu'à aujourd'hui, certains pouvaient encore percevoir cette proximité entre Aristote et Machiavel (preuve que dans les années 1570, l'on était sans doute dans une époque charnière de la philosophie politique). l'humaniste helléniste Louis Le Roy, traducteur du grec et professeur au collège de France, fait ainsi une référence importante à Machiavel, en cherchant à actualiser le propos de La Politique d'Aristote. Afin de proposer un remède aux troubles et aux dissensions qui bouleversaient à son époque le royaume de France, il discute la conception aristotélicienne des mutations proposée au livre V de La Politique. À ce sujet, il évoque énonce le couple Venise-Florence, la première incarnant la stabilité, la concorde et la duré, la seconde un devenir incertain et soumis à de nombreux changements. L'exemple florentin a une seconde fonction. Décrit dans les termes machiavéliens, il indique comment rétablir la paix civile: il s'agit de réguler institutionnellement le conflit des humeurs, c'est-à-dire de restaurer "l'égalité » entre les différentes parties de la cité. ${ }^{91}$

Si la relation entre Aristote et Machiavel, sur le sujet des «mutations» du gouvernement semble avoir été oubliée, en revanche, l'exégèse contemporaine accorde cependant une grande importance à sa pensée de la variation qualitative des temps, de la corruption des cités et de l'existence d'un conflit civil irréductible. On lui reconnaît généralement à ce sujet une certaine pertinence et une grande acuité dans le jugement, alors même qu'on ne pense plus aujourd'hui dans le cadre cosmologique machiavélien et que la représentation des cités comme corps mixtes caractéristiques qui structure sa réflexion nous est devenue étrangère.

\footnotetext{
${ }^{91}$ L. Le Roy, Les Politiques, traduction et commentaire, Paris, Michel de Vascosan, 1576., p. 323.
} 
Mais cette dimension de sa pensée contribue à éloigner Machiavel des préoccupations centrales de la philosophie politique moderne. Si l'examen de la relation nouée par Machiavel entre politique et religion permet d'établir qu'il existe des questions communes à son œuvre et à celles de la tradition philosophique, et qu'en outre Machiavel s'inscrit dans le sillage du geste fondateur de la philosophie politique dans l'Occident chrétien, en revanche, l'attention portée au changement et au conflit tend à le singulariser par rapport à celle-ci. Comme nous allons le voir, cette singularité s'accentue dès que l'on s'intéresse au traitement machiavélien de la vertu morale et de la norme en politique. 


\section{Du MAL, DE L'ÊTRE ET DE LA NORME EN POLITIQUE}

«Mais du fruit de l'arbre qui est au milieu du jardin, Dieu a dit : "Vous n'en mangerez pas, vous n'y toucherez pas, sous peine de mort». Le serpent répliqua à la femme: «Pas du tout! Vous ne mourrez pas! Mais Dieu sait que, le jour où vous en mangerez, vos yeux s'ouvriront et vous serez comme des dieux, qui connaissent le bien et le mal ». La femme vit que l'arbre était bon à manger et séduisant à voir, et qu'il était, cet arbre, désirable pour acquérir le discernement $»^{92}$

«Celui qui combat les monstres doit prendre garde de ne pas devenir monstre lui-même. Et si tu regardes longtemps un abîme, l'abîme regarde aussi en toi $\gg^{93}$

Diverses voix se sont élevées, dès le $16^{\text {ème }}$ siècle, pour défendre une bonne morale politique contre la réduction de la politique à la ruse, au mensonge et à la violence, opération attribuée à Machiavel. L'accusation de "machiavélisme », francisation d'une expression forgée en Angleterre dans les années 1560, s'est diffusée à partir de la parution de l'AntiMachiavel de Gentillet en 1576. Elle assimile la pensée de Machiavel à « une espèce de politique détestable qu'on peut rendre en deux mots par 1'art de la tyrannie ». ${ }^{94}$ Cette accusation d'immoralité a signé et signe encore pour beaucoup, de façon définitive, l'exclusion de Machiavel hors de la koinonia philosophique qui entend adopter, lorsqu'elle aborde les questions politiques, une posture morale. "Que vient faire cette canaille dans notre analyse ? » demande Socrate à Phèdre à propos d'Eupalinos, l'architecte aux principes douteux et aux édifices magnifiques. ${ }^{95}$ Les mots que Paul Valéry met dans la bouche du premier philosophe, beaucoup de ceux qui s'en considèrent le descendant, sinon le disciple, l'ont repris et le reprennent encore aujourd'hui à propos de Machiavel. Ils ne veulent surtout pas être embarqués dans la même galère (immorale) que l'auteur du Prince. Ainsi, Bayle, tout

\footnotetext{
${ }^{92}$ La Bible, Genèse, 3, 3-6, Paris, Les Éditions du Cerf, 1998, p. 41.

${ }^{93}$ Fr. Nietzsche, Par-delà bien et mal, tr. C. Heim, Paris, Gallimard, 1971, p. 91.

${ }^{94}$ L'Encyclopédie, p. 793.

${ }^{95}$ P. Valéry, Eupalinos ou l'architecte [1921], Dialogues, in : CEuvres, II, Paris, Gallimard, La Pléiade, 1960, p. 134.
} 
en s'insurgeant contre ceux qui parlent de l'œuvre de Machiavel sans la connaître et en insistant sur son amour de la liberté, rejette l'argument de ceux qui excusent Machiavel d'avoir avancé telle ou telle thèse au nom du fait qu'il se contente de décrire la pratique des princes : «cela ne disculpe point Machiavel ; il avance des maximes qu'il ne blâme pas ». ${ }^{96}$

Ces voix dénonciatrices ont largement dominé celles qui se sont efforcés de souligner qu'il n'y avait peut-être pas tant d'originalité dans l'immoralisme politique de Machiavel. Ces dernières se sont notamment fait entendre à propos du traitement de la tyrannie chez Machiavel. On a remarqué qu'il n'avait rien dit de plus ou d'autre qu'Aristote. Ainsi, Louis Le Roy, dans son commentaire de La Politique, cité précédemment, rappelle cette filiation et le fait avéré des mauvaises pratiques princières, censé relativiser le scandale que constitue le propos philosophique neutre à propos de la tyrannie : il déclare à propos de l'analyse aristotélicienne de la tyrannie que Machiavel «a tiré de ce passage la plupart de ses instructions, en y ajoutant exemples romains et italiens $»^{97}$ et ajoute qu' « Aristote semble avoir été trop curieux en la déduction des moyens tyranniques »: «les mauvais prince sont assez enclins d'eux-mêmes à inventer ce qui sert à leur grandeur et sûreté, sans qu'il soit besoin les instruire par livres $»{ }^{98}$ Ce qui vaut pour Machiavel vaut pour Aristote et vice-versa. Le commentateur prend ici ses distances avec l'auteur traduit. Mais ce propos n'a pas seulement une portée critique : il permet aussi de faire de Machiavel un auteur comme les autres au sein de l'histoire de la philosophie politique. En s'associant avec Aristote sur la tyrannie, Machiavel reproduit certes son erreur, mais il perd de son caractère diabolique : il n'a rien inventé, rien dit de plus que ce qui avait déjà été dit par l'un des plus grands penseurs de la politiques.

Cette observation est reprise un demi-siècle plus tard par Gabriel Naudé dans les Considérations politiques sur les coups d'État (1639). Ce dernier établit une filiation plus accusatrice encore à l'égard de l'hypocrisie de ceux qui voient en Machiavel l'incarnation politique du mal, puisqu'entre Aristote et Machiavel, Naudé insère Thomas d'Aquin : « et le même Aristote qui n'avait pas accoutumé de rien faire sans en être bien informé, lorsqu'il a traité de la politique et des gouvernements opposés à la monarchie, aristocratie et démocratie, qui sont la tyrannie, l'oligarchie et l'ochloratie, il donne aussi bien les préceptes de ces trois vicieux que des légitimes. En quoi il a été suivi par saint Thomas en ses Commentaires, où

\footnotetext{
${ }_{96}^{96}$ P. Bayle, 'Machiavel', Dictionnaire historique et critique, $5^{\text {ème }}$ édition revue, corrigée et augmentée de remarques critiques, t. IV, Amsterdam, Compagnie des Libraires, 1734.

${ }^{97}$ Les Politiques, V, p. 372.

${ }^{98}$ Les Politiques, V, p. 372.
} 
après avoir blâmé et dissuadé par toutes raisons possibles la domination tyrannique, il donne néanmoins les avis et les règles communes pour l'établir, au cas que quelqu'un soit si méchant de vouloir le faire [suit deux longues citations du texte de Thomas d'Aquin] Voilà certes des préceptes bien étranges en la bouche d'un saint, qui ne diffèrent en rien de ceux de Machiavel et de Cardan ... ». ${ }^{99}$

Ces remarques n'ont pas modifié la perception dominante de Machiavel comme penseur politique immoral. Cependant, il convient par ailleurs de noter que sa pensée a fait l'objet d'une réception parfois ambivalente. Ainsi, la correspondance de Descartes et de la princesse Elisabeth révèle une certaine ambiguïté dans l'interprétation de l'immoralité politique machiavélienne. La première lettre de Descartes repose sur la lecture du Prince et insiste sur l'extension au pouvoir légitime des techniques propres au tyran par usurpation et l'utilisation de la guerre comme moyen de gouvernement : « et je crois que ce en quoi l'auteur a le plus manqué est qu'il n'a pas mis assez de distinction entre les princes qui ont acquis un État par des voies justes, et ceux qui l'ont usurpé par des moyens illégitimes ». ${ }^{100}$

Cependant, la réprobation de Descartes s'avère ambiguë : d'une part, comme l'a souligné Michel Senellart, il s'avère qu'il y a peu de différence entre les thèses défendues par Machiavel et celles de Descartes. Ce dernier élabore une critère de légitimité du pouvoir fonction de la force, via la caution divine (« Dieu donne le droit à ceux auxquels ils donnent la force ») et de la conception que les princes s'en font, une action devenant injuste lorsqu'elle est pensée comme telle. ${ }^{101}$ En outre, Descartes reprend le point de vue machiavélien consistant à privilégier la question du maintien au pouvoir du prince et conteste les moyens tyranniques non dans une perspective morale, mais en raison de leur inefficacité à l'égard de cette finalité : «c'est un très mauvais sujet pour faire des livres que d'entreprendre d'y donner de tels préceptes, qui, au bout du compte, ne sauraient assurer ceux auxquels ils les donne $\gg .{ }^{102}$ Le raisonnement d'ensemble de Descartes s'avère circulaire dans la mesure où il affirme à la fois, dans cet échange avec Elisabeth, qu'un prince a le droit de faire la guerre à ses ennemis et qu'on peut traiter ceux à qui on veut faire la guerre comme des ennemis.

\footnotetext{
${ }^{99}$ G. Naudé, Considérations politiques sur les coups d'État, éd. de Fr. Marin et M-O. Perulli, Paris, Gallimard, Le promeneur, 2004, pp. 72-74.

${ }^{100}$ R. Descartes, Lettre de septembre 1646 à Elisabeth, in : Euvres philosophiques, III, éd. de F. Alquié, Paris, Classiques Garnier, Bordas, 1989, p. 665. M. Senellart, Machiavélisme et raison d'État, Paris, PUF, 1989, pp. 49-55, à qui nous empruntons une partie de cette analyse.

${ }^{101}$ R. Descartes, Ibid., pp. 666-667.

${ }^{102}$ Ibid., p. 666.
} 
Cette position cartésienne intéresse particulièrement qui s'interroge sur la signification d'un positionnement par rapport à Machiavel comme manière d'assumer une certaine posture philosophique. En effet, elle témoigne du fait qu'au $17^{\text {ème }}$ siècle, la tentative d'assimiler la pensée machiavélienne, de la faire sienne, va de pair avec l'impossibilité de se réclamer explicitement de la référence à Machiavel. L'on reconnaît dans la lecture que Descartes propose du Prince la légitimation de la politique de puissance de Richelieu, politique qui ne pouvait, sans être dénoncée comme tyrannique, revendiquer sa filiation à la pensée machiavélienne : « de là, cet étrange mouvement, chez Descartes, qui consiste à retourner Machiavel contre son double fantastique ou, si l'on préfère, à opposer au machiavélisme sauvage, présenté comme une politique de bête féroce, un machiavélisme rationnel ... ». ${ }^{103}$

Machiavel n'a rien dit, sur certains points, d'original ; certains philosophes ont pu, tels Descartes, formuler une conception de l'action politique où la force fait le juste, et non l'inverse : on peut mettre en avant ces aspects autant qu'on le voudra. Pour autant, on ne gomme pas le sentiment persistant d' " étrangèreté » de Machiavel par rapport à la philosophie politique en tant qu'elle revendique un projet normatif et une forte articulation entre morale et politique. Comment rendre compte de ce sentiment? La réduction de la pensée machiavélienne au machiavélisme est-elle légitime ou repose-t-elle sur une interprétation erronée de l'œuvre machiavélienne, une perception tronquée de celle-ci, fondée sur la seule lecture du Prince ? La confrontation entre Machiavel et Kant s'avère, sur ce sujet, éclairante.

Hommes de pouvoir machiavéliques, « machiavélistes » inavoués ou assumés : autant de figures que l'on peut décrire comme des «moralistes politiques», en reprenant la typologie exposés par Kant dans l'Appendice I du Projet de paix perpétuelle : c'est-à-dire des «êtres qui se forge[nt] une morale qui soit profitable à l'intérêt de l'homme d'État ». ${ }^{104}$ Contre ces moralistes politiques, les philosophes politiques ont généralement adhéré et revendiqué une autre identité : celle du "politique moral», "c'est-à-dire quelqu'un qui considère que les principes de la prudence politique peuvent coexister avec la morale », qu'il est possible de tenir un discours à la fois politique (« soyez prudents comme les serpents ») et moral (« et comme la colombe, soyez sans détour $») .{ }^{105}$

Dans cette seconde perspective, le projet de la philosophie politique est normatif, il vise la conception d'une société juste, digne, orientée vers la réalisation du bien commun, à

\footnotetext{
${ }^{103}$ M. Senellart, Machiavélisme et raison d'État, Opus cit., pp. 54-55.

${ }^{104}$ E. Kant, Vers la paix perpétuelle, tr. de J-F. Poirier et Fr. Proust, Paris, GF Flammarion, 1991, p. 112.

${ }^{105}$ Ibid., p. 112 et p. 110.
} 
distance d'une science politique qui se contenterait de décrire les pratiques du pouvoir sans chercher à les évaluer ou d'une pensée soumise à la seule finalité de la conservation du pouvoir. Le politique moral ne se contente pas des «maximes » sophistiques qui, dénoncées par Kant, rappellent irrésistiblement le propos de Machiavel :

"fac et excusa. Saisis l'occasion favorable pour t'emparer, de ta propre autorité du droit d'un État soit sur son peuple, soit sur un autre peuple voisin); la justification se présentera une fois le fait accompli, et permettra de maquiller la violence (...)

Si fecisti nega. Les méfaits que tu as commis, comme par exemple amener ton peuple à désespérer et par suite, à se révolter, nie en être responsable (...)

Divide et impera. Soit : si, dans ton peuple, il y a certains chefs privilégiés qui t'ont simplement choisi pour être leur chef suprême (primus inter pares), sème la désunion parmi eux et brouille-les avec le peuple : range-toi alors du côté du peuple en lui faisant miroiter une plus grande liberté, et tout dépendra alors de ta volonté inconditionnelle ${ }^{106}$

Dans la typologie proposée par Kant, Machiavel semble indiscutablement prendre place auprès des moralistes politiques. Attaché à évaluer la place et le rôle du mal dans l'action politique, il a en effet affirmé que la qualité des temps exigeait parfois de l'acteur politique qu'il «entre» dans le mal. ${ }^{107}$ En outre, il a souligné la nécessité d'anticiper ce moment, afin de ne pas commettre le mal dans des termes qui se retourneraient, par la suite, contre la finalité du maintien au pouvoir : il est selon lui plus profitable au prince de faire le mal d'un seul coup et de façon à ne pas avoir à réitérer le geste mauvais ou cruel, car il devient alors possible, par la suite, de l'effacer de la mémoire des hommes et de gagner leur affection par des bienfaits. Machiavel en vient dans cette perspective à définir un bon usage du mal et à défendre l'idée qu'une stricte délimitation de l'action mauvaise (sa cause, son contenu, sa fréquence et sa fin) permet au prince d'affermir son pouvoir sans devenir un tyran.

Ainsi agit Agathocle de Sicile qui sut, « après d'infinies trahisons et cruautés » vivre longtemps en sécurité dans sa patrie grâce à un usage prudent de la cruauté. ${ }^{108}$ Ainsi fit aussi César Borgia lors de sa conquête de la Romagne : afin d'y rétablir la paix civile, il conféra les pleins pouvoir à un homme aux moyens expéditifs, Remirro d'Orca, qu'il fit ensuite assassiner en place publique, afin d'impressionner le peuple mais aussi de lui faire comprendre que le temps des cruautés était révolus et de l'inciter par là à soutenir son pouvoir: «et parce qu'il avait connaissance que les rigueurs passées avaient engendré quelque haine à son égard, afin de purger les esprits de ces peuples et se les gagner

\footnotetext{
${ }^{106}$ Kant, Vers la paix perpétuelle, Opus cit., pp. 115-116.

${ }^{107}$ Le Prince, 18, p. 130.

${ }^{108}$ Le Prince, 8, pp. 92-93.
} 
entièrement, il voulut montrer que si quelque cruauté s'en était suivie, elle n'était pas causée par lui, mais par l'irascible nature du ministre $» .{ }^{109}$

De ce fait, même si Machiavel prône un usage parcimonieux du mal, on a lu sa pensée comme une considération froide et gestionnaire du mal, incité en ce sens par sa conviction explicite que le mal est une composante parmi d'autres de l'action politique. De la nécessité de penser l'action mauvaise, l'interprétation a glissé vers l'idée d'une acceptation du mal.

Ce glissement a pu être favorisé par d'autres éléments de l'œuvre machiavélienne. En effet, Le Prince incite par ailleurs à user de la ruse autant que de la force, à la fois en temps de guerre et en temps de paix. Les Devoirs de Cicéron affirmait que la force et la ruse sont les deux sources de l'injustice et la ruse, la chose la plus dégradante pour l'homme et qu'il n'est pire vice que de se donner l'apparence de l'homme de bien dans le moment où on fait le mal. Contre ces thèses, Machiavel avance de façon provocante : « vous devez donc savoir qu'il y a deux genres de combats : l'un, avec les lois, l'autre, avec la force : ce premier est propre à l'homme, ce second, aux bêtes. Mais parce que, maintes fois, le premier ne suffit pas, il convient de recourir au second (...) Étant donc dans la nécessité de savoir bien user de la bête, un prince doit prendre, de celles-ci, le renard et le lion, parce que le lion ne se défend pas des filets, le renard ne se défend pas des loups $\gg .{ }^{110}$ La loi incarne le mode "civil" de gouvernement, au double sens que peut recouvrir ce terme, honnêteté et douceur du rapport, absence de domination tyrannique. Au contraire, la ruse, comme la force, rompt avec ce mode de gouvernement : elle est tromperie dans le rapport à autrui, contrainte déguisée.

Tromper ses sujets : tel est donc, sans jeu de mots, l'impératif catégorique de l'action politique selon Machiavel. Au demeurant, ce n'est pas là chose facile: le prince doit « jouer», comme un acteur sur la scène d'un théâtre, les qualités qui le font aimer de son peuple : la foi, la pitié, l'humanité, l'intégrité, la fidélité. Or, selon Machiavel, c'est un art d'une difficulté extrême, car il exige moins de dissocier l'être de l'apparence (il s'agirait alors simplement de dissimuler ce que l'on est réellement) que de parvenir à n'avoir aucune qualité propre, à ne s'identifier soi-même à une quelconque personnalité. ${ }^{111}$ Cette absence de qualité, et elle seule, permet en effet les variations de choix qu'impose à l'action politique la « qualité des temps », éminemment variable : un jour cruel, un autre clément, un jour lion, un

\footnotetext{
${ }^{109}$ Le Prince, 7, p. 85.

${ }^{110}$ Le Prince, 18 , pp. 127-128.

${ }^{111}$ Cette dimension de la pensée machiavélienne a été justement mise en avant par G. Sfez, in : Le prince sans qualités, Paris, Kimé, 1999.
} 
autre renard, etc. Le prince doit en ce sens acquérir une forme de contrôle de soi bien différente de celle promue, au XVI ${ }^{\mathrm{e}}$ siècle, par les auteurs néo-stoïciens, qui consiste à discipliner la violence et les instincts primitifs afin d'éviter la dérive tyrannique. Ici, Machiavel ne nie pas l'existence de l'être au profit de l'apparence, pas plus qu'il ne nie le bien au profit du mal : il indique qu'en politique, il convient de se placer exclusivement dans la sphère de l'apparence. Le prince doit se contraindre à ne pas suivre sa nature, à ne pas figer sa manière d'être mais au contraire, à être constamment, en fonction de la qualité des temps, sculpteur de lui-même : seule cette forme extrême de plasticité de la personnalité permet de se maintenir au pouvoir.

La tromperie est associée à la finalité du maintien au pouvoir car, en faisant état de telle ou telle vertu, de tel ou tel vice, le prince peut établir avec ses sujets, grands et peuple, une relation susceptible d'étayer son pouvoir. En effet, prince nouveau et prince ancien ne peuvent combler l'absence de fondement de leur gouvernement. Selon Machiavel, ils peuvent tout au mieux la circonvenir en créant en instillant chez leurs sujets les passions favorables à leur maintien. Aussi Machiavel s'intéresse-t-il de façon spécifique aux manières que celui-ci doit adopter avec ses « sujets » et « amis », lorsqu'il invite le prince à suivre la vérité effective de la chose. Si le prince n'a pas le choix de ses partenaires sur la scène politique (les grands et le peuple sur le versant intérieur, les autres cités ou royaumes, alliés ou ennemis, sur le versant extérieur), il peut en revanche agir sur les passions des uns et des autres et susciter les sentiments d'amitié, d'amour, d'admiration, de crainte, de mépris, de haine, de colère, etc.

Si l'on veut donner un contenu à l'idée de vérité effective en matière de maintien au pouvoir, il faut lire l'analyse des qualités que doit manifester le prince pour s'attirer à lui la «louange» et non le «blâme", développée dans les chapitres 16 à 23 du Prince. La combinaison d'affects ou de passions la plus favorable au maintien au pouvoir du prince est celle de la peur ou de la crainte (mais non de la haine) et de l'estime ou de l'admiration (plutôt que de l'amour). Le prince peut se passer de l'amour ou de l'amitié de ses sujets, qui est de toute façon un lien inconstant et fragile, mais pas de la crainte. Machiavel l'a déjà suggéré à travers son récit de la conquête du pouvoir en Romagne par César Borgia dans le chapitre 7. Lorsque celui-ci fait assassiner son ministre Remirro d'Orca, ce n'est pas seulement pour montrer aux Romagnols qu'il n'est pas responsable des exactions et des cruautés commises par ce dernier. C'est aussi pour graver dans leur esprit l'idée qu'il dispose d'un pouvoir absolu. Et de fait, pour Machiavel, la mise en scène de la mort du ministre est une opération réussie, en ce qu'elle laisse le peuple "satisfait et stupide», autrement dit durablement impressionné par 
cette démonstration de puissance. De façon corrélative, Machiavel recommande dans les Discours de renouveler régulièrement la crainte du châtiment en cas de transgression de la loi dans le cœur des citoyens. De son côté, la haine doit être absente de cette combinaison d'affects ou de passions, car être haï de ses sujets implique d'être constamment la victime potentielle de complots internes et d'attaques ennemies soutenues par les sujets. Le mépris induit les mêmes risques. ${ }^{112}$ Enfin, la crainte doit elle-même être compensée par une autre passion, qui tient à une sorte d'estime ou d'admiration du peuple à l'égard d'un prince, lié à des comportements vertueux, aux preuves de sa magnificence et au fait de savoir tenir son rang, « la majesté de sa dignité ». ${ }^{113}$

Avec cet abandon, dans le cadre des rapports avec les sujets, de la norme morale ou plus exactement avec l'affirmation d'un jeu nécessaire autour de la norme morale en fonction de ce que son apparence peut apporter au prince, nous avons l'élément qui nous manquait pour comprendre quelle torsion Machiavel fait subir à la notion de «vertu » par rapport à son sens moral classique. Nous avons à faire chez lui, selon l'expression de Nietzsche, à « une vertu dépourvue de moraline $\gg .{ }^{114}$ La mise en évidence de la variation qualitative des temps, de la place occupée par l'imprévu dans le cours de l'action humaine, du surgissement inopiné d'une « occasion » qui ne se reproduira pas, suggérait déjà la nécessité de déployer pour le prince conquérant, le chef de guerre et le gouvernant en général, une capacité de réaction et d'adaptation hors du commun. L'action de fondation et celle de refondation, la réforme des cités corrompues exigent de leur côté une forme de vaillance, de capacité d'initiative, de fermeté dans l'action également extraordinaires. Ces qualités sont désignées par Machiavel par le terme de «vertu» virtù], qui perd dans cet usage toute signification morale. De fait, ici, nous constatons de nouveau que cette dimension éthique est dépourvue de pertinence dans la pensée machiavélienne de l'action en vue du pouvoir ou de sa conservation. « Dans le style de la renaissance », la «vertu » s'exerce en vue de la «puissance »: elle n'entretient qu'une relation indirecte, ténue et utilitaire avec la vertu entendue au sens moral. ${ }^{115}$

Cet « enseignement moral et irréligieux » de Machiavel apparaît scandaleux par ses propositions; il l'est aussi, indique L. Strauss, du fait qu'il est explicitement assumé par l'auteur du Prince: «il n'est certes pas le premier à exprimer de telles opinions. Elles

\footnotetext{
${ }^{112}$ Le Prince, 19, p. 131.

${ }^{113}$ Le Prince, 21, p. 152.

${ }^{114}$ Fr. Nietzsche, L'Antéchrist, 2, in : Oeuvres, II, éd. dirigée par J. Lacoste et J. Le Rider, Paris, Laffont, Bouquins, 1993, p. 1042. ${ }^{115}$ Ibid.
} 
appartiennent à un type de pensée et de pratique politiques aussi vieux que la vie politique ellemême. Mais aucun philosophe avant Machiavel n'avait appuyé de son nom tout ce qui appartient à ce type de pensée et de pratique $»{ }^{116}$ De fait, l'écart souligné entre la pensée machiavélienne et une pensée politique morale renvoie de manière ultime à une prise de position ouvertement polémique par l'auteur du Prince: affirmant qu'il lui «a paru plus convenable d'aller droit à la vérité effective de la chose qu'à l'imagination de celle-ci », Machiavel dit craindre d'être tenu pour présomptueux car, dit-il, sa réflexion emprunte un chemin peu parcouru. Autrement dit, Machiavel est parfaitement conscient d'énoncer une thèse qui va à l'encontre d'une politique morale et de la démarche suivie par ses prédécesseurs.

Comme l'a remarqué F. Gilbert, la revendication de réalisme qui pointe dans cette formule du Prince n'est pas totalement absente des écrits humanistes du Quattrocento: l'intérêt dont ces écrits témoignent à propos des qualités nécessaires à un gouvernant fragilise dans cette période le projet normatif de la philosophie politique, au sens où l'on se rend compte qu'un prince doit déployer, pour demeurer au pouvoir, des qualités qui ne sont pas nécessairement celles que l'on louerait, en général, d'un point de vue moral. Cependant, dans ces écrits, la conception idéaliste demeure globalement inchangée, l'évaluation morale de l'action politique perdure au détriment de l'analyse du facteur de puissance et des fins égoïstes qui dominent la vie politique, réservée à des textes moins nobles que les traités, tels que les mémoranda politiques.

En affirmant la nécessité de suivre la vérité effective de la chose, Machiavel va donc plus loin que les humanistes du Quattrocento, il radicalise une tendance présente dans leur pensée et lui donne sa pleine expression. Cet écart tient sans doute, selon F. Gilbert, aux effets théoriques des guerres d'Italie qui impriment chez les penseurs de l'époque, Machiavel, Guichardin et les autres, l'idée d'un pouvoir aux manifestations incontrôlables et difficilement compréhensibles : « les écrivains du Quattrocento, en concentrant leur attention sur le facteur personnel en politique, ouvrirent le chemin à une approche psychologique 'réaliste' de la politique, comme elle existe aujourd'hui ; mais tant que les limites du contrôle de l'homme sur l'histoire n'avaient pas été découvertes, comme c'était alors le cas, il n'y avait aucun besoin d'abandonner la norme idéale élaborée au Moyen Âge, et il était toujours possible de considérer la conception de l'être humain idéal, avec tout l'attrait pédagogique qu'une telle idée comporte, comme une contribution sérieuse à la pensée politique $» .^{117}$

\footnotetext{
${ }^{116}$ L. Strauss, Pensées sur Machiavel, Introduction, tr. de M-P. Edmond et T. Stern, Paris, Payot, 1982, p. 42.

${ }^{117}$ F. Gilbert, 'Le concept humaniste du Prince et Le Prince de Machiavel' [1939], in : Cahiers philosophiques, Dossier Machiavel coordonné par M. Senellart, n 97, avril 2004, p. 105.
} 
Machiavel, pour sa part, justifie pour le prince la nécessité de suivre la vérité effective de la chose par deux raisons. La première est la conviction selon laquelle les hommes sont « méchants » et indignes de confiance ou doivent du moins être supposés tels lorsqu'on prétend gouverner durablement : « comme le montrent tous ceux qui traitent de la vie civile, et comme en sont remplis toutes les histoires, il est nécessaire que celui qui instaure un État et y établisse des lois présuppose que tous les hommes sont mauvais, et qu'ils doivent toujours user de leur malignité d'âme chaque fois qu'ils en ont une libre occasion ». ${ }^{118}$ Face à de tels hommes, être vertueux, c'est courir à sa perte : le respect de la morale est inutile et même nuisible dès lors que l'on ne peut se fier à ceux que l'on gouverne. C'est cette thèse qui fait dire à L. Strauss qu'avec Machiavel, nous sommes dans la caverne et n'en sortons pas : c'est-à-dire qu'avec l'auteur du Prince, nous nous inscrivons dans la pensée politique d'une société qui s'est fermée à la philosophie, d'une société qui refuse d'entendre l'interprétation des phénomènes moraux et politiques «à la lumière de l'homme d'une très grande vertu ou à la lumière de la perfection $\gg .{ }^{119}$

La seconde raison qui rend compte, pour Machiavel, du statut assigné au discours du devoir-être est la nature du cadre de l'action politique, déjà commentée : la qualité des temps essentiellement variable, imprévisible, belliqueuse à laquelle tout gouvernant doit constamment s'adapter. Un telle cadre est contraignant. Il détermine entièrement l'action politique, À l'autorisation d'enfreindre la loi dans des circonstances extraordinaires et au nom du bien public, figurant dans les miroirs princiers, ces traités de sagesse politique qui circulèrent par milliers en Europe du moyen âge au $18^{\text {ème }}$ siècle, Machiavel substitue la " nécessité » qui régit l'action du prince indépendamment de recommandations éthiques : une nécessité qui n'est pas celle de l'état d'urgence des juristes et théologiens médiévaux, mais celle, permanente, de l'état de guerre qui règne entre les cités et, plus généralement, celle que la fortune impose, de manière imprévisible. ${ }^{120}$

Malgré ces deux justifications, la «morale politique» machiavélienne rencontre plusieurs objections. La première remarque que l'on peut faire à son égard est qu'elle ne paraît pas capable, pour Machiavel lui-même, de se débarrasser entièrement de la posture concurrente, celle du politique moral, dans le sens où une part non négligeable de la tromperie

\footnotetext{
${ }^{118}$ Discours, I, 3, p. 66.

${ }^{119}$ L. Strauss, Pensées sur Machiavel, Opus cit., p. 319.

${ }^{120}$ Cf. l'analyse de M. Senellart, Machiavélisme et raison d'État, Opus cit., p. 38 sqq.
} 
recommandée dans Le Prince est destinée à persuader les sujets que le prince est intègre, fidèle et sincère : « un prince doit donc avoir grand cure qu'il ne lui sorte de la bouche chose qui ne soit pleine des cinq qualités susdites et qu'il paraisse, à l'entendre et à le voir, toute pitié, toute foi, toute intégrité, toute humanité, toute religion, et il n’y a rien de plus nécessaire que de paraître avoir cette qualité ». ${ }^{121}$ Vers la paix perpétuelle souligne de manière analogue que les hommes «n'osent pas publiquement fonder la politique sur les simples artifices de la prudence » et rendent les honneurs au droit «quand bien même ils devraient imaginer des centaines de subterfuges et de déguisements pour s'y dérober dans la pratique $\gg .{ }^{122}$ Le moral politique doit apparaître comme le politique moral, sans quoi son pouvoir ne se maintiendra pas durablement. Machiavel comme Kant relève ce phénomène, sans le discuter, et le présentent comme un fait anthropologique: en politique, l'apparence de morale est indispensable.

Par ailleurs, Kant formule l'objection que le moral politique peut voir son action se retourner contre lui-même. L'objection est intéressante car l'anthropologie kantienne n'est guère plus tendre pour les hommes que celle de Machiavel et Kant place le fait de la guerre au centre de sa réflexion dans Vers la paix perpétuelle. Le cadre de sa réflexion présente des analogies significatives avec celui que pose Machiavel lorsqu'il exige de l'acteur politique qu'il suppose les hommes méchants et le temps de l'action imprévisible et changeant. Or Kant affirme que « le mal moral possède la propriété, inséparable de sa nature, d'être contradictoire avec ses propres desseins (particulièrement dans ses rapports avec ceux qui sont animés du même sentiment), de s'auto-détruire, et ainsi de faire de la place au principe (moral) du bien, même si la progression en est lente $» .{ }^{123}$ Machiavel n'est pas étranger à l'idée d'une sanction de l'histoire : en invitant à un usage réfléchi et parcimonieux du mal et de la cruauté, il indique au prince qu'il doit agir de telle sorte à n'être pas haï, sous peine d'encourir constamment le risque d'une rébellion de son peuple. Il n'est pas non plus hermétique à la considération des effets de l'action bonne en politique: l'évocation de la gloire, la critique des princes qui gouvernent sans gloire suggèrent qu'à ses yeux un régime politique ne peut être loué pour sa seule durée, mais que doivent être également pris en compte les modalités du gouvernement : cruautés et méfaits, ou politique civile et respectueuse des biens des sujets. Cependant, Machiavel ne va pas jusqu'à se rendre à la thèse de la contre-productivité de l'histoire. Il y a à ses yeux trop de contre-exemples historiquement avérés de la thèse kantienne : le cas

\footnotetext{
${ }^{121}$ Le Prince, 18, p. 130.

${ }^{122}$ E. Kant, Vers la paix perpétuelle, Opus cit., p. 118.

${ }^{123}$ Ibid., p. 121.
} 
d'Agathocle de Sicile, analysé dans Le Prince, 8, illustre de manière emblématique la possibilité d'un gouvernement durable mais dénué de gloire. Surtout, l'analyse des trajectoires de pouvoir de plusieurs empereurs romains, proposée par Machiavel dans Le Prince, 19, montre qu'à ses yeux, la nature morale de l'action ne rend pas compte à elle seule de la longévité d'un gouvernement, mais doit être combinée à divers autres paramètres pour expliquer celle-ci.

Cependant, l'argument de fond contre la «morale politique » machiavélienne semble être, toujours selon Kant, qu'« il n'y a $<$ donc $>$ objectivement (en théorie) aucune conflit entre la morale et la politique ", même s'il y en a d'un point de vue subjectif, c'est-à-dire en relation avec « le penchant égoïste de l'homme ». ${ }^{124} \mathrm{Si}$ l'on suit cette perspective, Machiavel a manqué de voir un plan argumentatif (objectif) où le fait de la méchanceté humaine, le constat qu'il existe des pouvoirs tyranniques durables ne vaut pas. Et l'idée qu'on puisse opposer à l'argument kantien le fait que Machiavel a énoncé sa thèse du primat de la vérité effective dans un contexte de crise et d'instabilité n'est pas alors fondé, puisque Kant met précisément en avant ce plan argumentatif à partir duquel, quelle que soit la fragilité réelle du pouvoir, le discours politique normatif conserve sa pertinence.

Cependant, il nous semble que la critique du «politique moral» à l'égard de la « morale politique » machiavélienne manque moins sa cible qu'elle ne manifeste un écart entre deux postures possibles du penseur politique. Le dilemme véritable ici semble moins se situer entre une pensée politique « exposée » au mal, ${ }^{125}$ et une pensée qui oublie cette exposition (car l'oubli peut être délibéré, comme c'est le cas dans la réflexion kantienne), qu'entre une réflexion orientée vers la finalité du maintien au pouvoir et une réflexion critique à l'égard du pouvoir politique et volontairement menée à distance des contraintes de son exercice.

En effet, en invitant le lecteur à suivre la vérité effective de la chose, Machiavel ne propose pas une critique de l'imagination comme faculté incapable de parvenir à la connaissance du vrai. L'imagination désigne ici un discours normatif peu soucieux de l'ambition personnelle du prince. L'opposition entre vérité effective et imagination traduit, comme l'indique le texte par la suite, celle qui existe entre « la manière dont on vit » et « celle dont on devrait vivre», entre «ce qui se fait» et «ce qui devrait se faire». Mais cette opposition n'est pas formulée dans l'absolu : elle est énoncée du point de vue d'un conseiller

\footnotetext{
${ }^{124}$ E. Kant, Vers la paix perpétuelle, Opus cit., p. 121.

${ }^{125}$ Selon l'expression de Th. Berns, 'Morales de la fondation', Lectures de Machiavel, dir. M. Gaille-Nikodimov \& Th. Ménissier, Paris, Ellipses, 2006, pp. 293-323.
} 
qui cherche à servir l'ambition du prince et non à le juger et à orienter son action dans le sens d'une politique morale. Au regard de cette ambition (se maintenir au pouvoir), le discours du devoir-être est non seulement une perte de temps mais aussi une source de danger. Jouer la vérité effective contre l'imagination, c'est, chez Machiavel, refuser de plier l'action du prince à une norme éthique, c'est privilégier un discours qui analyse les conditions de son maintien au pouvoir. Dans ce geste s'affirme avant tout le choix de servir l'ambition personnelle du prince. Cette posture est en porte-à-faux avec le projet d'une philosophie politique normative. De nouveau, l'on constate que « l'étrangèreté » de Machiavel par rapport à la philosophie, l'écart creusé en raison de sa conception du «bien » dans l'action politique, tient au fait que sa thèse met directement en cause une manière de faire de la philosophie politique, en l'occurrence ce à quoi elle s'identifie le plus souvent, à savoir l'énoncé d'un discours normatif à l'écart des pratiques du pouvoir.

On relève toutefois, dans la tradition philosophique occidentale, plusieurs façons d'énoncer la norme en politique. Aussi, quittons-le terrain de la critique de l'immoralisme de Machiavel pour nous intéresser à ces différentes façons et élucider la manière dont Machiavel se situe par rapport à chacune d'elle : les limites de sa pensée seront définies avec plus de précision, de même que la manière dont elle met, éventuellement, la philosophie politique dans l'embarras.

Michel Foucault rappelle que l'une des plus vieilles fonctions du philosophe a été de poser une limite au pouvoir, dès qu'il menaçait de tomber dans l'excès. Le philosophe a toujours eu, en ce sens, le profil de «l'anti-despote». Mais ce profil n'est pas univoque. En effet, le philosophe peut se faire législateur, comme Solon, mais aussi conseiller du prince ou philosophe-pédagogue, comme Platon auprès de Denys le tyran, ou encore demeurer à l'écart du pouvoir, tels que les Cyniques. ${ }^{126}$ À ces différentes figures, nous ajouterons celle de l'utopiste, qui est encore différente et qui a, par rapport à la critique machiavélienne de «l'imagination », une importance particulière pour notre discussion.

La première hypothèse que l'on peut en effet formuler est qu'en indiquant la nécessité de suivre la vérité effective de la chose plutôt que l'imagination qu'on s'en fait, Machiavel dénonce notamment, parmi les discours politiques normatifs, le genre utopique. A minima, il semble possible de reprendre à notre compte cette thèse machiavélienne pour indiquer les

\footnotetext{
${ }^{126}$ M. Foucault, "La philosophie analytique de la politique”, Dits et écrits, III, NRF Gallimard, 1994, pp. 536537.
} 
failles et les insuffisances de ce genre. Par une coïncidence troublante, L'Utopie de Thomas More (1516) est contemporaine du Prince de Machiavel (écrit, selon toutes probabilités, entre 1513 et 1514). Aussi est-il très tentant de confronter les deux œuvres et de lire, dans la préférence accordée à la vérité effective de la chose, une dénonciation de l'utopie. Certes, Machiavel ne pouvait penser à l'œuvre de Thomas More lorsqu'il rédigea le chapitre $15 \mathrm{du}$ Prince, mais nous-mêmes pouvons peut-être faire profit de sa formule pour dénoncer les « maîtres rêveurs " ${ }^{127}$ Loin des discussions qui ont opposé, au temps de la guerre froide, ceux qui associaient utopie et totalitarisme et ceux qui refusaient un tel rapprochement, Machiavel nous préviendrait de manière moins circonstancielle du danger que court tout homme politique sensible au discours de l'utopie. Il négligerait alors l'essentiel : d'une part, qu'aucun projet politique ne peut voir le jour s'il n'est pas fondé sur une analyse de ses conditions d'effectuation. Dans Le Prince, la figure de Savonarole, prophète désarmé, est à cet égard un signal sans ambiguïté : à la différence de Moïse, Cyrus, Thésée et Romulus, qui avaient pris soin d'asseoir leur pouvoir politique sur la force, au moins dans les premiers temps, Savonarole n'a pas cherché à s'assurer du soutien de ses partisans autrement que par le prêche. Leur croyance évanouie, il n'eut plus aucune assise et finit pendu et brûlé sur la piazza della signoria à Florence, en 1498, peu de temps avant que Machiavel n'accédât à la fonction de secrétaire de la Chancellerie. D'autre part, ce même homme politique omettrait à tort de considérer que l'action politique est vouée à l'échec si elle se tient aux motifs des actions plutôt qu'à ses effets. Pour le commentateur de l'histoire romaine qu'est Machiavel dans les Discours, cette injonction conduit à ne pas blâmer Romulus pour l'assassinat de son frère : Romulus a certes tué Rémus, mais ce faisant, il a fondé Rome et « si le fait l'accuse, il faut bien que l'effet l'excuse $\gg{ }^{128}$

Cependant, la critique de l'utopie fondée sur le propos machiavélien rencontre plusieurs limites. Elle est tout d'abord trop vague: l'utopie est diverse et peut difficilement être dénoncée sur un mode si général ; on recense en effet, comme le rappelle Miguel Abensour, des utopies fondées sur la rareté, d'autres sur l'abondance, des utopies reposant sur la conception d'un État fort, d'autres sur un rejet de l'État, etc. Elle n'est pas non plus la même à la Renaissance, au moment de la Révolution française et au XIX ${ }^{\mathrm{e}}$ siècle, trois temps de floraison de textes utopiques.

\footnotetext{
${ }^{127}$ L'expression est empruntée à M. Abensour : Le procès des maîtres rêveurs, suivi de Pierre Leroux et l'utopie, Arles, Sulliver, 2000.

${ }^{128}$ Discours, I, 9, p. 92.
} 
En outre, dénoncer dans l'utopie un discours peu soucieux des conditions effectives de mise en pratique du projet de cité idéale, c'est réduire sa portée : ne peut-elle être considérée émancipatrice en cela même, l'imagination donnant à voir ce que le réel ne permet pas, à un moment donné, de concevoir ? Certes, l'utopie n'explicite pas ses conditions de réalisation; mais, en réalité, là n'est pas la question : l'utopie, fondée sur le refus de la vie donnée, suggère une autre existence, un nouveau lien social, une vie civile différente. La pensée de Machiavel elle-même, de ce point de vue, n'est pas exempte d' « imagination » : de Hegel à Gramsci, de Foscolo à Mazzini en passant par de Sanctis, n'est-il pas considéré comme celui qui a conçu, avec plusieurs siècles d'avance, la nation italienne ? N'a-t-il pas conçu sa création dans un contexte historique a priori peu favorable à la formulation d'une telle idée, celui d'un territoire morcelé entre des puissances concurrentes et soumis à des invasions étrangères ? C'est du moins ce que laisse penser le chapitre final du Prince, intitulé de manière significative : « exhortation à prendre l'Italie et à la libérer des barbares ». Machiavel y évoque « l'Italie », et non pas seulement telle ou telle cité ou province, et il invite un homme, qu'il imagine valeureux, courageux, audacieux, énergique, résolu, et peut-être aussi vertueux (qualités condensées dans le seul terme italien de « virtù »), à conduire les « Italiens » au combat contre les Français, les Espagnols, les Suisses ou encore les Allemands.

Enfin, sans parler de dimension émancipatrice, on peut tout simplement attribuer au discours utopique une vertu critique, comme le fait Thomas More en rappelant que son voyageur a «relevé parmi ces peuples inconnus beaucoup de coutumes absurdes, mais aussi d'autres, assez nombreuses, que l'on pourrait prendre comme modèles pour corriger des erreurs commises dans nos villes, nos pays, nos royaumes $\gg .{ }^{129}$ Dénoncer l'utopie à partir de l'idée de vérité effective, c'est négliger une telle dimension.

Par conséquent, voir dans l'utopie un discours peu soucieux de la vérité effective de la chose est un geste qui tourne court. Par son nom même, ce discours revendique justement le droit de négliger cette vérité : l'utopie n'est-elle pas le «lieu de nulle part»? Raphaël Hytlodée, le voyageur de Thomas More, refuse en ce sens de faire le récit de son séjour au roi, considérant que les monarques demeurent sourds à tout conseil, même lorsqu'on leur montre leur véritable intérêt (le bonheur du peuple et l'amour du royaume, seuls à même de leur assurer richesse et sécurité). En bref, il n'est pas certain que l'utopie ait besoin de la vérité effective : elle trace son chemin sur un territoire différent de la pensée politique.

\footnotetext{
${ }^{129}$ Th. More, L'Utopie, tr. de M. Delcourt, Genève, Droz, 1965, p. 13.
} 
Le genre utopique n'est donc pas, en réalité, mis en cause par la posture machiavélienne. Venons-en maintenant à l'examen des figures d'anti-despote identifiées par M. Foucault (législateur, conseiller du prince ou philosophe-pédagogue, ou encore philosophe à l'écart du pouvoir, comme les Cyniques) afin d'examiner leur relation avec le choix affirmé dans Le Prince de servir l'ambition personnelle du prince : se maintenir au pouvoir. En recherchant les conditions de la préservation du prince, Machiavel n'est évidemment pas un Cynique. Par ailleurs, il semble poursuivre la finalité inverse de celle que vise le philosophe pédagogue. Le Prince ne cherche pas à éloigner son lecteur des chemins de l'abus du pouvoir. Il entend épouser, nous l'avons dit, la cause du prince et la soutient avec constance, loin de vouloir lui enseigner une « bonne » pratique du pouvoir. Le souci obsédant du Prince est celui du maintien au pouvoir, dans un principat acquis de fraîche date comme dans un principat ancien, où l'autorité du prince bénéficie du poids de l'habitude sans être jamais garantie. Dans les deux cas, il s'agit de montrer au prince comment il peut faire face aux ennemis de l'extérieur et ne pas s'attirer la haine du «peuple» et des «grands ». La distance avec le philosophe pédagogue est maximale lorsque Machiavel aborde de front la question du mal dans l'action politique et défend l'idée selon laquelle le prince doit se préparer à l'éventualité de devoir mal agir.

À travers la poursuite de l'utile, Machiavel affirme dans Le Prince, 15 une vocation de conseil au prince. Mais cette forme « utile » que Machiavel confère au conseil, rompt à son tour avec la tradition inaugurée par Platon: le philosophe au chevet du roi, à défaut du philosophe-roi, pour faire régner le bien dans la cité. Dans la Lettre VII, Platon décrit l'état d'esprit dans lequel il est allé une première fois séjourner auprès de Denys de Syracuse, en Sicile. Après la mort de Socrate, condamné à mort par le tribunal athénien, il se dit convaincu que les maux de la cité, de toute cité, ne cesseront que si la philosophie accède au pouvoir, soit que ses détenteurs «s'adonnent à la philosophie », soit que les philosophes l'acquièrent. Ce séjour auprès de Denys II est l'occasion ou jamais pour mettre en œuvre son projet de faire advenir le bien dans la cité politique. Nous savons que cette démarche aboutit à un échec. Mais peu nous importe ici. Ce qui compte est le sens que Platon donne à sa démarche. Or, de ce point de vue, entre le conseiller platonicien et le conseiller machiavélien, il ne semble guère y avoir de réconciliation possible.

Si Machiavel propose au penseur d'adopter la posture de conseiller du prince en un sens distinct de celui suggéré par Platon dans la Lettre VII, cela n'en fait pas pour autant un 
conseiller des tyrans. Machiavel privilégie en effet dans sa réflexion les princes capables de conserver durablement leurs royaumes et d'acquérir la gloire. Les tyrans, sauf exception, ne peuvent ni l'un ni l'autre, parce que leur pouvoir repose seulement sur la force. L'histoire est sans pitié pour ceux qui n'écoutent pas, à cet égard, le conseiller machiavélien. Si Raphaël Hytlodée, le voyageur de L'Utopie de Thomas More, affirme que le conseiller parle dans le vide et que les rois n'écoutent personne, sinon eux-mêmes, Machiavel, lui, n'envisage jamais ouvertement que le prince puisse faire la sourde oreille aux conseils qu'il dispense en vue de sa préservation. En s'adressant à tu et à toi à un prince lecteur virtuel, il ne semble guère douter d'être écouté et suivi. Il se soucie plutôt de la capacité du prince à écarter les flatteurs, à s'entourer de quelques conseillers choisis et, en dernier lieu, à décider seul. Cette apparente certitude d'être écouté semble tenir à l'idée d'une sanction de l'histoire, présente en filigrane dans les analyses des conquêtes, des fondations et des réformes politiques : à faire la sourde oreille à ses conseils, on encourt la « ruine» (même si, nous l'avons souligné, Machiavel évoque de nombreux contre-exemples à ce propos).

Dans Le Prince, la matière historique est décrite de telle sorte que le conseil s'impose par une nécessité immanente et les exemples historiques, anciens et modernes, jouent le rôle de rappels à l'ordre. La position de conseiller prônée par Machiavel n'a de sens que parce qu'il est porteur d'un savoir validé par l'histoire. Par exemple, dans le chapitre 3, la conduite exemplaire des Romains est sans cesse mise en avant, pour rendre compte de l'échec du roi français à se maintenir en Italie, après y avoir fait une entrée fulgurante. Le conseil est d'abord énoncé comme une règle générale : «ainsi advient-il dans les choses de l'état, parce qu'en reconnaissant de loin - ce qui n'est donné qu'à un homme prudent - les maux qui naissent dans celui-ci, on les guérit vite, mais quand, pour ne pas les avoir reconnus, on les laisse croître de telle sorte que chacun les reconnaisse, il n'y a plus de remède $»{ }^{130} \mathrm{Il}$ est ensuite illustré à travers l'évocation d'une décision des Romains au cours de leur campagne militaire en Grèce : ils ne diffèrent pas la guerre contre Philippe et Antochius, afin de ne pas avoir à la mener dans leur propre empire; ils ne cèdent pas de pouvoir aux puissants et confortent les moins puissants, etc. Le chapitre 24, intitulé : «Pourquoi les princes d'Italie perdirent leur royaume », montre pour sa part que la paresse et l'ignorance des conseils ont conduit ces princes à perdre leurs territoires et possessions : ils ne peuvent en accuser la mauvaise fortune. La posture semble-t-il typique de la pensée machiavélienne est donc celle de ce conseiller nourri par la connaissance historique des conditions de succès et d'échec de l'action politique.

\footnotetext{
${ }^{130}$ Le Prince, 3, p. 66.
} 
Il y a par ailleurs dans la pensée machiavélienne une dimension normative qui invite toutefois à analyser aussi, de plus près, sa relation avec la figure du philosophe législateur. Elle est surtout perceptible dans Les Discours sur la première décade de Tite-Live. Elle n'annule ni ne contredit le propos machiavélien développé dans Le Prince, mais l'enrichit et permet de lui assigner une place précise : la figure du conseiller est l'une seulement des postures politiques envisagées par Machiavel. Elle est majeure mais n'est pas la seule. Le propos machiavélien ne peut être réduit à un discours platement réaliste et cynique, parce que la description de la vérité effective se double chez lui d'une prescription politique.

Cette nouvelle posture ne peut être totalement assimilé à celle du philosophe-législateur envisagée par Foucault car une différence importante demeure entre les deux, celle qui existe entre une pensée du devoir-être et l'élaboration d'une prescription qui ne désigne jamais un meilleur régime absolu, mais détermine ses recommandations en fonction de la «qualité des temps ", des circonstances de la fondation de la cité, de la nature et de l'origine de ses institutions, et de la vertu de ses citoyens. Il y a bien chez Machiavel une forme de norme politique, mais elle est essentiellement multiple et de l'ordre de la convenance entre des conditions historiques et un mode de gouvernement. Le discours "prescriptif» élaboré par Machiavel ne rejoint donc pas celui qui détermine une norme absolue, mais il interdit de ne voir dans son œuvre qu'un souci de réalisme.

Il est intéressant de voir que la prescription politique machiavélienne se déploie essentiellement dans l'interprétation de l'histoire de deux cités, Rome et Florence, à laquelle se greffent quelques considérations éparses sur Sparte, Venise et les cités allemandes. Les commentaires proposés sur chacune d'entre elles n'ont, en grande partie, de sens que croisés, comparés, confrontés : c'est à la lumière de l'histoire de l'une que s'éclaire l'histoire d'une autre. On le constate aisément pour Rome et Florence. Ce travail le conduit à distinguer le passé de Florence tel qu'il a été (un cheminement tortueux et infructueux de la cité vers la liberté) d'un passé qui aurait pu être le sien, plus favorable à cette dernière. Or, dans cette opération, l'histoire de Rome joue un rôle essentiel : dans le commentaire de Tite-Live et L'Histoire de Florence, la mise en perspective de Florence par rapport à Rome permet de montrer pourquoi la première, malgré la manifestation récurrente du conflit civil dans son histoire (à partir de 1215, d'après L'Histoire de Florence), n'a pu établir un régime libre et durable, alors que ce conflit apparaît comme le fondement essentiel du «vivere libero » romain. Elle rend visible ce qui a manqué et manque encore à Florence. Ce rapport entre l'histoire de Rome et celle de Florence dans l'œuvre machiavélienne vaut aussi à propos de la 
comparaison entre Rome, Sparte, Venise et les cités allemandes : chacune incarne une forme spécifique de régime libre, et le va-et-vient entre leurs histoires permet de mettre en évidence les faisceaux de causes, les combinaisons de facteurs, les successions d'événements qui ont fait d'elles des cités libres, de manière à chaque fois différente.

Pour mener à bien une telle histoire comparative, destinée à énoncer les conditions de la liberté politique ou à comprendre l'échec d'une cité à devenir et demeurer libre, il fallait rendre commensurables des cités très dissemblables par leur mode de gouvernement, leur histoire, le temps où elles étaient nées, s'étaient développées et avaient éventuellement disparu. Machiavel trouve dans la théorie médicale l'instrument de cette comparaison, ce qui lui permet de donner une formulation et une justification précises à une conviction assez générale à son époque, notamment inspiré de la lecture des ouvrages aristotéliciens sur l'éthique et la politique, selon laquelle les circonstances particulières (la nature de la cité, son histoire, etc.) sont déterminantes pour la définition du bon régime. ${ }^{131}$

Les cités sont présentées, nous l'avons vu, comme des «corps mixtes » composés d'« humeurs ». Leurs histoires apparaissent toutes constituer des cheminements particuliers, irréductibles les uns aux autres, et plus ou moins aboutis, vers la liberté : Rome a connu la monarchie, mais a pu évoluer vers des institutions républicaines car son organisation politique initiale n'y était pas opposée. Cette transformation s'est faite au fil du temps, reposant sur la confrontation active des grands et du peuple combinée au projet de conquête impériale, sur la vertu des citoyens, leur dédain des richesses et les effets de la crainte des dieux, favorable à l'obéissance aux lois. Lycurgue a donné naissance à un régime libre à Sparte en établissant une constitution mixte, qui distribue inégalement les magistratures aux rois, aux optimates et au peuple, et en instituant une égale pauvreté entre les citoyens. À son action, il faut ajouter d'autres éléments, facteurs de stabilité : la fermeture des frontières, l'absence d'ambition impériale, une puissance militaire (telle que Sparte est crainte par ses voisins sans les inquiéter) et une population relativement peu nombreuse. Venise, pour sa part, n'a pas eu de législateur pour la doter d'institutions libres au moment de sa fondation. La république s'y est progressivement installée, dotée d'une puissance militaire semblable à celle de Sparte, se protégeant, comme elle également, des nouveaux venus ; mais, à la différence de celle-ci, elle est une cité commerçante, où les inégalités de fortune sont importantes. Enfin, la liberté des cités allemandes repose sur le rôle essentiel joué par la religion, la vertu de leurs habitants, leur

\footnotetext{
${ }^{131}$ J. Coleman, A History of Political Thought from the Middle Ages to the Renaissance, Oxford, Blackwell Publishers, 2000, pp. 58-59.
} 
mode de vie frugal, qui perdure grâce à l'absence de contact avec les autres pays, et la haine des nobles, qui les conduit à assassiner quiconque cherche à mettre en cause la nature égalitaire de leurs relations.

Mettre en évidence et penser les différences entre les voies empruntées par Rome, Sparte, Venise, les cités allemandes et Florence pour créer et maintenir des institutions libres à partir d'un cadre qui rend possible leur confrontation et leur comparaison : si la science médicale d'inspiration hippocratique sert si bien cette finalité de l'argumentation machiavélienne, c'est parce que la théorie humorale apparaît être dans les différents traités du corpus hippocratique, quelles que soient leurs divergences sur d'autres points, une grille où s'articulent le général et le particulier, une trame pour penser à la fois la spécificité de chaque cas considéré et leur nature commune. En effet, si les corps ont tous, aux yeux du médecin hippocratique comme pour Machiavel, une structure humorale, chacun présente son propre mélange, a un tempérament spécifique [complexio/ $\kappa \rho \alpha \sigma \iota \varsigma$ ] (sur lequel agissent en outre, dans le cas du corps humain, le climat, les saisons et le régime alimentaire. ${ }^{132}$ Cette trame permet d'établir, dans l'ordre du particulier, des prescriptions relatives à chaque cité et atteste par ellemême du souci de Machiavel de ne pas s'en tenir à un discours simplement descriptif.

La position de conseiller du prince n'exclut donc pas chez Machiavel celle de législateur. Les deux sont présentes dans son œuvre et aucune ne prévaut sur l'autre. La description de la vérité effective se double dans Le Prince et dans les Discours sur la première décade de Tite-Live d'une prescription politique, qui se traduit notamment en un discours sur l'ordre institutionnel de la cité, ce qu'il est possible d'envisager (république ?, monarchie ?) en fonction de l'histoire de la cité. Ce constat est important car il permet de rendre plus complexe le rapport de Machiavel au projet d'une philosophie politique normative, le plus souvent jugé en fonction de ses seules déclarations sur le mal, la cruauté, la ruse et la tromperie. On trouve chez Machiavel la conviction que le mal fait partie inhérente de l'action politique, articulée à une anthropologie de la «méchanceté », à une conception du temps de l'histoire humaine marqué par l'instabilité et la corruption et à l'ambition de servir, à titre de conseiller, le prince dans sa poursuite du pouvoir ou des conditions de son maintien. Cette conviction accroît le fossé qui sépare Machiavel des philosophes qui, en grand nombre, ont promu une approche normative des affaires de l'État.

Cependant, parallèlement à cette vision du mal en politique, s'élabore une autre posture dans la pensée machiavélienne, liée à la volonté de déterminer les institutions d'une cité, en

\footnotetext{
${ }^{132}$ Cf. notamment Du régime, Nature de l'homme et Airs, eaux, lieux.
} 
fonction de sa «nature», de son histoire et de l'état des mœurs des citoyens. Dans cette perspective, le primat de la vérité effective de la chose signifie moins la rupture avec une conception de type kantien sur l'articulation entre morale et politique qu'elle n'implique la connaissance des circonstances à partir desquelles le penseur définit une norme institutionnelle et partant d'une reconnaissance de la pluralité des normes politiques.

Le fossé qui tient Machiavel à distance de la philosophie politique ne se referme pas en raison de cette seconde posture. Mais il devient plus complexe à analyser : on se rappellera en effet d'une part qu'une telle perspective a également été formulée par Aristote dans $L a$ Politique, et d'autre part que Machiavel (de nouveau comme Aristote), tout en défendant l'idée d'une « excellence constitutionnelle multiple ${ }^{133}$ nourrissait une préférence pour un régime particulier (dans le cas de Machiavel, à propos de Florence, le régime républicain populaire ; dans le cas d'Aristote, le gouvernement dit « constitutionnel »). «L'étrangèreté » de Machiavel par rapport à la philosophie perdure, par conséquent, mais sur un mode composite : différents facteurs en rendent compte et à des degrés divers, de telle sorte qu'elle ne peut être conçue de manière simple.

\footnotetext{
${ }^{133}$ M. Crubellier et P. Pellegrin, Aristote, Le Philosophe et les savoirs, Paris, Le Seuil, Essais, 2002, p. 199.
} 
«Les objets de nos jugements sont des particuliers ouverts d'eux-mêmes à notre investigation. Naturellement nous n'appréhendons les particuliers que dans la mesure où nous les rangeons sous quelque universel. Un pur particulier (non classé) ne saurait être objet de jugement. Mais lorsque les universaux sous lesquels nous subsumons ces particuliers soumis au jugement se muent en habitudes de pensée figées, en règles et en normes ossifiées, 'en codes d'expression et de conduite conventionnels, standardisés', le danger est que nous ne soyons plus nousmêmes pleinement ouverts à la richesse phénoménale des apparitions qui s'offrent à notre jugement (...) Discerner ce à quoi nous sommes habitués de ce qui est vraiment inédit et différent requiert une qualité particulière du jugement. $\gg{ }^{134}$

À l'occasion d'un dialogue avec Leo Strauss sur le rapport entre le philosophe et le tyran, Alexandre Kojève a souligné l'opposition entre deux conceptions de la vérité. Kojève estime que le philosophe est beaucoup plus apte que n'importe qui à gouverner : par son art de raisonner, il voit mieux les failles des raisonnements; par son art de la dialectique, il se débarrasse plus aisément des préjugés ; par son ouverture au réel, il se rapproche davantage du concret que le profane. Aussi la question du pouvoir gouverner, pour le philosophe, n'est-elle pas réellement problématique à ses yeux. En revanche, celle du vouloir est d'une difficulté infinie, tout simplement parce qu'il faut du temps pour penser, et que tout homme jouit d'un temps limité. Cela l'oblige à faire un choix entre diverses possibilités existentielles. ${ }^{135}$

Face à cette contrainte, deux attitudes sont possibles : la première consiste en un isolement total. C'est celle choisie par «l'épicurien» (et par tous ceux qui renoncent à

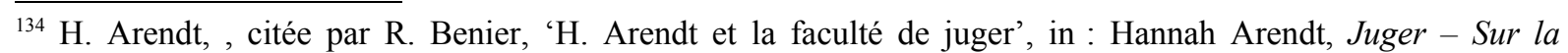
philosophie politique de Kant, Seuil, 1991, tr. de M. Revault d'Allones, pp. 157-158.

${ }_{135}$ A. Kojève, Tyrannie et sagesse', in : L. Strauss, De la tyrannie, tr. de H. Kern, revue par A. Enegrèn, suivie de la Correspondance avec Alexandre Kojève (1932-1965), NRF Gallimard, 1997, p. 167.
} 
l'ingérence dans la vie politique en échange de la paix accordée pour vaquer aux occupations théoriques) : il souhaite voir le gouvernement traiter son jardin comme un château fort inviolable, d'où il ne ferait lui-même aucune sortie. Mais un tel choix repose sur la conviction, qui ne va nullement de soi, que la vérité, objet de la quête philosophique, est essentiellement immuable et se donne à l'homme soit à travers la révélation, soit à travers l'effort intellectuel. ${ }^{136}$

Si l'on demeure dubitatif à propos de cette conception de la vérité, si l'on considère au contraire que l'être se révèle essentiellement dans un devenir historique, il faut alors fuir la solitude et fréquenter les membres de la cité. Certains philosophes ont fait, au moins à certains moments de leur existence, ce choix, en renonçant à l'isolement et en cherchant à intervenir activement dans la vie de leurs gouvernements. En témoignent, selon Kojève, les voyages de Platon à Syracuse ou encore la collaboration entre Spinoza et de Witt. Platon et Spinoza ont sans doute alors reconnu que la vérité se donne dans le devenir de l'histoire ou du moins, qu'il faut affronter l'âpreté de celle-ci pour découvrir celle-là. Dans cette perspective, la connaissance de la vérité entretient une relation constitutive avec l'expérience.

De cela, Machiavel est également convaincu. Ce qu'il offre au prince Laurent de Médicis le jeune, ce qu'il estime le plus parmi ses possessions, c’est-à-dire « la connaissance des actions des grands hommes », il la tire d'une « longue expérience des choses modernes » et d'une continuelle leçon des anciennes $» .{ }^{137}$ Quand il ne recourt pas à son expérience, c'est-àdire à ce qu'il a pu lui-même observer et entendre au cours des années passées au service de la chancellerie florentine (1498-1512), il exploite celle des historiens antiques. L'usage de l'exemple, chez Machiavel, a de ce point de vue une importance particulière : la matière concrète qu'ils exposent n'est pas simplement présentée pour illustrer une idée, une thèse, mais elle est le lieu même de son exposition et de sa démonstration. L'exemple est d'autant plus important que, comme nous l'avons vu à propos des passions que le prince doit cultiver chez le peuple pour maintenir son pouvoir ou les vertus qu'il doit exhiber, rien n'est valable si l'on se situe sur un plan d'abstraction : un comportement, un choix ne prend tout son sens et sa valeur qu'inscrit dans le contexte particulier où il est adopté.

D’un point de vue épistémologique, ce va-et-vient historique est fondé, dans la pensée machiavélienne, sur la conviction que les conditions de l'action humaines demeurent

\footnotetext{
${ }^{136}$ A. Kojève, Ibid. p. 169.

${ }^{137}$ Le Prince, Dédicace, p. 57.
} 
identiques à travers le temps de l'histoire. Il existe certes à chaque fois des circonstances particulières et sur le temps long de l'histoire, de significatifs changements, dont Machiavel ne sous-estime pas l'importance (par exemple le passage de l'ère païenne à l'ère chrétienne, commenté dans les Discours II, 2). Toutefois, les hommes nourrissent perpétuellement les mêmes passions et désirs et sont composés des mêmes humeurs. Le contexte cosmologique est également identique à lui-même : s'il est possible d'imiter une action passée, ou plus exactement de reproduire la vertu d'un acte ancien, c'est que « le ciel, le soleil, les éléments et les homme » n'ont pas « varié de mouvement, d'ordre et de puissance par rapport à ce qu'ils étaient autrefois $\gg{ }^{138}$

Dans un tel cadre d'analyse, la tendance à évaluer de manière exhaustive le champ des possibles, notamment exprimée à travers la structure dilemmatique «ou ... ou », apparaît très marquée dans l'œuvre de Machiavel. Celui-ci organise ainsi les premiers chapitres du Prince en procédant à une série de distinctions entre différents types de principats : héréditaires ou acquis ; dans ce second cas, acquis dans des provinces aux coutumes et à la langue similaires à celles de l'état conquérant ou non, acquis par fortune, par vertu, par scélératesse ou avec l'appui de l'une des deux humeurs (grands ou peuples), avec ses armes propres ou l'aide militaire d'un allié.

Cependant, la typologie des cas et des situations s'avère proliférante et ce, de manière indéfinie. En outre, elle ne répond pas toujours à un principe de cohérence. Dans l'exemple des premiers chapitres du Prince, s'ajoute à la liste des principats mentionnés ci-dessus le principat ecclésiastique qui semble n'obéir, nous l'avons vu, à aucune des règles envisagées à propos des précédents : il se maintient sans être gouverné, que son gouvernant soit vertueux ou non. Comme l'a indiqué Claude Lefort, l'«impression de lecture» fondamentale qui émane du Prince (et peut-on ajouter des Discours sur la première décade de Tite-Live et de L'Histoire de Florence) est paradoxale : elle renvoie à la fois à un discours rigoureux et à une «pensée divagante, qui perce soudain à l'occasion d'un détour, se rétracte ou s'arrête au moment où elle paraît s'élancer librement dans la direction qu'elle s'était fixée et revient nombre de fois sur son tracé, pour le modifier, voire en inverser le sens $»{ }^{139}$ De ce fait, on est conduit à se demander si « la recherche d'une rationalité immanente aux conduites politiques ne va pas de pair avec la découverte de ses limites », si « l'approche du réel en même temps qu'elle requiert

\footnotetext{
${ }^{138}$ Discours, I, Avant-propos, p. 51.

${ }^{139}$ Cl. Lefort, Le travail de l'œuvre Machiavel, Paris, Gallimard, Tel, 1972, p. 345.
} 
une détermination croissante des phénomènes n'expose pas à une indétermination fondamentale $» .{ }^{140}$

La structure disjonctive existe de manière incontestable chez Machiavel, elle est même récurrente, mais elle apparaît prise dans une série d'éléments gigognes dont on ne percevrait toujours qu'une partie : d'autres configurations sont possibles, qui se laisseront appréhender au moment où elles se donneront à voir dans l'expérience. Si Machiavel délivre une connaissance, celle-ci est moins le savoir d'un objet qu'une manière d'analyser, un savoir-penser qui, à la lumière de l'expérience des choses modernes et la lecture des Anciens, cherche à mettre en évidence les conditions de l'action, les différents paramètres de celle-ci et les effets de variation qu'ils impliquent sur son résultat.

L'expérience machiavélienne s'avère inépuisable. La vérité se rencontre à son contact, mais il s'agit le plus souvent d'une vérité hic et nunc, non généralisable : « quant à la vérité elle-même, il est de son essence qu'elle advienne dans le hic et nunc de l'action et donc qu'elle se dérobe toujours, pour une part, à la représentation ». ${ }^{141}$ Cette dimension de la vérité machiavélienne demeure pertinente que l'on adopte une interprétation stricte ou non du cadre cosmologique de l'action humaine présenté plus haut : qu'on estime que celui-ci laisse place au nouveau ou autorise seulement la reproduction d'événements survenus auparavant, mais qui se présentent selon une apparence différente, la vérité est énoncée dans l'ordre du particulier. De ce fait, l'un des enseignements que Machiavel cherche à transmettre à son lecteur est qu'il doit lui-même, dans les circonstances qui sont les siennes, s'efforcer de déceler la vérité effective de la chose et choisir une modalité d'agir. Il ne pourrait jamais se contenter de s'appuyer sur ses lectures. En effet, si l'approche du réel «expose » à une indétermination fondamentale, ${ }^{142}$ aucune oeuvre issue de la tradition ne peut être considérée comme le lieu du savoir par excellence. Corrélativement, s'il faut lire les Anciens, c'est donc avec circonspection et en sachant prendre des libertés. Machiavel lui-même, tout en multipliant les références entretient un rapport extrêmement libre à l'égard des auteurs auxquels il fait référence, reprenant certaines de leur thèses, explicitant ou non son désaccord avec d'autres, plagiant de manière plus ou moins fidèle leur propos: en aucune manière, les Anciens ne sont chez lui des autorités. La conception machiavélienne de la vérité est inconfortable car, pour celui qui cherche à déterminer les conditions et les modalités de son action, elle induit une relation essentiellement instable et inachevée avec celle-ci. Mais elle est sans doute un gage de lucidité,

\footnotetext{
${ }^{140}$ Ibid.

${ }^{141}$ Ibid., p. 438

${ }^{142}$ Ibid., p. 345.
} 
et permet d'échapper à la rassurante illusion de pouvoir prétendre énoncer un savoir définitif en politique.

L'autre spécificité de la relation que Machiavel établit entre vérité et expérience réside dans la nature de cette dernière. Il s'agit d'une expérience « filtrée », transformée, grimée en fonction du message que Machiavel veut délivrer. Au service de la chancellerie florentine, il devait être les yeux et les oreilles des gouvernants ; dans les missives qu'il leur adressait, il avait pour tâche première de relater ce qu'il avait observé, sans commentaire, ni proposition ; on lui recommandait de demeurer aussi neutre que possible dans ses jugements et d'éviter de prononcer des opinions trop tranchées. Dans ses écrits, en revanche, l'expérience personnelle et moderne, ou ancienne et relatée, ne renvoie pas au sens strict aux fruits de l'observation directe, aux choses telles qu'elles ont été vues et recensées, mais à une analyse et à une évaluation qui se présentent sous les traits d'un exemple emprunté à l'histoire. Ainsi, le propos de Tite-Live n'est-il pas directement repris mais commenté, discuté, croisé avec celui d'autres historiens ou reformulé à propos de l'histoire de Rome. Surtout, les héros, princes et rois de l'antiquité apparaissent, selon les besoins du questionnement, sous des aspects divers, comme Philippe de Macédoine, ennemi vaincu des Romains au chapitre 3 du Prince, homme de guerre courageux et prévoyant au chapitre 24 . À travers l'exemple, il est moins fait référence à la réalité «telle qu'elle est» pour l'observateur qu'à la signification que veut en extraire Machiavel, au prix éventuel d'un « maquillage » des faits.

Sur ce point, on peut faire intervenir dans l'interprétation de la méthode machiavélienne, une première référence à la théorie picturale (la seconde viendra, sous peu, à propos de la question du bon point de vue pour rendre compte de la réalité). La manière dont Machiavel traite de l'histoire ancienne ou moderne dans son œuvre suggère qu'il partage avec Leon Battista Alberti la conviction que l'imagination doit intervenir dans le rendu de la réalité afin de « produire un effet de réel plus efficace qu'un décalque de la réalité ». ${ }^{143}$ "L'expérience machiavélienne » est le fruit combiné d'une volonté de représenter la réalité et de la conscience aiguë que cette représentation exige d'en passer par les ressources de l'imagination et de l'illusion.

C'est pourquoi l'expérience de pensée a également sa place dans le raisonnement machiavélien. L'expérience renvoie en effet à l'histoire, mais éventuellement à l'esprit qui s'exerce, de façon imaginaire, à envisager les situations possibles et les réponses à donner en

\footnotetext{
${ }^{143}$ Th. Ménissier, 'De la perspective au perspectivisme : Machiavel et la nouvelle conception de l'espace à la Renaissance', in : Symboliques et dynamiques de l'espace, dir. J. Dokic, Ph. Drieux et R. Lefebvre, Publications de l'Université de Rouen, 2001, p. 73, note 28.
} 
fonction des différences circonstances. Philipoemen, prince des Achéens, est à cet égard un modèle présenté dans Le Prince, 14, puisqu'il a la sagesse de lire les auteurs anciens, mais aussi de mener des campagnes de guerre fictives : « et quand il était à la campagne avec les amis, souvent il s'arrêtait et raisonnait avec eux : 'si les ennemis étaient sur ce col et que nous nous trouvions ici avec notre armée, qui de nous aurait l'avantage ? Comment pourrait-on, en gardant l'ordre, aller les trouver? Si nous voulions nous retirer, comment devrions-nous les suivre ?' Et il leur proposait, en avançant, tous les cas qui peuvent se présenter à une armée, il écoutait leur opinion, disait la sienne, la confortait par des raisons, si bien que, grâce à ces continuelles cogitations, il ne pouvait jamais, lorsqu'il guidait les armées, naître aucun accident dont il n'avait pas le remède $» .{ }^{144}$

Enfin, l'expérience de Machiavel est particulière en cela qu'elle ne peut être décrite et interprétée en vue de la vérité de façon satisfaisante à partir d'un seul point de vue. Cela tient au fait qu'il existe, sur la scène politique, des regards essentiellement différents, à la fois du point de vue de leur capacité de vision et de la nature des désirs et humeurs qui orientent ce regard. Chaque acteur de la cité distingué par Machiavel (pour l'essentiel, les grands, le peuple, le prince et exceptionnellement l'armée, comme au chapitre $19 \mathrm{du}$ Prince), a sa propre vision de la réalité. Tout d'abord, aucun ne voit la même chose parce qu'ils n'ont pas la même capacité d'observation : «et les hommes jugent généralement plus avec les yeux qu'avec les mains, parce qu'il échoit à chacun de voir, à peu de sentir » et les grands «voient mieux et sont plus rusés » que le peuple ». ${ }^{145}$ Le peuple est ainsi celui qui se laisse tromper aisément car il « voit» mal, à la différence des grands. Cette différence dans la capacité de vision a des effets déterminants pour la pratique du pouvoir. Ainsi, dans le cas d'un principat, une fois combiné avec la puissance du nombre, ce facteur implique que le prince doit surtout se soucier de ce que voit le peuple dans la mesure où « dans le monde, il n'y a que le vulgaire et le petit nombre n'y a pas de place, quand le grand nombre a de quoi s'appuyer $\gg .{ }^{146}$ Par conséquent, un prince doit certes se soucier de la ruse des grands et de leur discernement, mais avant tout se préoccuper de ce qu'il donne à voir au peuple, dont le soutien est le fondement premier de son maintien au pouvoir.

La différence de vision tient ensuite à la nature des désirs et des passions qui déterminent le regard de chacun. Nous avons vu par exemple que l'intervention des grands dans la cité est motivée par le désir de dominer. De ce fait, ils perçoivent avant tout le peuple

\footnotetext{
${ }^{144}$ Le Prince, 14, p. 117-118.

${ }^{145}$ Le Prince, respectivement, 18, p. 130 et 9, p. 95.

${ }^{146}$ Le Prince, 18, p. 130.
} 
comme une force qui contrarie leur ambition et ils sont incapables de discerner dans l'action du peuple, ses protestations et ses revendications, autre chose qu'un obstacle à sa réalisation. Ils ne l'envisagent que comme une masse fauteuse de troubles. À cet égard, l'un des motifs importants des Discours sur la première décade de Tite-Live est de proposer une autre vision du peuple, dans laquelle il n'est plus simplement une multitude hurlante et agitée, mais un acteur politique à part entière, mu par un désir spécifique, plus légitime même que celui des grands en vue de préserver la liberté. La proposition d'une autre vision du peuple intervient au début de l'œuvre, lorsque Machiavel critique les contempteurs des «tumultes » populaires : « je dis que ceux qui condamnent les tumultes entre les nombres et la plèbe me semblent blâmer ce qui fut la cause première du maintien de la liberté de Rome et accorder plus d'importance aux rumeurs et aux cris que ces tumultes faisaient naître qu'aux bons effets qu'ils engendraient (...) Et si quelqu'un disait que ces façons de procéder étaient extraordinaires et presque inhumaines - quand on voyait le peuple rassemblé huer le sénat, le sénat huer le peuple, les gens courir tumultueusement dans les rues, les boutiques fermer, la plèbe entière quitter Rome, toutes choses qui effrayent rien qu'à les lire - moi, je dirais que toutes les cités doivent avoir des usages grâce auxquels le peuple puisse donner libre cours à son ambition, surtout les cités qui, dans les affaires importants, veulent se valoir du peuple $» .{ }^{147}$

Inégalité des capacités de visions, orientation du regard en fonction de passions et désirs distincts : le constat de ces deux éléments n'a pas seulement une incidence pour l'acteur politique. Il comporte également des implications pour l'analyse même du fait politique. Pour Machiavel, ils exigent de l'analyste de la scène politique qu'il cherche le bon point d'observation, et plus exactement les bons points, et développe une capacité à se déplacer d'un point à un autre. La métaphore picturale est une façon de rendre compte de cette exigence de manière parlante. La dédicace du Prince indique en effet que Machiavel, en vue de décrire cette scène politique au prince désireux de conquérir et de ceux maintenir au pouvoir, a fait comme un peintre : « comme ceux qui dessinent les pays s'établissent dans la plaine pour considérer la nature des montagnes et des autres lieux hauts, et pour considérer celle des lieux bas, s'établissent en haut sur les montagnes, de même, pour connaître bien la nature des peuples, il faut être prince et pour connaître bien celle des princes, il convient d'être du peuple $» .^{1.88}$

\footnotetext{
${ }^{147}$ Discours, I, 4, pp. 69-71.

${ }^{148}$ Le Prince, Dédicace, p. 56.
} 
Cette métaphore picturale de Machiavel n'est pas anodine. Si l'association entre voir et savoir est fréquente en philosophie comme dans le langage courant, ici, elle fait sans doute écho de manière spécifique au souci des peintres contemporains de Machiavel de proposer une représentation de la réalité à partir du point de vue adéquat. L'élaboration d'une conception de la perspective et d'une représentation picturale fondée sur cette dernière précède probablement d'un siècle les œuvres de Machiavel. Elle a ses théoriciens majeurs : Piero della Francesca puis Leon Battista Alberti. En outre, à Florence même, La vie de Brunelleschi, écrit hagiographique d'Antonio Manetti, mentionne que Brunelleschi aurait « inventé » dans les années 1420 la perspective en invitant à regarder ses peintures depuis un trou, petit comme une lentille du côté de la peinture et large comme un ducat de l'autre côté : le spectateur croyait voir, contemplant la peinture dans un miroir plan où elle venait se réfléchir, « la réalité même ». ${ }^{149} \mathrm{La}$ reprise de la métaphore picturale par Machiavel dans la dédicace du Prince témoigne d'une familiarité avec cette recherche esthétique du bon point de vue, relayée dans le domaine de la perspective théâtrale, diplomatique ou militaire, domaines dont Machiavel était également proche. Cependant, tout comme Machiavel n'a pas été entièrement fidèle à la pensée médicale dont il a pourtant beaucoup nourri sa réflexion institutionnelle, il emprunte de manière libre à l'idée fondatrice de la théorie de la perspective. Dans la mesure où il estime qu'il existe, sur la scène politique, des points de vue différents et irréductibles les uns aux autres, il ne retient pas l'idée d'une fixité du bon point de vue et il ne cherche pas un point de vue surplombant ou totalisant à partir duquel envisager, de manière globale, les différentes acteurs de la cité. L'exigence demeure d'un déplacement dans les différents lieux appropriés pour l'observation de tel ou tel élément et d'une vision essentiellement mobile: le conflit des humeurs est insoluble dans l'histoire de la cité ; corrélativement, l'observation, depuis un même lieu, des différents points de vue recensés pour rendre compte de façon pertinente d'une situation politique, est impossible. ${ }^{150}$

Le savoir politique, chez Machiavel, s'avère essentiellement inachevé et difficile à conquérir, même dans ses résultats fragmentaires : s'il ne fait aucun doute que Machiavel est

\footnotetext{
${ }_{149}$ A. Manetti et G. Vasari, Filippo Brunelleschi: 1377-1446, la naissance de l'architecture moderne, biographie, tr. de Cl. Lauriol, Paris, L'équerre, 1980.

${ }^{150} \mathrm{C}$. Ginzburg a souligne la relation entre la pensée politique machiavélienne et la question de la perspective in : 'Distanza e prospettiva, due metafore' [1997], in : Occiachi di legno, nove riflessioni sulla distanza, Milan, Feltrinelli, 1998, pp. 171-193 ; cf. aussi Th. Ménissier, 'De la perspective au perspectivisme : Machiavel et la nouvelle conception de l'espace à la Renaissance', art. cit. A. Fontana a souligné l'importance de cette dimension in : 'Les ambassadeurs après 1494 : la diplomatie et la politique nouvelles', Italie 1494, Presses de la Sorbonne nouvelle, 1994, pp. 142-178.
} 
convaincu de la nécessité de plonger au cœur de l'expérience pour découvrir la vérité en matière d'action politique, la notion même d'expérience s'est avérée complexe. Elle renvoie autant à ce qui peut être observé dans le présent qu'au récit des historiens antiques. Cela implique du point de vue épistémologique la possibilité de circuler entre passé et présent, autrement dit, cela exige un cadre de pensée dans lequel événements d'autrefois et événements contemporains soient commensurables. Machiavel a un tel cadre à sa disposition, fondé sur une conception de l'identité cosmologique et passionnelle des conditions de l'action humaine. Cela requiert en outre qu'il n'existe pas une différence fondamentale entre ce qui relève du témoignage indirect et ce qui renvoie à l'observation directe : chez Machiavel, un tel phénomène est rendu possible parce qu'il ne considère pas le témoignage du passé ou le récit de l'observation présente comme des relations immédiatement en prise avec la « vérité ». Sa « vérité » est construire, élaborée, au travers des exemples; elle n'est pas inscrite à même l'événement. Celui-ci est une matière retravaillée par le penseur politique afin qu'il rende compte de la vérité qu'il veut transmettre. Enfin, l'expérience est une notion complexe car elle ne se laisse appréhender que si l'on accepte de tirer les conséquences épistémologiques de l'existence d'une pluralité de points de vue irréductibles dans la cité et de la nécessité d'en rendre compte, sans prétendre dépasser leur pluralité.

On peut refuser de s'inscrire dans le cadre d'analyse de l'action humaine proposée par Machiavel, tout en conservant la leçon relative au savoir politique proposée par son œuvre. Leçon de modestie et mise en garde : nul ne peut prétendre aboutir à un savoir politique définitif. Cela n'implique pas le renoncement dans la recherche d'une certaine rationalité à propos des moyens de l'action politique, mais plutôt la conviction que cette recherche est sans cesse à poursuivre, même lorsqu'on a le sentiment d'être parvenu à un résultat satisfaisant : comme le prince présenté aux chapitres 22 et 23 du Prince, il convient d'être et de demeurer « un large demandeur $»$, un grand questionneur. ${ }^{151}$

De ce fait, «l'esprit de système » est absent chez Machiavel. Si la leçon relative à l'inachèvement du savoir politique peut sans aucun doute être entendue par les philosophes, il est certain qu'elle implique une écriture en rupture avec les exigences les plus fréquemment assignées à l'écriture philosophique (cohérence, systématicité, conceptualisation) et suggère à son tour que cette écriture pèche peut-être parfois par son manque de sens historique, son « 'égypticisme' ». ${ }^{152}$ En ce sens, l'analyse de la conception machiavélienne du savoir politique

\footnotetext{
${ }^{151}$ Le Prince, 23, p. 155.

${ }^{152}$ Fr. Nietzsche, Le Crépuscule des idoles, p. 25.
} 
nourrit le sentiment d'une " étrangèreté » de Machiavel par rapport à la philosophie, autant que celle de l'articulation proposée dans son œuvre entre politique et morale, et le primat accordé au questionnement sur le changement, la corruption et le conflit. 
«En fait, lorsque nous savons déchiffrer ces philosophies historiques, et pénétrer l'âme de leurs formules et de leurs théories, c'est un flot de vie philosophique qui nous submerge avec toute la force et la richesse de ses impulsions vivantes $»^{153}$

Admettons, malgré les éléments qui étayent l'idée d'une « étrangèreté » de Machiavel à l'égard de la philosophie, qu'il soit l'héritier du geste de Thomas d'Aquin, fondateur pour la philosophie politique occidentale et qu'il ait eu l'intuition d'un problème qui reste toujours à notre charge (celui de la relation entre religion et politique), entendons que sa conception du savoir politique conserve pour nous une certaine pertinence, en nous mettant en garde contre des prétentions excessives au regard d'une réalité qui se dérobe sans cesse à nous. Ces dimensions plaident plutôt en faveur d'un rapprochement, ou du moins d'une connivence entre Machiavel et la philosophie politique.

Cependant, il est temps que le machiavélien le plus passionné reconnaisse qu'aujourd'hui, la distance entre Machiavel et la philosophie politique s'est creusée plus fortement qu'autrefois. En effet, le métier légitime du philosophe n'est-il pas, de nos jours, de se consacrer à la pensée de la démocratie, de ses conditions, de ses différentes dimensions (politique, civile, économique, sociale, scolaire, etc.), de sa meilleure forme ? ${ }^{154}$ Or, de démocratie, il n'y a point dans la pensée et l'œuvre de Machiavel.

L'idée d'un gouvernement du grand nombre n'était certes pas inconnue à Machiavel. Elle faisait partie d'une catégorisation de la pensée politique grecque, connue à son époque, de pair avec l'aristocratie (gouvernement du petit nombre) et la monarchie (gouvernement de l'un). Sans doute lit-on une référence directe, quoique rapide, au gouvernement du grand nombre dans le chapitre I, 2 des Discours où Machiavel reprend partiellement l'analyse du cycle des régimes parcouru par les cités proposé par Polybe dans son Histoire de Rome (livre

\footnotetext{
${ }^{153}$ E. Husserl, La philosophie comme science rigoureuse, tr. de M. B. de Launay, Paris, PUF, Épiméthée, pp. 8485.

${ }^{154}$ A. Kalyvas, 'La politique de l'autonomie et le défi de la délibération : Castoriadis contra Habermas', in : Les Temps modernes, Juin-Juillet-Août 2000, $\mathrm{n}^{\circ}$ 609, pp. 71-103.
} 
VI). Il est en effet dit dans ce chapitre qu'au cours de son histoire, une cité passe du gouvernement de l'un au gouvernement du petit nombre; puis, au gouvernement du grand nombre, en raison de la corruption du petit nombre ; et qu'à son tour ce gouvernement se corrompt et «sombre rapidement dans la licence ». ${ }^{155}$ Mais le terme de «démocratie » ne figure pas dans le texte, qui parle de «stato popolare» et de «licenzia » (littéralement, gouvernement populaire et licence) et quand bien même il serait utilisé, il renverrait à cette catégorisation et non au sens dans lequel nous employons aujourd'hui ce terme.

La démocratie n'était pas, en effet, l'objet de Machiavel ni sa préoccupation. Elle ne faisait pas partie de son paysage historique et théorique. Sa pensée s'est concentrée sur d'autres formes de gouvernement, celles qui structuraient la vie collective de son temps et qui lui semblaient être des formes viables de gouvernement dans des temps particulièrement instables. D’une part, les gouvernements d'un seul homme : «principat », dénomination générique pour le gouvernement d'un seul homme, qui peut prendre les formes particulières de la monarchie (alors exemplifiée par le royaume de France), de l'empire (alors incarné, de manière fragile, par l'Allemagne), et enfin de la tyrannie ; d'autre part, le gouvernement républicain, régime de la liberté, dans sa version populaire ou aristocratique, respectivement illustrée par Florence de 1494 à 1512 ou Rome et par Venise dans les Discours.

De ce point de vue, il y a, semble-t-il, une inactualité radicale, indéniable, indépassable de Machiavel pour la philosophie politique contemporaine, parce que celle-ci est centrée sur le questionnement relatif à la démocratie. Pour ce questionnement, l'œuvre machiavélienne ne peut plus prétendre être un matériau ou un outil de réflexion : elle est plus modestement un document d'époque pour historiens de la philosophie ou historiens tout court. En raison de cet ancrage historique de la pensée machiavélienne, il serait donc peut-être bon, et même nécessaire, d'adopter le mode de lecture proposé par l'historien Paul Veyne à son égard : à savoir, une lecture irrespectueuse. Une telle façon d'envisager sa pensée permettrait d'envisager Le Prince sous un jour nouveau et de le lire sans se faire d'illusion sur ce que l'on peut y trouver: "au lieu d'un classique consacré, on aura devant les yeux un bibelot d'époque », qui ne dit pas des vérités définitives sur la politique et " ne communique pas de frisson sacré », une œuvre qui s'avère «historiquement éclairante», car elle permet de caractériser ce que fut la politique en Europe, du $15^{\text {ème }}$ au $18^{\text {ème }}$ siècle, quand les rois avaient

\footnotetext{
${ }^{155}$ Machiavel, Discours, I, 2, p. 62.
} 
cessé d'être très-chrétiens et n'étaient pas devenus des rois constitutionnels ». ${ }^{156}$ Rien de moins, rien de plus.

Cependant, de façon paradoxale, l'on repère aujourd'hui une série conséquente d'usages de Machiavel, sans rapport avec ceux, omniprésents jusqu'à la fin du $18^{\text {ème }}$ siècle au moins, focalisés sur l'articulation entre morale et politique. Machiavel est aujourd'hui réquisitionné dans la réflexion sur la démocratie alors qu'il semble ne rien avoir à dire de particulier à son propos. En outre, il est convoqué par des partis théoriques les plus divers, voire contraires: libéraux, républicains et marxistes. Enfin, on observe que malgré les différences parfois radicales entre les options des uns et des autres, il existe un point commun dans leur reprise de Machiavel : celui-ci joue dans tous les cas le rôle d'un rappel, d'un gardefou contre l'oubli. On a à faire ici à une modalité de lecture tout à fait particulière de Machiavel : la plupart des philosophes et penseurs politiques qui s'y réfèrent se tournent vers lui parce qu'ils estiment trouver dans son œuvre des questions qui, ailleurs, ne sont pas ou n'ont pas été formulées avec la même acuité ou qui sont ou ont été considérées comme mineures et secondaires.

Mais l'oubli de quoi ? Si cette modalité de lecture suggère que Machiavel offre encore au penseur politique contemporain quelques ressources pour l'analyse des situations et la formulation de propositions relatives à la démocratie, la nature des emprunts varie de manière significative selon le contexte théorique et politique. En empruntant l'expression de «moment machiavélien » à l'historien des idées J. G. A. Pocock, S. Audier a proposé de distinguer aujourd'hui deux « moments machiavéliens » dans la pensée politique du $20^{\text {ème }}$ et de notre $21^{\text {ème }}$ commençant : l'un ancré dans un contexte anglo-saxon, initialement identifié et théorisé par Pocock lui-même, caractérisé par la référence à un Machiavel républicain et partisan de la citoyenneté active; l'autre, enraciné dans un contexte français, orienté vers un Machiavel penseur de la relation entre conflit et liberté. ${ }^{157}$

Dans le premier «moment machiavélien », Machiavel se dévoile essentiellement sous son visage républicain. Spinoza et Rousseau avait déjà suggéré qu'il était plutôt l'ami du peuple que celui des princes, y compris (et peut-être surtout) dans Le Prince : « en feignant de donner des leçons aux Rois, il en a donné de grandes aux peuples. Le Prince de Machiavel est

\footnotetext{
${ }^{156}$ P. Veyne, Préface au Prince et autres textes, Paris, NRF Gallimard, 1980, p. 8 et p. 13 pour les citations.

${ }^{157}$ S. Audier, Machiavel, conflit et liberté, Paris, Vrin/EHESS, 2005.
} 
le livre des républicains $»{ }^{158}$ Cependant, cette seconde modalité de lecture ne se développe véritablement dans une exégèse nourrie de Machiavel et de la pensée républicaine de la Renaissance qu'au $20^{\text {ème }}$ siècle. Le Moment machiavélien de Pocock, publié en 1975, tout en assumant le caractère partiel de son interprétation, travaille ce portrait d'un Machiavel républicain, nourri par la conception aristotélicienne de la citoyenneté. L'interprétation de Pocock met en scène la cité républicaine soumise à un chaos d'événements (guerres avec les « barbares » étrangers et conflits civils), dont elle ne maîtrise pas, ou mal, le cours : le temps de l'action politique y apparaît de manière essentielle comme celui de la contingence, du transitoire, de l'inconnu. Elle formule une conception de la citoyenneté active en relation avec la question de la corruption et propose un Machiavel « aristotélisé ». Selon Pocock, « la théorie de la polis - qui est, dans un certain sens, la théorie politique dans sa plus pure forme originelle - était cruciale dans la théorie constitutionnelle des cités italiennes et des humanistes italiens. Elle offrait un paradigme de la façon dont un corps politique pouvait maintenir sa cohérence quand il était conçu, comme devait l'être une commune italienne, comme une cité composée de personnes en interaction ... $\gg .^{159}$

Cette perspective interprétative sert, chez Pocock, un projet à la fois historiographique et politique : celui de se positionner vis-à-vis du libéralisme politique à la fois en tant que courant de pensée politique et grille d'intelligibilité de l'histoire de la pensée politique. L'auteur du Moment machiavélien entend dénoncer une prétention d'exclusivité : celle du libéralisme à être la seule source de la pensée politique américaine et la seule capable de répondre aux interrogations politiques du présent. L'ouvrage propose en effet une vision de l'histoire politique américaine en rupture avec l'idée d'un triomphe, progressif mais indiscutable, du libéralisme et avec la confusion qui en découle entre pensée politique et pensée du droit. ${ }^{160}$ Cette idée dissimule selon lui une composante essentielle de la pensée politique anglaise et américaine : le républicanisme, dont les sources doivent être recherchées dans la réflexion des humanistes civiques de la Renaissance.

Dans la pensée politique anglo-saxonne, le chemin de J. G. A. Pocock était déjà balisé par les travaux de deux autres exégètes importants de Machiavel et de la pensée politique de la Renaissance, Hans Baron et de Felix Gilbert, tous deux des européens émigrés aux État-Unis

\footnotetext{
158 J-J. Rousseau, Du Contrat social, III, 6, in : Euvres complètes, III, Paris, Gallimard, Bibliothèque de la pléiade, 1964, p. 409. Pour Spinoza, Traité politique, V, Opus cit., p. 139.

159 J. G. A. Pocock, Le Moment machiavélien, la pensée politique florentine et la tradition républicaine atlantique, tr. de L. Borot, Paris, PUF, 1997, p. 84, cf. aussi p. 3.

${ }^{160}$ En français : J. G. A. Pocock, Le Moment machiavélien, la pensée politique florentine et la tradition républicaine atlantique, tr. de L. Borot, Paris, PUF, 1997.
} 
avant ou au moment de la seconde guerre mondiale. Baron, notamment, avait entrepris de remettre en cause l'hypothèse de l'historien de l'art suisse du $19^{\text {ème }}$ siècle, Jacob Burckardt, sur les ambivalences de la modernité et de l'individualisme inventé à la Renaissance. ${ }^{161}$ Il avait proposé une vision positive de la modernité, caractérisée selon lui par l'idée de participation politique, de gouvernement constitutionnel et de sûreté dans la possession privée ainsi qu'une interprétation de la Renaissance comme moment où de semblables valeurs avaient été cultivées et défendues. Baron avait utilisé dans cette intention le terme de «Bürgerhumanismus » (civic humanism, humanisme civique) en 1925 pour désigner la réunion de deux courants de pensée présents à Florence, développés en réaction à l'expansionnisme milanais qui menaçait l'indépendance de la cité : l'humanisme pétrarquiste et la pensée politique guelfe, patriotique et favorable aux institutions républicaines. L'humanisme civique, qui résulte de leur fusion, exalte selon lui la défense de la liberté politique et un engagement actif du citoyen dans celleci. Comme tel, cet humanisme lui apparaissait être le maillon essentiel de transmission de la conception antique de la citoyenneté à l'époque moderne. Machiavel pouvait de prime abord apparaître comme un élément rebelle dans cette conception de la Renaissance. H. Baron s'intéresse de près à son œuvre: 'Machiavelli, the Républican Citizen and the Author of The Prince', article publié en 1961, lui permet de réconcilier Machiavel avec la tradition républicaine florentine : il y défend l'idée que Le Prince est une œuvre isolée au sein du corpus machiavélien et qu'elle a été composée bien avant les Discours sur la première décade de Tite-Live. C'est cette œuvre qui rend compte des convictions véritables de Machiavel, en l'occurrence républicaines, et permet à son exégète d'en faire un héritier de Leonardo Bruni.

« Le moment machiavélien » défini par Pocock s'est ensuite nourri, en contexte anglosaxon, d'autres travaux et notamment de ceux de l'historien de la philosophie politique Quentin Skinner, qui en a sensiblement infléchi la signification. Skinner est moins critique de la tradition libérale qu'il ne veut la réorienter dans une direction spécifique. Il propose une sorte de libéralisme républicain, si paradoxale que puisse apparaître dans un premier temps cette combinaison. On comprendra les raisons de formuler un tel hybride en revenant à la distinction faite par le penseur politique Isaiah Berlin entre deux questions : 'par qui suis-je gouverné ?' et 'jusqu'à quel point suis-je gouverné ?' [By whom am I governed ?/ How much am I governed ?]. L'idée de liberté positive répond, pour Berlin, à la première question, et celle de liberté négative à la seconde. La liberté négative désigne l'espace dans lequel l'homme agit

\footnotetext{
${ }^{161}$ J. Burckhardt, Die Cultur der Renaissance in Italien, Basle, 1860 [Civilisation de la Renaissance en Italie, 3 vol., tr. de H. Schmitt, revue par R. Klein, préface de R. Klein, Paris, Le Livre de Poche, 1958.
} 
sans rencontrer d'obstacles posés par autrui à son action, tandis que la liberté positive renvoie à l'idée d'être son propre maître. ${ }^{162}$ Pour Skinner, les libéraux qui excluent l'idée de liberté positive de leur outillage théorique ont tort : en s'en tenant à une notion négative de la liberté, on sape les conditions même de la liberté.

Afin de démontrer cette thèse, il recourt à la pensée machiavélienne. Comme Pocock dans Le Moment machiavélien, il entend exhumer et présenter un courant de pensée négligé dans la pensée politique contemporaine, le républicanisme classique, qui serve sa propre réflexion sur la démocratie contemporaine. Dans le courant républicain de la Renaissance italienne, la pensée des conditions de la liberté se déploie dans une interrogation sur la liberté des cités, et non sur celle des individus. Une cité peut être dite libre lorsqu'elle est indépendante et/ ou que ses citoyens déterminent ensemble les fins qu'elle doit poursuivre, au sein d'un gouvernement républicain. Skinner fait de ce cadre de réflexion le fondement de son argumentation et donne à Machiavel un rôle de premier plan au sein de celui-ci. ${ }^{163}$ Pour lui, l'intérêt du républicanisme machiavélien tient à l'obsession qui le hante des risques internes et externes encourus par la cité libre et au fait qu'il présente une vision pluraliste des fins poursuivies par les citoyens articulée à une théorie de la participation active des citoyens à la vie civique. Machiavel met en évidence que l'ambition personnelle de certains citoyens est un danger, le plus grave qui soit, à l'encontre de la liberté et de la vie d'une république. ${ }^{164}$ Dans cette perspective, la vigilance est la première qualité requise chez les citoyens pour préserver la liberté de leur cité. Il leur faut être soldat pour se prémunir contre les attaques extérieures, mais aussi prendre des dispositions contre la libido dominandi de certains citoyens ambitieux. ${ }^{165}$ Skinner voit donc dans la pensée de Machiavel une articulation de l'idéal antique de vertu civique et du concept moderne de liberté individuelle, à partir de laquelle il est possible de proposer une conception de la démocratie pluraliste à la fois distincte de la vision libérale et de la vision communautarienne de la démocratie. Il propose, à travers l'interprétation de l'œuvre machiavélienne, une conception libérale-républicaine de la liberté.

Alors que les méthodes de travail de Pocock et Skinner diffèrent, elles ont un effet identique sur la constitution de leur objet : l'attention au contexte linguistique et la volonté de dégager un paradigme à la fois politique et linguistique conduisent toutes deux à faire du

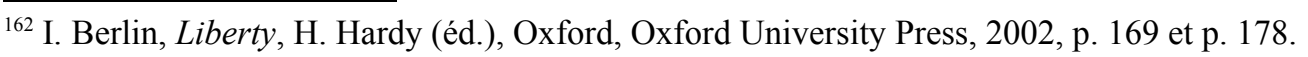

${ }^{163}$ Q. Skinner : 'Sur la justice, le bien commun et la priorité de la liberté', in : Communautariens et libéraux, in : Libéraux et Communautariens, textes réunis et prés. par A. Berten, P. de Silveira et H. Pourtois, PUF, 1997, p. 216.

${ }^{164}$ Q. Skinner, Ibid., pp. 218-219.

${ }^{165}$ Q. Skinner, Ibid., p. 221, cf. Aussi pp. 225-226.
} 
conflit et des rapports de force un élément très secondaire dans le républicanisme machiavélien. Chez Pocock, cette dimension est tout à fait absente, et se justifie au demeurant par le fait que l'auteur du Moment machiavélien ne prétend pas proposer une exégèse de Machiavel. Il entend plutôt dégager le « moment machiavélien » comme concept permettant de penser certaines situations politiques. Skinner, en revanche, propose une interprétation de la pensée machiavélienne qui mérite, au sujet du conflit, d'être discutée. Il n'a pas ignoré l'importance de la théorie du conflit civil chez Machiavel. Elle est à ses yeux, avec la dissociation de la virtù et des exigences de la foi chrétienne, la source de l'écart entre Machiavel et la tradition de l'humanisme civique. Mais il en donne une interprétation trop irénique : selon lui, les tumultes sont la conséquence d'un « engagement politique intense et donc la manifestation de la plus haute virtù civique »; ils « cimentent» la communauté au lieu de la dissoudre. Ce propos dissimule, derrière sa généralité, plusieurs inexactitudes. Machiavel ne parle nulle part, à propos des désirs des grands et du peuple, d'engagement civique. Il semble difficile de les interpréter en ce sens, car à Rome tout au moins, cette manifestation semble provenir d'une situation vécue comme contradictoire: la plèbe est requise militairement mais n'a aucune part au gouvernement de la cité. Et c'est en raison de ce décalage qu'elle en vient à revendiquer une part dans les magistratures, en échange de sa participation à la guerre. Enfin, Skinner envisage la participation civique comme l'accomplissement, actif et vigilant, des devoirs civiques. Cela sert évidemment l'usage qu'il fait du républicanisme machiavélien à l'adresse des citoyens d'aujourd'hui.

Cependant, les Discours et L'Histoire de Florence invitent à concevoir la participation des citoyens dans ses formes institutionnelles, mais aussi extra-institutionnelles. Celles-ci constituent même la forme par excellence de la participation du peuple, puisqu'il existe toujours un décalage entre ce à quoi il prétend et ce dont il jouit, en raison de la nature dynamique de leur désir et de l'opposition des grands. La liberté ne fait pas l'objet d'un don : Rome devient et demeure une république parce que la plèbe force l'ordre institutionnel établi et contraint le Sénat à des réformes en échange de sa participation à la guerre. ${ }^{166}$ L'action de la plèbe s'apparente en ce sens à une effraction de l'ordre institutionnel établi. L'émergence et le maintien de la liberté apparaissent donc relever d'une violation répétée de l'ordre institutionnel établi. ${ }^{167}$ En effet, dans la mesure où le peuple se trouve initialement dépourvu de tout statut institutionnel, il ne peut réclamer une part des magistratures que sous la forme de la protestation, de la lutte, du coup de force. C'est un trait continu de la participation populaire :

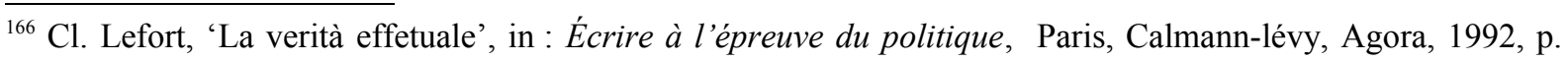
170.

${ }^{167}$ Discours sur la première décade de Tite-Live, I, 4, pp. 68-72. 
une fois acquis un statut institutionnel, le peuple continue à emprunter la même voie pour revendiquer toujours plus que ce qu'il a déjà obtenu.

Ce qui est passé sous silence ou interprété de manière parcellaire dans le «moment machiavélien » anglo-saxon est au centre du « moment machiavélien » français identifié par S. Audier. Pour en comprendre la nature, il faut revenir à l'analyse du conflit civil qui n'est pas seulement, chez Machiavel, un élément d'instabilité dans l'histoire des cités, au même titre que le processus de corruption et les soubresauts de la fortune, la constante variation de la qualité des temps. Chez Machiavel, le conflit civil a en outre la particularité de faire l'objet d'une évaluation positive : à la différence de la plupart des penseurs politiques, il estime en effet que la dynamique à l'origine de ce conflit, c'est-à-dire la confrontation entre le désir de dominer des grands et celui, populaire, de ne pas être dominé, peut avoir, dans certaines conditions historiques, des effets favorables à la liberté.

Dans cette perspective, si le conflit civil est toujours une cause de fragilité des régimes politiques, en ce qu'il impose de constantes mesures de régulation, difficile à produire, il peut aussi avoir une fonction positive puisqu'en son sein, s'expriment des forces et se joue une lutte qui peuvent être favorables à la liberté politique. Cette thèse est énoncée dans Les Discours qui offrent un commentaire de l'histoire de la république romaine populaire. On y voit progressivement Machiavel constituer cette histoire en paradigme à la fois positif et négatif du régime libre : positif quand le conflit civil débouche sur un accroissement de la liberté, négatif quand ce même conflit prend des formes incompatibles avec le maintien du gouvernement selon la loi. On apprend tout d'abord ce que Le Prince laissait entendre, sans l'expliciter : le conflit civil prend des formes très diverses, de l'insulte sur la place publique à l'affrontement armé et que cette variation d'intensité et de forme est un indice du degré de corruption des mœurs des citoyens. On y découvre ensuite qu'aux yeux de Machiavel, l'opposition entre grands et peuple, lorsqu'elle parvient à s'exprimer dans les institutions existantes, est source de la liberté politique entendue comme gouvernement des citoyens par la loi : «celui qui examinera bien le résultat de ces tumultes ne trouvera pas qu'ils aient engendré des exils ou des violences au détriment du bien commun, mais plutôt des lois et des institutions à l'avantage de la liberté publique $»{ }^{168}$ Plus précisément, dans une république telle que la conçoit Machiavel et ses contemporains, tous les citoyens ne sont pas nécessairement égaux au sens où tous n'ont pas une part égale dans les magistratures. Mais le régime est libre lorsque la

\footnotetext{
${ }^{168}$ Discours, I, 4, p. 70.
} 
répartition du pouvoir entre les « humeurs » est telle qu'aucune ne domine l'autre au détriment du régime de la loi. C'est l'opposition du peuple, en tant qu'il ne désire pas être dominé, à l'ambition des grands qui est génératrice de la liberté. Le peuple est en ce sens, tant que son désir de ne pas être dominé ne s'est pas corrompu, un meilleur gardien de la liberté que les grands dans la cité. ${ }^{169}$

En mettant au centre de l'analyse ce que le «moment machiavélien » anglo-saxon met entre parenthèse ou minore, les philosophes qui ont contribué à l'émergence d'un " moment machiavélien » français, Raymond Aron, Maurice Merleau-Ponty et Claude Lefort, s'inscrivent dans une relation à Machiavel plus exégétique que les historiens de la pensée politique Pocock et Skinner, même si leur lecture n'est pas indépendantes de préoccupations et d'interrogations relatives à leur actualité théorique et politique. Chez Lefort, par exemple, Machiavel est constitué comme un penseur de « la division originaire du social». Le souci de penser une telle division du corps social s'inscrit dans une réflexion sur la démocratie et sa spécificité par rapport au système totalitaire. Pour Lefort, le totalitarisme se définit comme un mode de socialisation qui nie l'existence d'un conflit au sein de la cité entre des forces sociales, ou prétend en tout cas y mettre fin. En ce sens, un système totalitaire est un système politique qui s'est donné une vocation universelle, une logique identitaire : le corps politique est ou doit être « un », sans division. C'est contre cette prétention que se définit pour lui la démocratie : elle renvoie au contraire à la conception d'un corps social essentiellement divisé, à une acceptation du conflit entre les forces qui le composent, sans prétention à la nier, ni à réconcilier ses forces. La démocratie renvoie à ses yeux à l'instauration de mécanismes institutionnels qui permettent l'expression des conflits au sein de la cité.

À l'aide du chapitre 9 du Prince et du chapitre I, 4 des Discours, Lefort construit sa vision d'un corps social divisé, marqué par un conflit des humeurs infiniment reconduit. D'autre part, avec l'analyse de l'évolution des institutions de la république romaines que Machiavel mène dans les Discours, il envisage comment une forme libre de gouvernement met en place des institutions qui permettent aux humeurs de s'exhaler [sfogare] de manière civile, c'est-à-dire qui donnent cours au conflit civil tout en le canalisant dans un jeu institutionnel afin d'éviter son débordement dans la violence. Dans cette perspective, l'organisation du pouvoir repose sur la composition du corps social parce qu'elle organise l'expression civile de sa division et aussi parce qu'elle s'offre à un questionnement permanent suscité par le conflit civil, dont les différents moments sont autant d'occasions pour redistribuer les magistratures.

\footnotetext{
${ }^{169}$ Discours, I, 5.
} 
La démocratie, pour Lefort, doit être comprise dans cette perspective comme la seule forme de régime à même d'éviter le danger de dérive vers le totalitarisme. ${ }^{170}$

De façon générale, dans ce «moment machiavélien » français, la relation critique à la pensée marxiste s'avère essentielle. Elle l'est à la fois par la sensibilité conférée aux conflits civils dans l'observation de la réalité politique et par le désir de dépasser une explication strictement socio-économique de ces conflits, identifiée à l'argumentaire marxiste. Dès lors qu'on lit en lui, en effet, la conception d'une société sans classes, dans laquelle les causes socio-économiques du conflit, liées aux rapports de production, auraient été supprimées, la pensée machiavélienne apparaît comme une alternative en ce qu'elle permet de dénoncer l'illusion selon laquelle les dissensions internes à une société peuvent être analysées en termes strictement socio-économiques et pourraient être résolues dans les mêmes termes : chez Machiavel, nous l'avons vu, les humeurs ne cessent en effet jamais de s'exprimer et de s'opposer; elles sont liées à des passions et des désirs irréductibles à une revendication d'ordre socio-économique.

Une pensée « économiste » de Marx a certes des éléments sur lesquels s'appuyer. S'il est vrai que Le Manifeste permet d'envisager la notion de "prolétariat » comme une notion politique, au sens où elle constitue la seule «classe réellement révolutionnaire », ${ }^{171}$ la conception socio-économique des classes apparaît prégnante dans la pensée marxiste. Elle est manifeste dans la définition des catégories de bourgeois et de prolétaire qu'il propose dans $L e$ Manifeste : le premier terme désigne « la classe des capitalistes modernes qui sont propriétaires des moyens sociaux de production et emploient du travail salarié $»$, tandis que le second renvoie à « la classe des ouvriers salariés modernes qui, ne possédant en propre aucun moyen de production, en sont réduits à vendre leur force de travail pour pouvoir vivre $\gg{ }^{172}$ Cette double définition insiste sur la place des bourgeois et des prolétaires dans le système de production. Celui-ci est encore au centre de l'analyse du processus historique qui conduit à la substitution d'un couple de classes antagonistes par un autre. ${ }^{173}$ À chaque moment, le résultat est identique: sous l'impulsion des rapports sans cesse plus complexes entre l'offre des producteurs et les « besoins », apparaissent de nouvelles classes, dont la relation est cependant toujours de l'ordre de l'oppression. En ce sens, pour Marx, toute "société» est une

\footnotetext{
${ }^{170} \mathrm{Cf}$. notamment de Cl. Lefort : L'invention democratique, Fayard, 1981 ; Écrire à l'epreuve du politique, Calmann-Lévy/ Agora, 1992.

${ }^{171}$ K. Marx, Le Manifeste, tr. de É. Bottigelli, GF Flammarion, 1998 p. 86.

${ }^{172}$ Ibid., p. 73.

${ }^{173}$ K. Marx, Ibid., pp. 74-75.
} 
organisation sociale déterminée par un certain mode de production et les « rapports sociaux » qui lui sont propres se définissent comme un mode d'oppression d'une classe sur une autre. Par la suite, dans la pensée de Marx, le rapport de production continue à jouer le rôle essentiel qui lui a été conféré dans Le Manifeste. En 1859, l'Avant-propos à la Critique de l'économie politique évoque des rapports de production déterminés, nécessaires et indépendants de la volonté des hommes, correspondant «à un degré donné du développement de leurs forces productives matérielles ». ${ }^{174} \mathrm{La}$ description de la société se fait donc chez lui essentiellement en termes économiques et c'est à partir de cette description des catégories qu'il est possible d'envisager une solution au conflit, précisément de type socio-économique : la société sans classes.

Par rapport à cette analyse, une pensée d'inspiration machiavélienne refuse de considérer qu'une redistribution des moyens et des ressources résoudrait le conflit civil : elle invite à concevoir ce dernier sous une forme plus complexe que ne le permet la grille de lecture socio-économique. Cette dimension de la pensée machiavélienne a une actualité particulière aujourd'hui, qui tient au repérage, dans l'histoire récente des démocraties, de conflits qui ne semblent pouvoir être résolus au moyen d'une redistribution économique. Selon l'économiste politique Albert Hirschman, par exemple, les démocraties apparaissent aujourd'hui confrontées à la multiplication des conflits internes liés à des valeurs, des identifications culturelles, des croyances. Ce sont des conflits «non quantifiables» [non divisible]. «Que dieu nous rendent nos conflits de classe !» s'exclame à leur propos Hirschman, car leur résolution pouvait être plus facilement pensée et mise en œuvre, à travers des mesures de redistribution. ${ }^{175}$ On peut relativiser la pertinence de ce point de vue sur la nature des conflits civils contemporains : en réalité, beaucoup d'entre eux ont très probablement une dimension quantifiable. Exposer et assumer une identité «culturelle » est généralement un acte qui s'inscrit dans un rapport de forces en partie quantifiable. ${ }^{176}$ Toutefois, il n'en reste pas moins que dans certains cas, les conflits d'ordre identitaire, moral ou culturel nous invitent à dépasser la grille d'analyse socioéconomique du conflit et à envisager des «tumultes » aux paramètres multiples et des formes peut-être irréductibles de désaccord. Si Machiavel a, à ce sujet, une certaine pertinence, ce n'est pas parce qu'il aurait proposée de manière anticipée une interprétation de ce type de

\footnotetext{
${ }^{174}$ K. Marx, Critique de l'économie politique, in : Euvres, Économie, I, éd. de M. Rubel, Paris, Gallimard, NRF, La Pléiade, 1963, pp. 272-273.

${ }^{175}$ A. Hirschman, 'Social Conflicts as Pillars of Democratic Market Societies' [1993], A propension to selfsubversion, Harvard University Press, 1995, p. 247.

${ }^{176}$ N. Elias et J. L. Scotson, The Established and the Outsiders : inquiry into community problems, Londres, Thousand Oaks (California) et New-Delhi, SAGE, 1965.
} 
conflit, mais parce qu'il nous place dans un horizon irréductiblement conflictuel et s'efforce de penser les régulations institutionnelles possibles d'un conflit toujours présent et insoluble à travers la redistribution de ressources.

On repère encore, outre ces deux usages de la pensée machiavélienne dans la réflexion contemporaine sur la démocratie, identifiés sous le nom de «moment machiavélien anglosaxon » et « moment machiavélien français » deux autres formes d'emprunt à Machiavel. L'un s'inscrit en faux contre l'interprétation de la pensée marxiste en termes strictement socioéconomiques qui nourrit la définition du «moment machiavélien français » dans l'analyse de S. Audier. Miguel Abensour avait déjà repris à son compte l'expression de J. G. A. Pocock et parlé d'un «moment machiavélien » de Marx. ${ }^{177}$ Selon lui, il faut aussi lire dans la pensée de Marx lui-même la présence d'une analyse politique du conflit social, autrement dit d'une conception qui rend ce conflit irréductible à des paramètres socio-économiques. Dans sa critique de la «statolâtrie », Marx aurait donné selon lui un nouveau sens à la relation entre conflit et liberté, auquel Machiavel ne pouvait songer, dont la réflexion sur les totalitarismes peut particulièrement tirer profit. Le «moment machiavélien » de Marx est liée, dans cette optique, à la conscience d'une lutte nécessaire, en vue de l'émancipation des hommes en société, contre la tendance inéluctable de l'État à se figer dans un exercice du pouvoir toutpuissant et oppressant. ${ }^{178}$

L'affirmation de ce nouveau «moment machiavélien» va de pair avec une dénonciation de l'identification entre la démocratie et l'État de droit, fondée sur le soupçon que l'entité étatique tend à s'autonomiser par rapport au peuple des citoyens et à absolutiser son pouvoir, alors que ce dernier devrait être soumis à la volonté collective du peuple. Dans cette perspective, Abensour conçoit la démocratie non pas comme le refus de la forme, mais comme celui d'une forme qui se prétendrait toute-puissante. ${ }^{179}$ Une pensée de la démocratie qui se garde véritablement contre cette prétention doit conférer une place au « principe libertaire $»{ }^{\mathbf{1 8 0}}$ Dans une «vraie démocratie », le moteur de l'État demeure toujours le peuple : « dire que le point de gravité de l'État réside hors de lui-même indique plutôt qu'il faut rapporter l'État à ce mouvement qui l'excède, qui le met hors de ses gonds, à cette sursignification qui le transit et dont le sujet réel n'est autre que la vie active du dêmos. ${ }^{181}$ C'est parce qu'il conçoit des

\footnotetext{
${ }^{177}$ M. Abensour, La démocratie contre l'État, Marx et le moment machiavélien, Paris, Collège International de Philosophie, 1997

${ }^{178}$ Ibid., p. 108.

${ }^{179}$ Ibid., p. 112.

${ }^{180}$ Ibid., pp. 112-114..

${ }^{181}$ M. Abensour, Ibid., p. 49.
} 
moments où le peuple s'auto-détermine et s'auto-constitue, les temps mêmes de la politique, et leur accorde une importance fondamentale dans certaines parties de son œuvre que Marx participe à sa manière à un « moment machiavélien ${ }^{182}$

On peut enfin suggérer un emprunt à Machiavel, fondé sur l'idée machiavélienne qu'aucune détermination du régime politique et aucune distribution du pouvoir ne sont des données définitives. Bien que Jacque Rancière ne se soit jamais réclamé de la pensée machiavélienne, il développe une pensée politique qui n'est pas sans proximité avec cette thèse. Sa réflexion sur la démocratie peut nous aider à identifier cette dimension de la relation établie par Machiavel entre conflit civil et liberté, et partant de mieux comprendre une raison supplémentaire à celles déjà commentées de convoquer Machiavel dans la discussion contemporaine sur la démocratie.

Lorsqu'on s'intéresse au forçage institutionnel produit par le peuple dans son opposition au désir de domination des grands, on constate que la cité est, d'un point de vue institutionnel, essentiellement perméable. Dans les Discours sur la première décade de TiteLive, Rome apparaît comme un espace politique ouvert et transformable : une communauté peut conquérir ou perdre un statut institutionnel. Cela modifie la répartition des magistratures, bien sûr : c'est cela que les fondateurs du «moment machiavélien » français se sont surtout attachés à commenter. Mais cela change aussi la composition même de cette cité, la nature de ses parties.

Or, sur ce point, Rancière a proposé d'intéressantes analyses. Malgré l'existence de différences dans l'argumentation, l'idée d'un espace politique ouvert et perméable (et son envers : la négation de certains sujets dans l'espace public, qui doivent en conséquence lutter pour apparaître et devenir des sujets politiques à part entière) est centrale dans son affirmation d'une «part des sans part» et son analyse des processus de subjectivation. ${ }^{183}$ Dans La Mésentente, Rancière a pour point de départ un constat : celui du retour de la «philosophie politique » après l'effondrement des régimes communistes à la fin des années 1980. Or, cette "philosophie politique » autoproclamée est, à ses yeux, problématique : elle s'apparente plutôt à une forme de pensée qui légitimerait les démocraties libérales. L’idée même de «philosophie

\footnotetext{
${ }^{182}$ On rencontre chez A. Negri l'affirmation d'une filiation entre Machiavel et Marx très proche de la réflexion développée ici par M. Abensour sur la «démocratie contre l'État, in : Le pouvoir constituant, essai sur les alternatives de la modernité, tr. de E. Balibar et Fr. Matheron, Paris, PUF, Pratiques théoriques, 1997.

${ }^{183} \mathrm{Cf}$. aussi sur le même sujet: J. Butler, Vie précaire, les pouvoirs du deuil et de la violence après le 11 septembre 2001, de J. Butler, tr. de J. Rosanvallon et J. Vidal, Paris, Éditions Amsterdam, 2005 [1 $1^{\text {ere }}$ éd. en anglais : 2004] et notamment son commentaire sur la délimitation de l'espace public comme détermination des sujets politiques viables.
} 
politique » et l'activité de pensée qu'elle implique n'ont en fait rien d'évident ; aussi pose-t-il la nécessité de définir le lieu de rencontre de la philosophie et de la politique. Cette opération constitue la première étape de sa réflexion. Elle tient dans une référence au livre III de $L a$ Politique d'Aristote : «'De quoi il y a égalité et de quoi il y a inégalité, la chose porte à aporie et à philosophie politique'. La philosophie devient 'politique' quand elle accueille l'aporie ou l'embarras propre à la politique. $\gg{ }^{184}$ Le questionnement sur la philosophie et son rapport à la politique conduit Rancière à signaler l'existence d'un «embarras " propre à la politique. L'embarras a pour objet une distribution qui se pense en termes d'égalité et d'inégalité. Ce sont des «parts » de communauté que l'on distribue, en tenant compte de «titres » qui donnent droit à faire part de la communauté.

Or, selon Rancière, la leçon que nous pouvons tirer de la pensée des classiques est que le compte des parties de la communauté est toujours faux. En effet, le titre du peuple, qui légitime sa présence dans la cité, est la liberté : « qu'est-ce donc en revanche que la liberté apportée par les gens du peuple à la communauté ? Et en quoi leur est-elle propre ? C'est ici que se révèle le mécompte fondamental $\gg .{ }^{185} \mathrm{Ce}$ titre - la liberté -, qui est celui des hommes qui n'ont rien d'autre (ni richesse, ni excellence), confère au peuple un statut très particulier : il possède en effet comme titre la qualité commune de la cité. Ainsi, celui-ci fait l'objet d'un litige, puisque la liberté n'appartient pas en propre au peuple. Comme tel, ce titre dévoile le tort qui est fait par les autres parties au peuple : « ce qui est sans part - les pauvres antiques, le tiers état ou le prolétariat moderne - ne peut en effet avoir d'autre part que le rien ou le tout $\gg .{ }^{186}$

Ce commentaire des titres de communauté met à la disposition de Rancière une représentation de la cité antique, qui lui permet de définir ce qu'est la politique. Elle permet notamment de concrétiser l'idée formulée initialement: la politique comme activité dont le principe est l'égalité. À partir de cette représentation, elle peut en effet se concevoir comme la rupture avec un ordre de distribution conçu comme allant de soi et, simultanément, comme l'institution d'une part des sans-parts : «la politique existe lorsque l'ordre naturel de la domination est interrompu par l'institution d'une part des sans-parts. (...) En dehors de cette institution, il n'y pas de politique. Il n'y a que l'ordre de la domination ou le désordre de la révolte. $»^{187}$ Dans cette perspective, la notion de «politique » a un sens lié à des temps où la

\footnotetext{
${ }^{184}$ J. Rancière, Ibid., p. 11. Aristote cherche, au début du livre III des Politiques, à définir le bien politique. Celui-ci réside dans le juste, qui consiste à attribuer aux gens égaux une part égale. Mais cette définition fait surgir une interrogation, que $\mathrm{J}$. Rancière reprend dans le cadre de sa réflexion sur la philosophie politique : «Mais il ne faut pas laisser dans l'ombre sur quoi porte l'égalité et sur quoi l'inégalité, car il y a là une difficulté et <matière à> philosophie politique.»12, 1282 b, Opus cit., p. 247.

${ }^{185}$ J. Rancière, Ibid., p. 26.

${ }^{186}$ Ibid., p. 28.

${ }^{187}$ Ibid., p. 31.
} 
communauté opère un nouveau compte de ses parties, par adjonction d'une nouvelle, en vertu du principe d'égalité. Ces temps révèlent, souligne J. Rancière, le caractère contingent de tout ordre social. Ils sont marqués par l'apparition et la prise en compte de parties qui n'existaient pas avant la remise en cause de l'ordre de distribution de la communauté. Aussi peut-on parler d'un « processus de subjectivation » : « la politique est affaire de sujets, ou plutôt de modes de subjectivation. Par subjectivation, on entendra la production par une série d'actes d'une instance et d'une capacité d'énonciation qui n'étaient pas identifiables dans un champ d'expérience donné, dont l'identification donc va de pair avec la refiguration du champ de l'expérience $\gg{ }^{188}$ Pour l'auteur de La Mésentente, les parties qui réclament le droit à faire part de la communauté n'existent pas (elles ne sont pas comptées) avant de formuler cette revendication. La refiguration de la communauté ne marque pas seulement une modification de la distribution du pouvoir, mais aussi la naissance de nouvelles parties et donc d'une nouvelle vision du corps politique.

De la même façon, chez Machiavel, la plèbe romaine n'est constituée comme membre de la cité qu'à partir du moment où elle a revendiqué une part des magistratures : en gagnant celle-ci, elle acquiert aussi le droit d'être compté comme un membre à part entière de la cité et de figurer dans celle-ci. La cité, comme espace politique, s'élargit, en même temps que de nouveaux membres y apparaissent pour revendiquer et conquérir une part; elle change aussi d'identité car lorsque de nouveaux entrants y trouvent leur place, ils modifient la configuration de celle-ci. Dans cette perspective, il n'y a, en politique, aucun ordre « naturel » des choses, ni dans la composition des cités, dans la définition de ses membres et de ses étrangers, de ses citoyens actifs et de ses citoyens passifs. Il s'agit là d'une implication de la thèse de Machiavel sur la relation entre conflit civil et liberté qu'il convient, selon nous, d'ajouter au dossier du « moment machiavélien » français.

Dans la réflexion contemporaine sur la démocratie, le recours à Machiavel emprunte, on le constate aisément, des voies diverses selon les contextes épistémologiques, théoriques et politiques. Rares sont les interprétations de Machiavel qui reprennent littéralement sa pensée et elles ne prétendent pas toutes au même degré de fidélité exégétique. Certaines se contentent délibérément de recevoir de son œuvre l'impulsion nécessaire pour emprunter un chemin perçu comme inexploré ou mal défriché de la philosophie politique. On repère donc différentes formes d'emprunt dans cette modalité de lecture qui va chercher chez Machiavel ce qu'elle ${ }^{188}$ Ibid., p. 61. 
estime absent ou insuffisamment pensé dans la tradition ou le questionnement initiale de référence : le cadre libéral pour Pocock, la réduction de la notion de liberté à la liberté négative pour Skinner, l'oubli de la dimension conflictuelle de la cité politique, sa positivité éventuelle en vue de la liberté, son irréductibilité à une analyse en termes socio-économiques pour le «moment machiavélien » français, et ajouterons-nous à titre personnel, la nécessité de penser les « refigurations » du corps politique, étant donné la contingence de tout ordre institutionnel et la perméabilité de l'accès à la citoyenneté.

Le point commun de ces emprunts réside sans doute dans une sorte de libre appropriation de la pensée Machiavélienne. À travers celle-ci, ils sont plus ou moins fidèles à la lettre de sa pensée, réitérant le geste de Machiavel, qui s'était également approprié, non sans une certaine désinvolture, la pensée des Anciens afin d'élaborer sa propre réflexion sur les conditions d'un ordre institutionnel stable et celles de la liberté politique. On peut affirmer en ce sens qu'il y a chez Machiavel comme chez les penseurs politiques contemporains qui y font référence une forme d'irrespect quant à la lettre du texte lu et commenté, au sens où l'emprunt est partiel, plus ou moins fidèle du point de vue exégétique et toujours lié à des interrogations extérieures à l'œuvre de Machiavel. Mais cet irrespect permet d'envisager autrement que comme un «bibelot d'époque » l'œuvre de Machiavel. Elle donne lieu à une pensée politique inventive et susceptible de renouveler nos interrogations sur le sens de la démocratie politique et les conditions de son approfondissement.

\section{ÉPILOGUE}

Aujourd'hui, à certains égards, l'hypothèse de "l'étrangèreté » de Machiavel par rapport à la philosophie paraît moins pertinente qu'autrefois. Plus exactement, elle aurait eu sa part de vérité : cette « étrangèreté » serait chose du passé. Dans les usages dont il fait l'objet à 
propos de la démocratie contemporaine, Machiavel serait même de nos jours au plus près de l'exercice de la pensée philosophique, si nous acceptons de définir celui-ci de manière large, au sens où nous philosophons lorsque nous «entrons en dialogue avec les philosophes", débattons «avec eux de ce dont ils parlent», «ce qu'ils disent» et «ce à partir de quoi ils parlent $»{ }^{189}$ Et même si nous nous détournons de cette conception de la philosophie, force est de constater que la richesse des emprunts dont Machiavel fait l'objet et leur effet d'impulsion de la pensée politique contemporaine conduisent à mettre entre parenthèses, voire à oublier cette « étrangèreté » de Machiavel par rapport à la philosophie.

Avons-nous, pourtant, intérêt à la mettre de côté ? Ce n'est pas certain. Il est bon de s'en souvenir au moment où l'on aborde la question pour laquelle son œuvre semble avoir le moins de pertinence : celle de la démocratie, afin de ne pas postuler a priori une congruence, voire une équivalence, entre les thèses de Machiavel et celles que l'on peut défendre dans le contexte politique contemporain.

En outre, de manière plus générale, la pensée machiavélienne produit ses effets théoriques majeurs plutôt dans l'écart et le décalage que dans l'adéquation ou la confirmation de telle ou telle thèse. On l'a vu à propos du rôle et du statut de la religion dans le champ politique, de la pensée de la dynamique conflictuelle propre à l'histoire des cités, de la relation entre morale et politique, ou encore de l'écriture politique.

Enfin et surtout, en reléguant au passé cette « étrangèreté », nous risquons de ne plus comprendre les enjeux de «clivages » établis par des philosophes entre ce qu'ils estimaient être leur tâche théorique et la pensée de Machiavel. Si nous pouvons aujourd'hui les estimer « réducteurs », grâce à la constitution d'un « vaste savoir positif » sur sa pensée, ${ }^{190}$ nous ne devons pas être aveugles à leurs significations dans d'autres cadres théoriques, politiques et historiques que le nôtre. Sans cette appréhension des choses, nous courons le risque de perdre de vue une certaine «épaisseur» de la pensée machiavélienne et de la philosophie. La première comporte peut-être encore des strates inexplorées, que de futurs contextes politiques et théoriques mettront à jour. La seconde gagne, d'un point de vue théorique, à être comprise comme tradition, ensemble de questions, de problèmes, de thèses qui se constitue indéfiniment au fil du temps, en excluant ou en incorporant des «matières étrangères » et des styles de pensée.

\footnotetext{
${ }^{189}$ M. Heidegger, 'Qu'est-ce que la philosophie ?', in : Questions I et II, tr. de K. Axelos, J. Beaufret, W. Biemel, L. Brau, Paris, Galliamrd, Tel, 1990, pp. 334-335.

190 Cf. G. Sfez et M. Senellart, L'enjeu Machiavel, Avant-propos, Paris, PUF/Collège international de philosophie, p. 2.
} 


\section{BibliogRAPHIE}

\section{De Machiavel (traductions en français)}

Le Prince,

tr. de J-L. Fournel et J-Cl. Zancarini, Paris, PUF, 2000

tr. de M. Gaille-Nikodimov, Paris, Le Livre de Poche, 2000

tr. de Y. Lévy, Paris, Garnier-Flammarion, 1980

(édition bilingue) tr. de G. Luciani, Paris, Gallimard

Discours sur la première décade de Tite-Live

tr. de A. Fontana et X. Tabet, Paris, Gallimard, 2004

Histoire de Florence, cf. Cuvres

Toutes les lettres officielles et familières, celle de ses seigneurs, de ses amis et des siens, 2 volumes, tr. de E. Barincou, Paris, Gallimard, 1955

Cuvres, tr. dir. Ch. Bec, Paris, Laffont, 1996 [comprend, en sus des textes mentionnés ci-dessus, L'Art de la guerre, les œuvres littéraires, des extraits de la correspondance de Machiavel et des textes politiques dits « mineurs »]

\section{Sur la vie de Machiavel}

Ch. Bec, Machiavel, Paris, Balland, 1985

M. Gaille-Nikodimov, Machiavel, Paris, Tallandier, 2005

R. Ridolfi, Machiavel - vie de Niccolò Machiavel, tr. de F. Hayward, Paris, Fayard, 1960

O. Tommasini, La vita e gli scritti di Niccolà Machiavelli nella loro relazione col machiavellismo, Bologne, Il Mulino/Istituto per gli studi storici, 1994 [1 1 ère éd. : 18831911]

P. Villari, Niccolò Machiavelli e i suoi tempi, éd. Ulrico Hoepli, 1895

E. Weibel, Machiavel. Biographie politique, Fribourg, Éditions Universitaires Fribourg Suisse, 1988

\section{Sur la pensée de Machiavel}

R. von Albertini, Firenze dalla repubblica al principato, Storia e conscienza politica, Turin, Einaudi, 1970, 1995

M. Abensour, La démocratie contre l'État, le moment machiavélien de Marx, Paris, Collège international de philosophie, 1997

L. Althusser, 'Solitude de Machiavel', in : Solitude de Machiavel, éd. de Y. Sintomer, Paris, PUF, 1998, pp. 311-324

G. M. Anselmi, Ricerche sul Machiavelli storico, Pise, Pacini, 1979

R. Aron, Machiavel et les tyrannies modernes, Paris, éd. de Fallois, 1993

S. Audier, Machiavel, conflit et liberté, Paris, Vrin/EHESS, 2005

G. M. Barbuto, La politica dopo la tempesta - ordine e crisi nel pensiero di Francesco Guicciardini, Naples, Liguori editore, 2002

H. Baron,

The Crisis of the Early Italians Renaissance, Volume I, Princeton University Press, 1955

In Search of Florentine Civic Humanism, Essays on the Transition from Medieval to Modern Thought, I et II, Princeton University Press, 1988 
Th. Berns, Violence de la loi à la Renaissance - l'originarité du politique chez Machiavel et Montaigne, Paris, Kimé, 2000

G. Bock, Q. Skinner, M. Viroli, Machiavelli and Republicanism, Cambridge University Press, 1990

G. Cadoni, Crisi della mediazione politica nel pensiero di Niccolò Machiavelli, Francesco Guicciardini, Donato Giannotti, Jouvence, Rome, 1994

E. Cassirer, Le mythe de l'Etat, tr. de B. Vergely, Paris, Gallimard, 1993 [trad. de The myth of the State, 1946]

F. Chabod, Scritti su Machiavelli, tome 1, Turin, Einaudi,1964

Scritti sul Rinascimento, tome 2, Turin, Einaudi, 1967

F. Chiappelli,

Studi sul linguaggio del Machiavelli, Florence, Le Monnier, 1952

Nuovi studi sul linguaggio, Florence, Florence, Le Monnier, 1969

Machiavelli e la 'lingua fiorentina', Bologne, M. Boni, 1974

G. Colonna d'Istria et R. Frapet, L'art politique chez Machiavel, Paris, Vrin, 1980

G. Costa, Le antichità germaniche nella cultura italiana da Machiavelli a Vico, Naples, Bibliopolis, 1997

E. Cutinelli-Rendina,

Chiesa e religione in Machiavelli, Pise-Rome, Istituti Editoriali e Poligrafici Internazionali, 1998

Introduzione à Machiavelli, Rome, Laterza, 1999

F. Del Lucchese, Tumulti e indignatio. Conflitto, diritto e moltitudine in Machiavelli e Spinoza, Milan, Edizione Ghibli, 2004

A. Ehnmark, Les secrets du pouvoir. Essai sur Machiavel, tr. de M. de Gouvenain et

L. Grumbach, Arles, Actes Sud, 1988

R. Esposito, Ordine e conflitto, Machiavelli e la letteratura politica del Rinascimento italiano, Naples, Liguori Editore, 1984

J.-L. Fournel J.-L. et J.-Cl. Zancarini,

'Face à l'état d'urgence : sermons et écrits politiques de Savonarole (14941498)', in : Italie 1494, Paris, Publications de la Sorbonne/ Presses de la Sorbonne nouvelle, 1994, pp. 15-39

La politique de l'expérience - Savonarole, Guicciardini et le républicanisme florentin, Turin, Edizioni dell’Orso, 2002

J. G. Fichte, Machiavel et autres écrits philosophiques et politiques de 1806-1807, tr. de L. Ferry et A. Renaut, Paris, Payot, 1981

C. Galli, 'Il volto demoniaco del potere ? Alcuni momenti e problmei della fortuna continentale di Machiavelli, in : Machiavelli e le Romagne, Il Ponte vecchio, 1998, pp. 101-127

M. Gaille-Nikodimov,

Conflit civil et liberté, la politique machiavélienne entre histoire et médecine, Paris, Champion, 2004

(co-dir. avec Th. Ménissier), Machiavel, Paris, Ellipses, 2006

E. Garin,

Moyen-âge et Renaissance, tr. de Cl. Carme, Paris, Gallimard, Tel, 1969

Machiavel entre politique et histoire, tr. de F. del Lucchese et Fr. Gabriel Paris, Allia, 2006 ('Polybe et Machiavel' et 'Les 'Histoire florentines')

F. Gilbert, 
Niccolò Machiavelli e la vita culturale del suo tempo, tr. de A. de Caprariis, Florence, Il Mulino, 1964 ; $2^{\mathrm{ème}}$ édition enrichie : Machiavelli e il suo tempo, Florence, Il Mulino, 1977 [contient la traduction italienne des plus importants articles de Gilbert].

Machiavel et Guichardin. Politique et histoire à Florence au XVIème siècle, tr. de J. Viviès, Paris, Le Seuil, 1996, "L'univers historique". [1 ${ }^{\text {ère }}$ éd. Machiavelli and Guicciardini. Politics and History in Sixteenth-Century Florence, Princeton University Press, 1965 ; tr. italienne Turin, Einaudi, 1970]

A. Gramsci, Note sulle Machiavelli, sulla politica e sullo stato moderno, Rome, Editori Riuniti, 1991

F. Guichardin, Dalle considerazioni intorno ai Discorsi del Machiavelli sopra la 'Prima Deca' di Tito Livio (1530), in : F. Guicciardini, Opere, Bari, éd. de R. Palmarocchi, 1933, vol. VIII [en fr. : Considérations à propos des Discours de Machiavel sur la première décade de Tite-Live, tr. de L. De Los Santos, Paris, L'Harmattan, 1997]

P. Larivaille, La pensée politique de Machiavel - Les Discours sur la première décade de Tite-Live, Presses Universitaires de Nancy, 1982

Cl. Lefort,

Le travail de l'ouvre Machiavel, Paris, Gallimard, 1972

'Machiavel : la dimension économique du politique', 'Machiavel et les jeunes', 'Réflexions sociologiques sur Machiavel et Marx : la politique et le réel', in : Les formes de l'histoire - Essais d'anthropologie politique, Paris, Gallimard, 1978, respectivement pp. 215-237, pp. 259-285, pp. 286-333

'Machiavel et la verità effetuale', in : Écrire à l'epreuve du politique, Paris, Calmann-Lévy, 1992, pp. 141-179

P. Manent, Naissances de la politique moderne: Machiavel, Hobbes, Rousseau, Paris, Payot, 1977

H. C. Jr Mansfield H. C.,

Machiavelli's New Modes and Orders - A study of the Discourses on Livy, Cornell University Press, 1979

Le Prince apprivoisé - De l'ambivalence du pouvoir, tr. de P-E. Dauzat, Paris, Fayard, L'esprit de la cité, 1999 [1 ${ }^{\text {ère }}$ éd. en anglais : Taming the prince : the ambivalence of modern executive power, New-York, The Free Press, et Londres, Collier Macmillan, 1989]

J.-J. Marchand, Niccolò Machiavelli. I primi scritti politici (1499-1512), Padoue, Editrice Antenore, 1975

A. Matucci, Machiavelli nella storiografia fiorentina - per la storia di un genere letterario, Florence, Leo S. Olschki Editore, 1991

Th. Ménissier, Machiavel, la politique et l'histoire - enjeux philosophiques, Paris, PUF, 2001

M. Merleau-Ponty, 'Note sur Machiavel', Signes, Paris, Gallimard, 1960, pp. 343-362

A. Parel,

The Political Calculus. Essays on Machiavelli's Philosophy, Toronto University Press, 1972

The Machiavellian Cosmos, New-haven, Londres, Yale University Press, 1992

J. G. A. Pocock, Le Moment machiavélien. La pensée politique florentine et la tradition républicaine atlantique, tr. de L. Borot, Paris, PUF, Léviathan, 1997 [1 1 ère éd. en anglais : The Machiavellian Moment. Florentine Political Thought and the Atlantic Republican Tradition, Princeton University Press, 1975] 
E. Raimondi, Politica e commedia - Il centauro disarmato, Il Mulino, Bologne, 1998 [1972]

G. Sasso,

Machiavelli e Cesare Borgia : storia di un giudizio, Rome, Edizioni dell'Ateneo, 1966

Niccolò Machiavelli, I, Storia del suo pensiero politico, Bologne, Il Mulino, 1980 [1 $1^{\text {ère }}$ éd. : Istituto per gli Studi Sotrici di Napoli, 1958] et II, La Storiografia, Bologne, Il Mulino, 1993

In margine al $V^{\circ}$ Centenario di Machiavelli. Filologia, erudizione, filosofia, Naples, Guida Editori, 1972

Machiavelli e gli antichi e altri saggi, Milan-Naples, Riccardo Ricciardi Editore, I, 1987, II et III, 1988 et IV, 1989

G.Sfez,

Le prince sans qualité, Paris, Kimé, 1998

Machiavel, la politique du moindre mal, Paris, PUF, 1999

L'Enjeu Machiavel cf. M. Senellart

Léo Strauss, lecteur de Machiavel - la modernité du mal, Paris, Ellipses, 2003

Q. Skinner, Machiavel, tr. de M. Plon, Paris, Le Seuil, 1989 [1 ${ }^{\text {èr }}$ éd. en anglais : Machiavelli, Oxford, Past Master Pieces, 1981]

L. Strauss,

Pensées sur Machiavel, tr. de M-P. Edmond et Th. Stern, Paris, Payot, 1982 [1ère éd. en anglais : Thoughts on Machiavelli, The University of Chicago Press, 1978]

Qu'est-ce que la philosophie politique ?, tr. de O. Sedeyn, PUF/ Léviathan, 1992 [1 ${ }^{\text {ère }}$ éd. en anglais : What is Political Philosophy?, Jerusalem, The Magnes Press, 1955]

D. Taranto, Le virtù della politica : civismo e prudenza tra Machiavelli e gli antichi, Naples, Bibliopolis, 2003

M. E. Vatter, Between Form and Event : Machiavelli's Theory of Political Freedom, Dordrecht-Boston-Londres, Kluwer Academic Publishers, 2000

P. Valadier, Machiavel et la fragilité du politique, Paris, Le Seuil, 1996

M. Viroli, Machiavelli, Oxford University Press, 1988

L. Vissing, Machiavel et la politique de l'apparence, Paris, PUF, La politique éclatée, 1986 